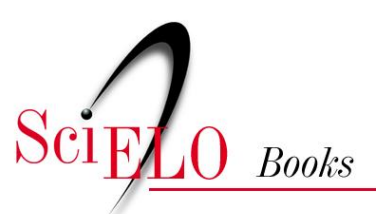

\title{
Pentatominae do Sul de Santa Catarina
}

\author{
Thereza de Almeida Garbelotto \\ Luiz Alexandre Campos
}

GARBElOTTO, TA., and CAMPOS, LA. Pentatominae do Sul de Santa Catarina [online]. Curitiba: Sociedade Brasileira de Zoologia, 2014, 80 p. Zoologia: guias e manuais de identificação series. ISBN 978-85-98203-08-9. Available from SciELO Books $<$ http://books.scielo.org $>$.

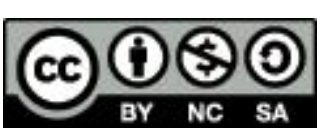

All the contents of this chapter, except where otherwise noted, is licensed under a Creative Commons Attribution-Non Commercial-ShareAlike 3.0 Unported.

Todo o conteúdo deste capítulo, exceto quando houver ressalva, é publicado sob a licença Creative Commons Atribuição Uso Não Comercial - Partilha nos Mesmos Termos 3.0 Não adaptada.

Todo el contenido de este capítulo, excepto donde se indique lo contrario, está bajo licencia de la licencia Creative Commons Reconocimento-NoComercial-CompartirIgual 3.0 Unported. 


\section{Série 7oologia \\ GUIAS E MANUAIS}

Pentatominae do

Sul de Santa Catarina

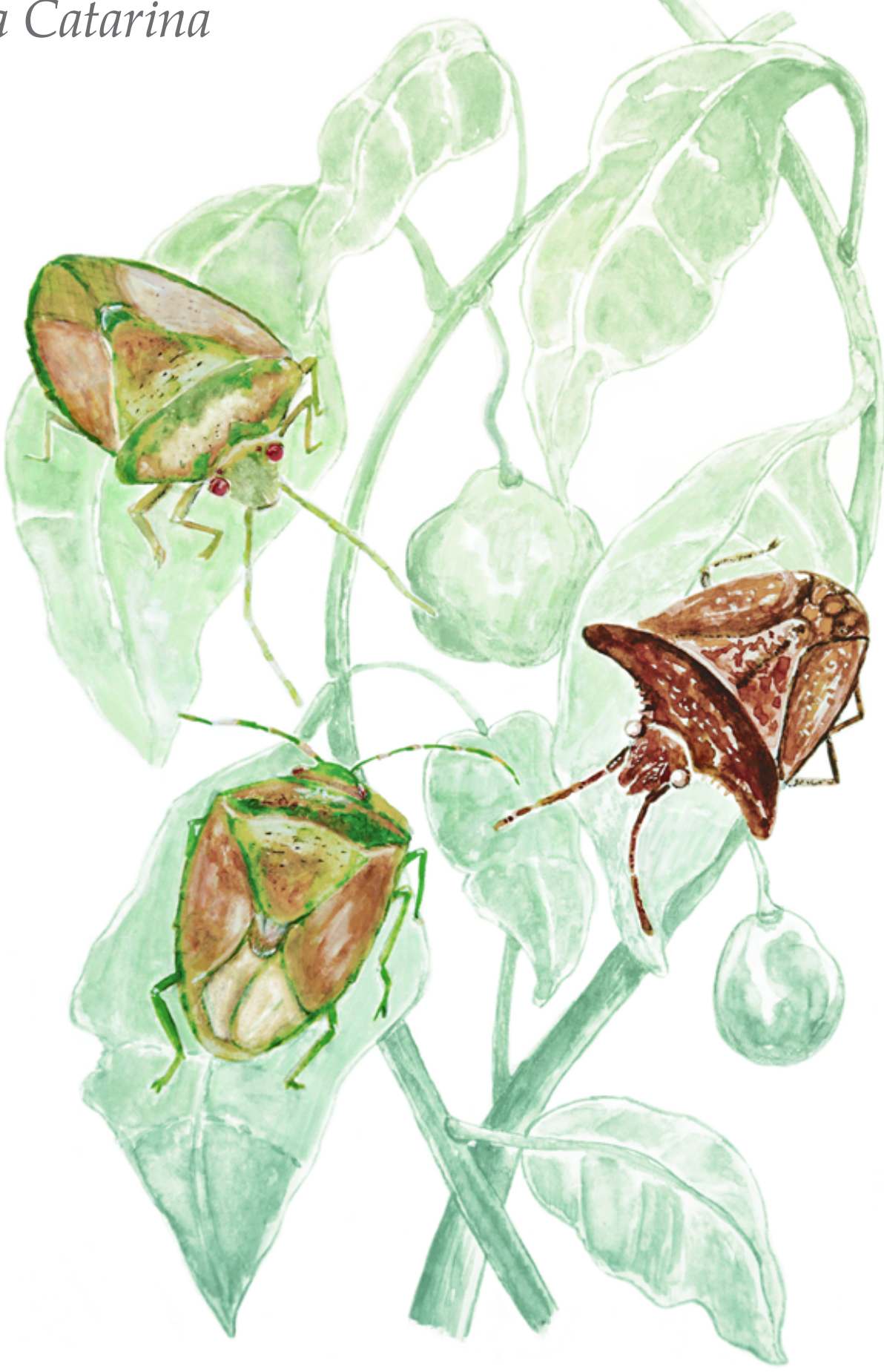

Thereza de Almeida Garbelotto 


\section{Pentatominae do Sul de Santa Catarina \\ Thereza de Almeida Garbelotto Luiz Alexandre Campos}

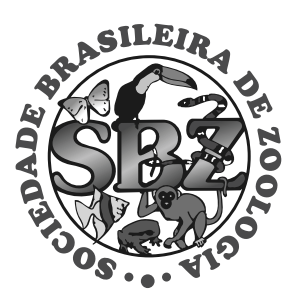

Série Zoologia GUIAS E MANUAIS DE IDENTIFICAÇÃO

Curitiba, 2014 


\section{Autores}

Thereza de Almeida Garbelotto

$\square$ therezagarbelotto@hotmail.com

(autor para correspondência)

\section{Luiz Alexandre Campos}

$\square$ luiz.campos@ufrgs.br

Universidade Federal do Rio Grande do Sul

Dep. Zoologia, PPG Biologia Animal

Av. Bento Gonçalves 9500,

prédio 43435, sala 201.

CEP: $91501-970$

Porto Alegre, RS, BRASIL.
Sociedade Brasileira de Zoologia (SBZ) -

Departamento de Zoologia, UFPR

Caixa Postal 19020, 81531-980

Curitiba/PR

$\square$ secretaria@sbzoologia.org.br

(C) (41) 3266.6823

Coordenação

Rosana Moreira da Rocha

$\checkmark$ rmrocha@ufpr.br

Sionei Ricardo Bonatto

$\square$ sbz@sbzoologia.org.br

Projeto Gráfico e-Book/ ilustração capa

Trillo Comunicação e Design

www.agenciatrillo.com.br

$\square$ bernardo@agenciatrillo.com.br

Universidade Federal do Paraná

Sistema de Bibliotecas

ISBN 978-85-98203-08-9

Garbelotto, Thereza de Almeida,

Pentatominae do Sul de Santa Catarina [recurso eletrônico] / Thereza de Almeida Garbelotto, Luiz Alexandre Campos - Curitiba : Sociedade Brasileira de Zoologia, 2014.

1 recurso eletrônico ; $(80$ p.) - (Série Zoologia : guias e manuais de identificação / Sociedade Brasileira de Zoologia)

Modo de acesso: World Wide Web. URL: http://books.scielo.org/id/fs5j4

1. Percevejo (Inseto) - Santa Catarina. 2. Livros eletrônicos. I. Título II. Campos, Luiz Alexandre, III. Sociedade Brasileira de Zoologia. Série Zoologia : guias e manuais de identificação. 


\section{Sumário}

\section{Apresentação}

O Sul Catarinense

A subfamília Pentatominae

Pentatominae, não classificados em nenhuma das tribos

Capivaccius bufo Distant, 1883

Thyanta (A.) humilis Bergroth, 1891

Thyanta (T.) perditor (Fabricius, 1794)

\section{Carpocorini}

Acledra fraterna (Stål, 1859)

Agroecus scabricornis (Herrich-Schäffer, 1844)

Caonabo pseudoscylax (Bergroth, 1891)

Dichelops (D.) nigrum Bergroth, 1914

Dichelops (D.) furcatus (Fabricius, 1775)

Dichelops (D.) phoenix Grazia, 1978

Euschistus (L.) aceratos Berg, 1894

Euschistus (L.) triangulator

(Herrich-Schäffer, 1842)

Euschistus (M.) hansi Grazia, 1987

Galedanta bituberculata

Amyot \& Serville, 1843

Glyphepomis adroguensis Berg, 1891

Hypatropis inermis (Stål, 1872)

Mormidea hamulata Stål, 1860

Mormidea notulifera Stål, 1860

Mormidea v-luteum (Lichtenstein, 1796)

Oebalus poecilus (Dallas, 1851)

Oebalus ypsilongriseus (De Geer, 1773)

Paramecocephala australis

Frey-da-Silva \& Grazia, 2002

Proxys albopunctulatus

(Palisot de Beauvois, 1805)

Sibaria armata (Dallas, 1851)

Tibraca exigua Fernandes \& Grazia, 1998

Tibraca limbativentris Stål, 1860

Catacanthini
11

12

13

14

15

16
Arocera (E.) spectabilis (Drury, 1782) 4

\section{Chlorocorini 43}

Arvelius albopunctatus (DeGeer, 1773) 44

Arvelius latus Breddin, $1909 \quad 46$

Chlorocoris (C.) tau Spinola, 1837

Chloropepla vigens (Stål, 1860) $\quad 48$

Loxa deducta Walker, $1867 \quad 49$

Loxa virescens Amyot \& Serville, $1843 \quad 50$

Loxa viridis (Palisot de Beauvois, 1805) 51

Mayrinia curvidens (Mayr, 1864) 52

Nezarini 53

Chinavia difficillis (Stål, 1860) 54

Chinavia nigrodorsata (Breddin, 1901) 55

Chinavia obstinata (Stål, 1860) 56

Chinavia pengue (Rolston, 1983) 57

Chinavia runaspis (Dallas, 1851) 58

Nezara viridula (Linnaeus, 1758) 59

Pentatomini $\quad 62$

Banasa maculata Campos \& Garbelotto, 201063

Banasa sulcata Thomas, $1990 \quad 64$

Janeirona stali (Kormilev, 1956) 65

Myota aerea (Herrich-Schäffer, 1841) 66

Pallantia macula (Dallas, 1851) 67

Pellaea stictica (Dallas, 1851) 68

Serdia indistincta Fortes \& Grazia, 200569

Serdia maxima Fortes \& Grazia, $2005 \quad 70$

Stictochilus tripunctatus Bergroth, 1918

Piezodorini $\quad 72$

Piezodorus guildinii (Westwood, 1837) 73

Procleticini $\quad 75$

Thoreyella maracaja Bernardes, Schwertner \& Grazia, 2011

Metodologias de coleta e conservação 77 Glossário $\quad 79$

Referências $\quad 80$




\section{Apresentação}

Não é exagero dizer que os insetos governam a Terra, a sua diversidade e abundância desafiam a imaginação de qualquer um. Os insetos habitam quase todos os habitats concebíveis no meio terrestre e na água doce e, de forma menos comum, até zonas de rebentação, entremarés e a superfície dos oceanos. Eles também são encontrados em locais muito improváveis como poços e lagos de óleo, nascentes sulfúricas, riachos glaciais e lagoas marinhas (Brusca \& Brusca 2007).

As estimativas mais recentes apontam que existe quase um milhão de espécies de insetos descritas no mundo (Grimald \& Engel 2005). Essa diversidade de insetos influencia a dinâmica dos ecossistemas por intermédio de numerosos mecanismos, tais como, decomposição da serrapilheira, polinização, supressão do crescimento de plantas e servindo como presa a carnívoros (Thomazini \& Thomazini 2000). Alguns grupos de insetos também são indicadores para monitoramento de mudanças ambientais. Os percevejos da família Pentatomidae são um desses grupos na Floresta Atlântica Brasileira, onde respondem principalmente à diversidade química e taxonômica das plantas, com acréscimo de diversidade quando os impactos sobre a vegetação são baixos a moderados e com diminuição de diversidade quando os distúrbios são altos (Brown Jr. 1997).

Este guia ilustrado pretende apresentar a diversidade do grupo de percevejos com maior número de espécies no sul do Estado de Santa Catarina, a subfamília Pentatominae. Também se destina a estudantes e pesquisadores que atuam (ou gostariam de atuar) com Pentatomidae, especialmente os pentatomíneos, como um auxiliar na identificação dos insetos em laboratório e guia de identificação em campo.

O guia possui uma seção introdutória com uma breve apresentação sobre a Mata Atlântica e a região sul catarinense, ao mesmo tempo o limite sul da floresta ombrófila densa e região de coleta das espécies aqui incluídas. Na mesma seção é caracterizado o grupo de percevejos da subfamília Pentatominae, com suas principais características morfológicas e taxonômicas. Em seguida são apresentadas as 52 espécies de Pentatominae registradas no sul catarinense, incluindo fotos, diagnoses rápidas, principais referências sobre as espécies e informações de plantas hospedeiras quando disponíveis em literatura.

Ao final as metodologias de coleta utilizadas são brevemente descritas incluindo desenhos esquemáticos dos equipamentos. Os principais métodos de conservação também são explicados, e um glossário dos termos morfológicos e as referências utilizadas na parte geral do guia são fornecidos.

"Pentatominae do Sul de Santa Catarina" também foi desenvolvido a fim de despertar o interesse pelo estudo destes insetos. 


\section{O Sul Catarinense}

A região sul do Estado de Santa Catarina compreende aproximadamente 45 municípios (Fig. 1) inteiramente inseridos na Mata Atlântica Brasileira, com destaque para as formações de Floresta Ombrófila Densa.

A Mata Atlântica Brasileira é um dos biomas com maior diversidade no país e considerada um hotspot para prioridade de conservação. Originalmente se estendia do Rio Grande do Sul ao Piauí, ocupando em Santa Catarina a totalidade do território estadual (Myers et al. 2000; SOS Mata Atlântica 2008).

Santa Catarina é o terceiro Estado do país em área de remanescentes de mata, representando 1,12\% de cobertura do território brasileiro (Campanili \& Prochnow 2006), e a maior parte dessas áreas é considerada prioritária para conservação da biodiversidade (Heringer \& Montenegro 2000). No sul do Estado quase a totalidade do território está dividida em áreas consideradas de alta e extrema importância biológica para conservação de diversos grupos taxonômicos, ao mesmo tempo em que é considerada uma região com altos índices de pressão antrópica (Heringer \& Montenegro 2000).

Os percevejos da família Pentatomidae, por ser um dos grupos de insetos indicadores para monitoramento de mudanças ambientais na Floresta Atlântica Brasileira (Brown Jr. 1997), estão entre os invertebrados que podem subsidiar informações para monitoramento e conservação dos fragmentos de floresta na região. O maior levantamento de diversidade de pentatomídeos no Estado foi realizado por Campos et al. (2009) na região sul.

Figura 1: Mapa do estado de Santa Catarina destacando os municípios do sul que possuem registros de ocorrência de Pentatomíneos.

\section{Paraná}

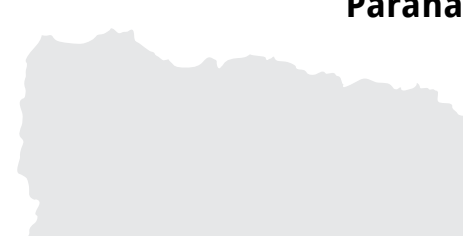

Araranguá

Braço do Norte

Cocal do Sul

Criciúma

Forquilhinha

Içara
Imbituba

Maracajá

Nova Veneza

Sombrio

Timbé do Sul

Urussanga
Rio Grande do Sul
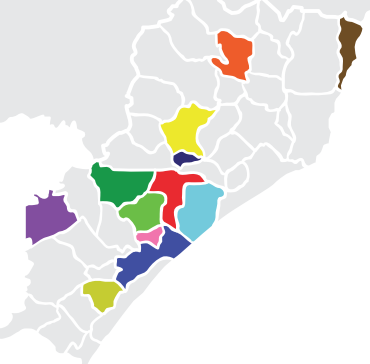


\section{A subfamília Pentatominae}

Os insetos da ordem Hemiptera, vulgarmente chamados percevejos, constituem um grupo de insetos grande e diversificado (Triplehorn \& Johnson 2011). A maioria das espécies é terrestre e existem espécies aquáticas; muitos se alimentam da seiva de plantas, alguns sendo pragas sérias de plantas cultivadas; outros são predadores e muitos destes são benéficos à agricultura; e outros ainda atacam o homem e outros animais, sendo alguns destes vetores de doenças (Triplehorn \& Johnson 2011, Grazia et al. 2012).

Os hemípteros são caracterizados principalmente pela estrutura das peças bucais que são do tipo 'picador-sugador', apresentando o lábio articulado (Triplehorn \& Johnson 2011). A subordem Heteroptera constitui o maior e mais diverso grupo de insetos com metamorfose incompleta, sendo encontrados em todos os continentes (Schuh \& Slater 1995). As asas anteriores de Heteroptera são bastante características e denominadas hemiélitros, cuja parte basal é espessada e coriácea e a apical, membranosa; as asas posteriores são inteiramente membranosas (Triplehorn \& Johnson 2011).

Pentatomidae é a quarta família mais numerosa e diversa de Heteroptera, com 896 gêneros e 4.722 espécies, e ampla distribuição mundial (Schuh \& Slater 1995; Grazia \& Fernandes 2012; Rider 2011). Estes insetos são popularmente conhecidos como percevejo-do-mato, percevejo-fedorento, percevejo-verde, frade, fede-fede e Maria-fedida. São chamados assim por produzirem um odor desagradável através de suas glândulas de cheiro, que nos adultos se abrem na região ventral do tórax próximo às pernas, e nas ninfas no dorso do abdômen (Panizzi et al. 2000). São reconhecidos facilmente por suas antenas geralmente com cinco segmentos, escutelo amplo e triangular que se estende até a base da membrana dos hemiélitros, esses sempre mais ou menos visíveis, e tamanho variando de 4 a 20 mm (Costa Lima 1940; Schuh \& Slater 1995; Grazia \& Fernandes 2012).

A subfamília Pentatominae, alvo deste guia, é a mais diversa e abundante de Pentatomidae, com 3.336 espécies reunidas em 621 gêneros no mundo e aproximadamente 338 espécies e mais de 70 gêneros no Brasil (Grazia \& Schwertner 2011; Rider 2011). É também a subfamília mais frequentemente coletada e que apresenta o maior número de espécies consideradas pragas de plantas cultivadas. Estes percevejos variam na forma e coloração do corpo, podem apresentar os ângulos umerais do pronoto desenvolvidos e o escutelo não atinge o ápice do abdômen (Fig. 2). Com ampla distribuição mundial, o grupo tem uma grande representatividade na região Neotropical (Schuh \& Slater 1995; Grazia et al.1999; Grazia \& Fernandes 2012).

A classificação de Pentatominae apresenta algumas diferenças conforme o autor consultado, podendo ser dividida desde oito até 42 tribos. Schuh \& Slater (1995) reconhecem oito tribos, Grazia et al.(1999) e Grazia \& Fernandes (2012) reconhecem nove tribos, e Rider (2011) reconhece 42 tribos, sendo 33 delas formadas por gêneros incluídos em Pentatomini em classificações anteriores.

A classificação de tribos de Pentatominae utilizada neste guia é a apresentada por Rider (2011). Devido à inexistência de chaves de identificação para as tribos, estas e as 52 espécies aqui incluídas estão organizadas alfabeticamente. As fotografias foram tomadas de espécimes conservados a seco e as escalas representam $1 \mathrm{~mm}$.

Para confirmar se o percevejo que você tem em mãos pertence à Pentatominae consulte a chave para subfamílias de Pentatomidae que ocorrem no Brasil apresentada a seguir. 
Chave para subfamílias de Pentatomidae (Modificada de: Rolston \& McDonald 1979; e Grazia \& Fernandes 2012).

1. Primeiro artículo do rostro robusto, estendendo-se bem além das búculas. Ou tíbia anterior foliácea Asopinae

- Primeiro artículo do rostro pouco alargado, repousando entre as búculas (ainda que, frequentemente seja mais longo do que as búculas). Tíbia anterior pouco expandida

2. Metasterno projetado anteriormente sobre o mesosterno ou raramente até o prosterno, formando um processo metasternal bifurcado anteriormente. Rostro não ultrapassando as mesocoxas Edessinae

- Mestasterno raramente projetado anteriormente até o mesosterno, nesse caso o rostro se estende até o abdomen. Rostro usualmente alcançando pelo menos as mesocoxas 3

3. Escutelo amplo e dotado de protuberância dorsal espinhosa. .Cyrtocorinae

- Escutelo de tamanho variável, sem protuberância dorsal

4. Rostro origina-se sobre ou posteriormente à linha transversal tangente ao limite anterior dos olhos Discocephalinae

- Rostro origina-se anteriormente à linha transversal tangente ao limite dos olhos......Pentatominae

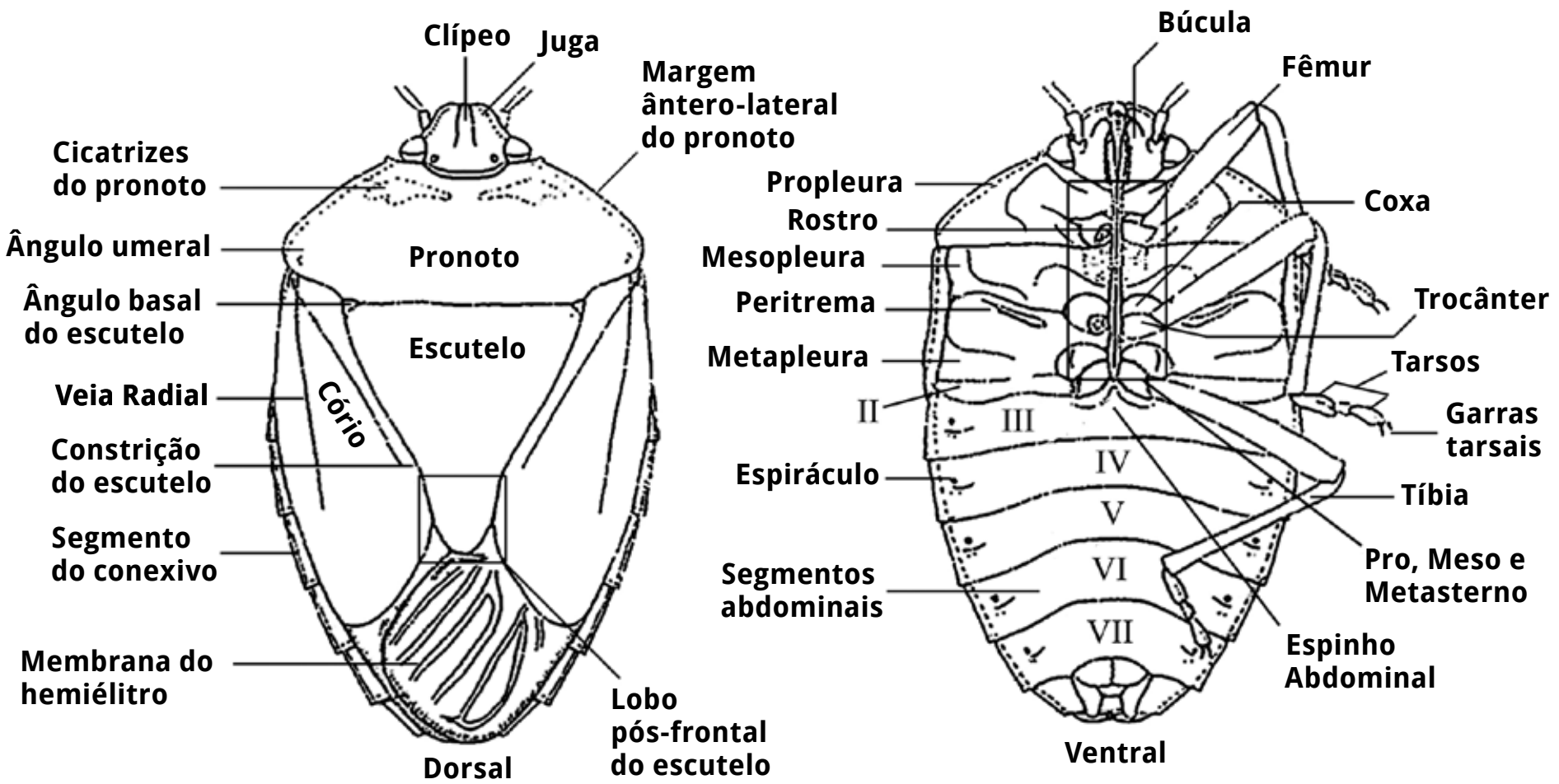

Figura 2: Esquema da morfologia de um pentatomídeo. Modificado de Schwertner \& Grazia, 2007. 


\section{Pentatominae, não classificados em nenhuma das tribos}

Capivaccius bufo Distant, 1883

Thyanta (Argossoma) humilis Bergroth, 1891

Thyanta (Thyanta) perditor (Fabricius, 1794) 


\section{Capivaccius bufo} Distant, 1883

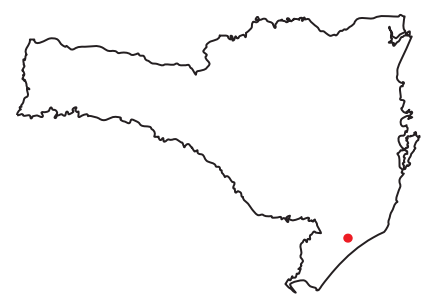

Diagnose: Coloração geral castanho claro; margens das jugas, clípeo e cicatrizes do pronoto negras. Manchas negras na metade posterior do pronoto, entre os ângulos umerais, no disco do escutelo e porção central do cório. Mácula marfim no centro do lobo pós-frenal do escutelo. Membrana mais longa que o abdômen.

Tamanho dos adultos: 7,6-9,2 mm.

Metodologia de coleta: coleta manual e guarda-chuva entomológico.

Local de Coleta: Criciúma.

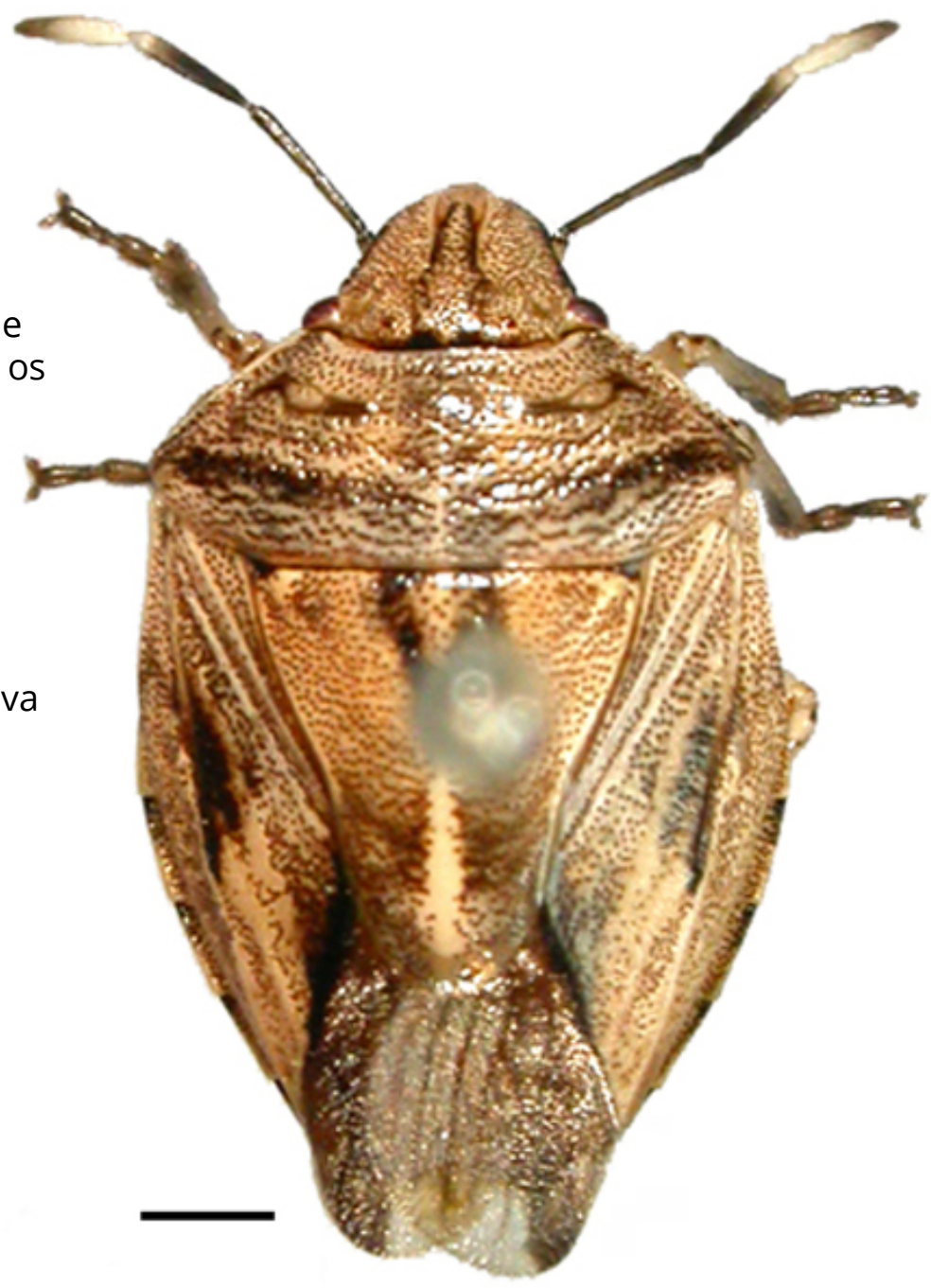

\section{Bibliografias:}

Brailovsky, H. \& Rolston, J. H. 1986. Dos nuevas especies de Pentatomidos neotropicales (Hemiptera-Heteroptera-Pentatomini). Folia Entomológica Mexicana, 68: 29-40. 


\section{Thyanta (A.) humilis Bergroth, 1891}

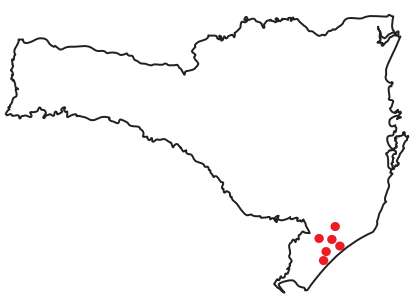

Diagnose: Superfície dorsal verde a castanha, muitas vezes com faixas vermelhas a roxas entre os ângulos umerais, no dorso da cabeça e ápice do escutelo. Margens anterolaterais do pronoto retas a pouco côncavas em vista dorsal; ângulos umerais arredondados a agudos, projetados lateralmente além da margem do cório (Rider \& Chapin 1991).

Tamanho dos adultos: 7,2-9,4 $\mathrm{mm}$.

* Fotos ilustrando a variação de padrões de coloração, como descrito acima e sem as faixas avermelhadas.

Metodologia de coleta: coleta manual, guarda-chuva entomológico e rede de varredura.

Local de Coleta: Araranguá, Criciúma, Içara, Maracajá, Nova Veneza e Urussanga.

\begin{tabular}{|l|l|l|}
\hline & Planta hospedeira & Nome popular \\
\hline Malvaceae & Gossypium arboreum L. & Algodoeiro \\
\hline
\end{tabular}

\section{Bibliografias:}

Grazia, J. 1977. Revisão dos Pentatomineos citados no Quarto Catálogo dos Insetos que Vivem nas Plantas do Brasil (Hemiptera: Pentatomidae, Pentatomini). Dusenia, 10 (3): 161-174.

Rider, D.A. \& Chapin, J.B. 1991. Revision of the genus Thyanta Stål, 1862 (Heteroptera: Pentatomidae) I. South America. J New York Entomol Soc, 99 (1): 1-77.

Rider, D.A. \& Rolston, L.H. 1995. Nomenclatural changes in the Pentatomidae (Hemiptera-Heteroptera). Proc Entomol Soc Wash, 97 (4): 845-855.
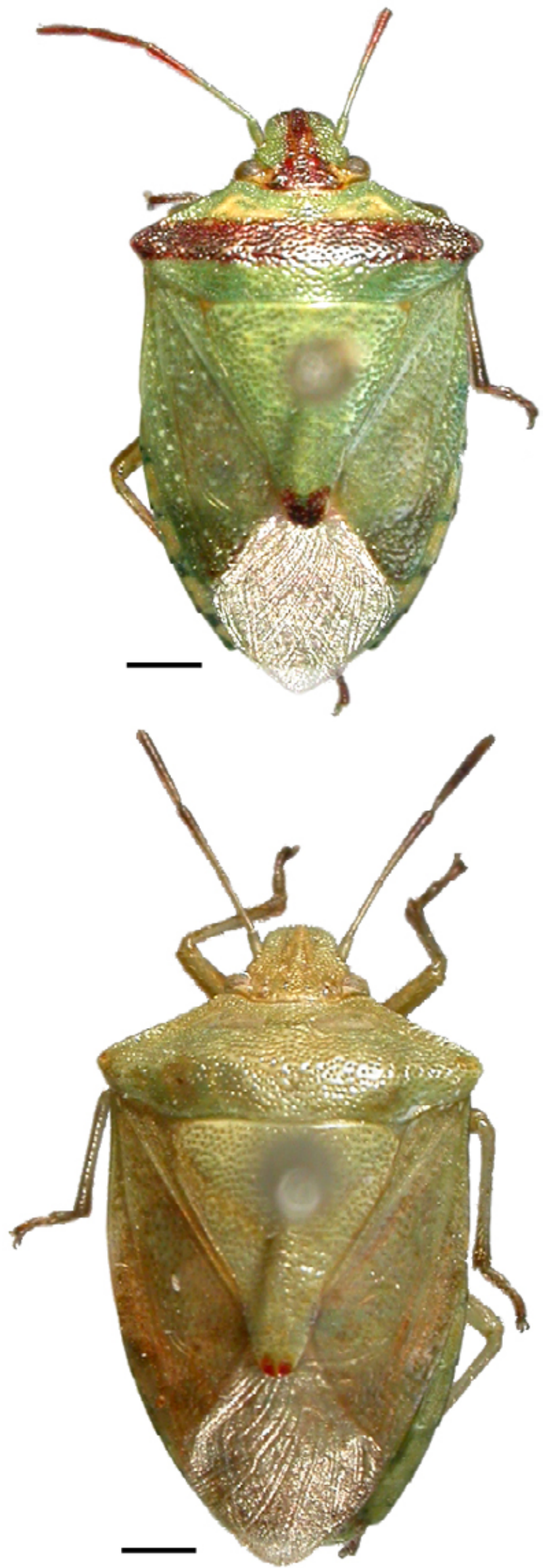


\section{Thyanta (T.) perditor (Fabricius, 1794)}

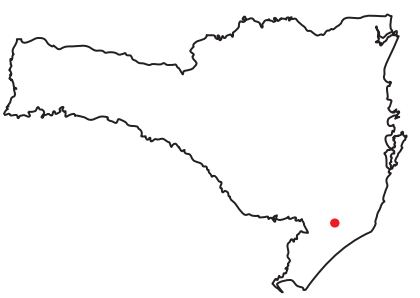

Diagnose: Coloração geral verde; frequentemente com uma mancha ferrugínea no clípeo e dorso da cabeça. Ângulos umerais espinhosos, direcionados anterolateralmente além da margem do cório. Pronoto usualmente com uma banda ferrugínea entre os ângulos umerais; cicatrizes do pronoto com cada canto mediano negro (Rider \& Chapin 1991).

Tamanho dos adultos: 10,6-10,8 mm.

Metodologia de coleta: coleta manual.

Local de Coleta: Urussanga.

Nome popular: percevejo-do-trigo.

\begin{tabular}{|c|c|c|}
\hline & Planta hospedeira & Nome popular \\
\hline Asteraceae & $\begin{array}{l}\text { Baccharis trimera (Less.) } \\
\text { DC.; Helianthus annuus L. }\end{array}$ & Carqueja; Girassol; \\
\hline Brassicaceae & $\begin{array}{l}\text { Nasturtium officinals L.; Brassica } \\
\text { napus L. var. oleifera Meitzg. }\end{array}$ & $\begin{array}{l}\text { Agrião-d'água; } \\
\text { Colza; }\end{array}$ \\
\hline Fabaceae & $\begin{array}{l}\text { Lupinus albus L.; Glycine } \\
\max (\text { L.) Merrill }\end{array}$ & $\begin{array}{l}\text { Tremoço- } \\
\text { branco; Soja }\end{array}$ \\
\hline Linaceae & Linum usitatissimum L. & Linho \\
\hline Poaceae & $\begin{array}{l}\text { Brachiaria plantaginea (Link) } \\
\text { Hitchc.; Orysa sativa L.; Sorghum } \\
\text { vulgare L.; Triticum aestivum L. }\end{array}$ & $\begin{array}{l}\text { Papuã; Arroz; } \\
\text { Graminae; Trigo }\end{array}$ \\
\hline Solanaceae & Solanum paniculatum L. & Jurubeba \\
\hline
\end{tabular}

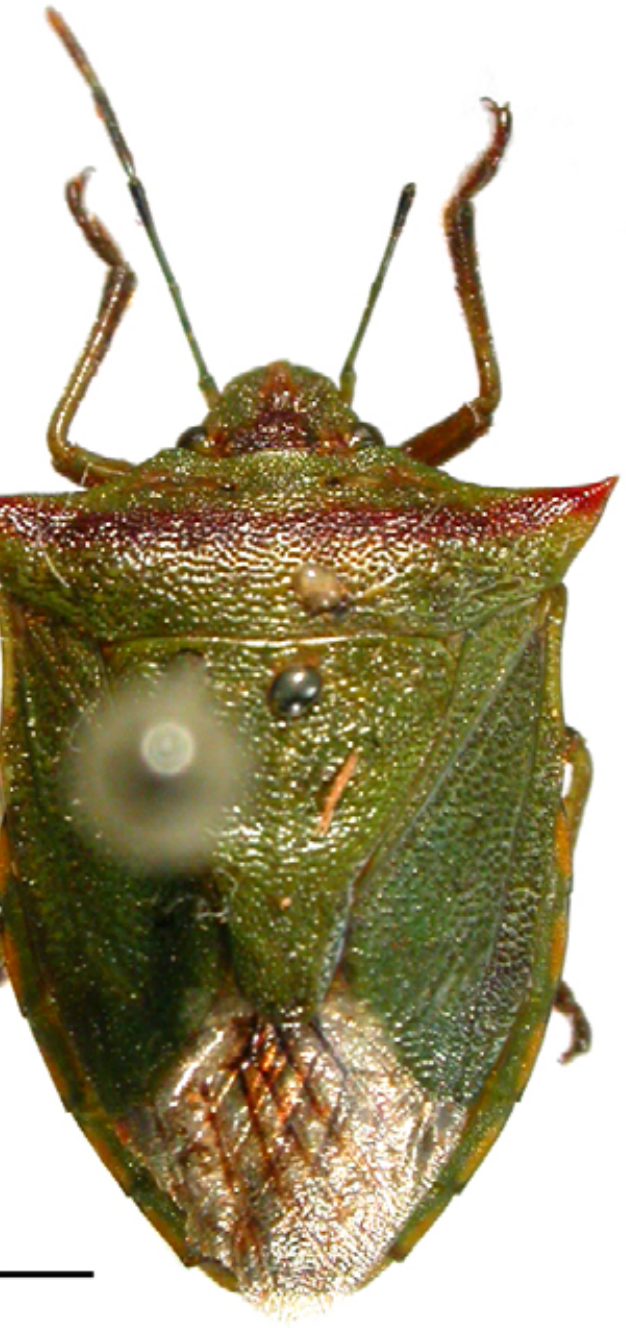

Bibliografias:

Link, D. \& Grazia, J. 1987. Pentatomídeos da região central do Rio Grande do Sul (Heteroptera). An. Soc. Entomol. Bras. 16 (1): 115-129.

Malaguido, A.B. \& Panizzi, A.R. 1998. Pentatomofauna associated with sunflower in Northern Paraná state, Brazil. An. Soc. Entomol. Bras. 27 (3): 473-475.

Panizzi, A.R. 1997. Wild hosts of Pentatomids: ecological significance and role in their pest status on crops. Annu. Rev. Entomol. 42: 99-122.

Panizzi, A.R.; McPherson, J.E.; James, D.G.; Javahery, J.M. \& McPherson, R.M. 2000. Stink Bugs (Pentatomidae), p. 421-474. In: C.W., Schaefer \& A.R., Panizzi (Org). Heteroptera of economic importance. USA, CRC Press.

Rider, D.A. \& Chapin, J.B. 1991. Revision of the genus Thyanta Stål, 1862 (Heteroptera: Pentatomidae) I. South America. J. New York Entomol. Soc. 99 (1): 1-77.

Salvadori, J.R.; Lau, D. \& Pereira, P.R.V.da S. 2009. Pragas e métodos de controle. Embrapa Trigo, Sistemas de Produção No. 4. Cultivo de Trigo. Disponível online em: http://sistemasdeproducao.cnptia. embrapa.br/FontesHTML/Trigo/CultivodeTrigo/pragas.htm [Acesso em: 19 dez. 2013.] 


\section{Carpocorini}

Acledra fraterna (Stål, 1859)

Agroecus scabricornis (Herrich-Schäffer, 1844)

Caonabo pseudoscylax (Bergroth, 1891)

Dichelops (Dichelops) nigrum Bergroth, 1914

Dichelops (Diceraeus) furcatus (Fabricius, 1775)

Dichelops (Diceraeus) phoenix Grazia, 1978

Euschistus (Lycipta) aceratos Berg, 1894

Euschistus (Lycipta) triangulator (Herrich-Schäffer, 1842)

Euschistus (Mitripus) hansi Grazia, 1987

Galedanta bituberculata Amyot \& Serville, 1843

Glyphepomis adroguensis Berg, 1891

Hypatropis inermis (Stål, 1872)

Mormidea hamulata Stål, 1860

Mormidea notulifera Stål, 1860

Mormidea v-luteum (Lichtenstein, 1796)

Mormidea rugosa Rolston, 1978

Oebalus poecilus (Dallas, 1851)

Oebalus ypsilongriseus (De Geer, 1773)

Paramecocephala australis Frey-da-Silva \& Grazia, 2002

Proxys albopunctulatus (Palisot de Beauvois, 1805)

Sibaria armata (Dallas, 1851)

Tibraca exigua Fernandes \& Grazia, 1998

Tibraca limbativentris Stål, 1860 


\section{Acledra fraterna (Stål, 1859)}

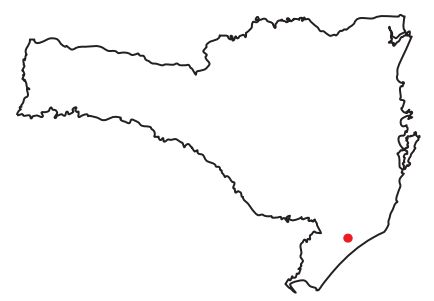

Diagnose: Coloração esverdeada a amarelada. Ângulos umerais arredondados; cicatrizes do pronoto com manchas escuras no ângulo interno. Escutelo esverdeado com ápice pálido. Cório com mancha escura no ápice da veia radial (Rider 2007; Faúndez \& Verdejo 2010).

Tamanho dos adultos: $8,9 \mathrm{~mm}$.

Metodologia de coleta: coleta manual.

Local de coleta: Criciúma.

\begin{tabular}{|l|l|l|}
\hline & Planta hospedeira & Nome popular \\
\hline Fabaceae & Glycine max (L.) Merr. & Soja \\
\hline
\end{tabular}

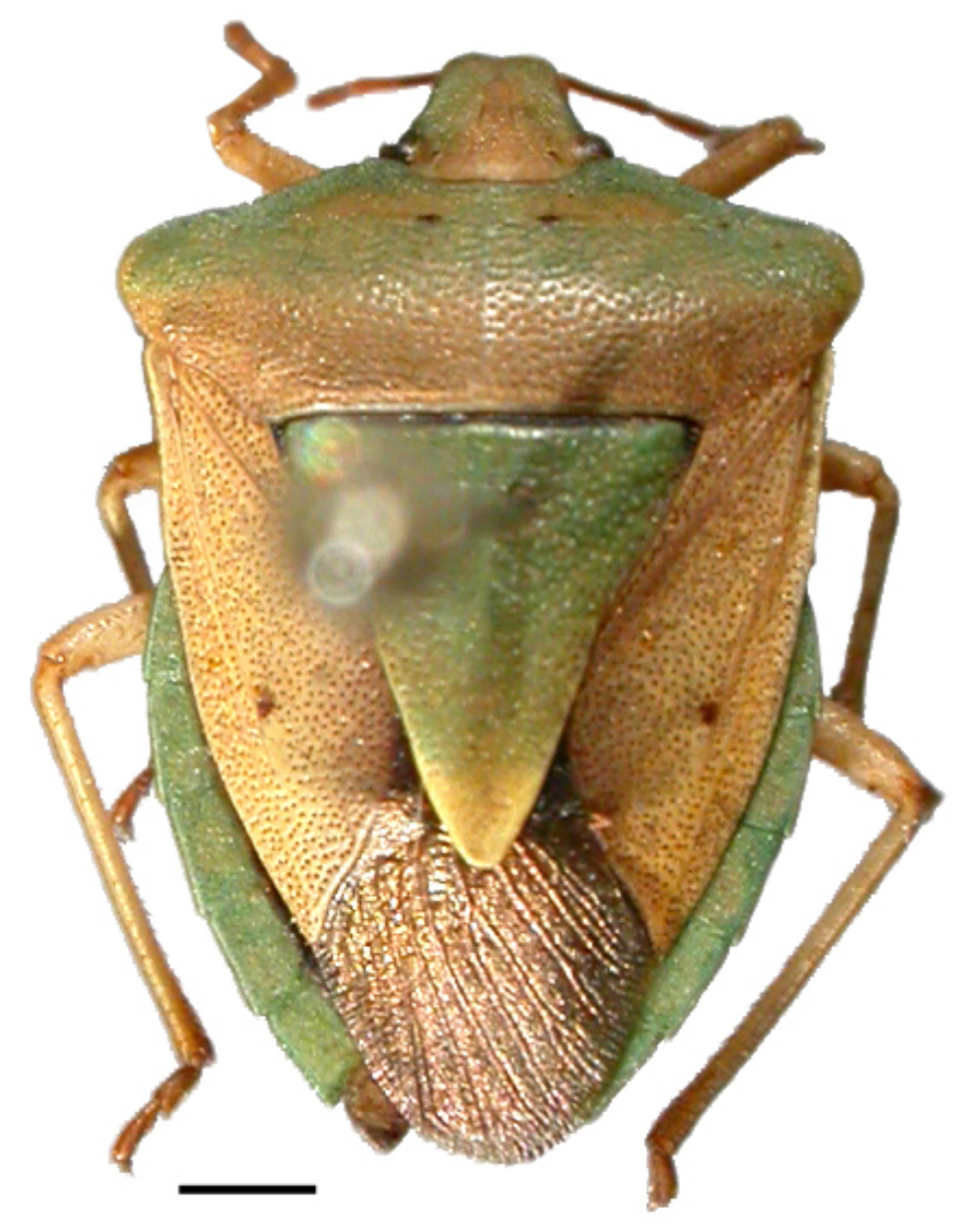

\section{Bibliografias:}

Faúndez, E.I. \& Verdejo, L.M. 2010. La singular morfologia de Acledra haematopa (Spinola, 1852) dentro del género Acledra Sgnoret, 1864 (Hemiptera: Heteroptera: Pentatomidae): Un caso de mimetismo batesiano, com descrepcións de um nuevo subgénero. Boletín de la S.E.A. 46: 77-82

Link, D. \& Grazia, J. 1987. Pentatomídeos da região central do Rio Grande do Sul (Heteroptera). An. Soc. Entomol. Bras. 16 (1): 115-129.

Rider, D.A. 2007. Pentatomoidea Home Page. North Dakota: North Dakota State University. Disponível online em: http://www.ndsu.nodak.edu/ndsu/rider/Pentatomoidea/Species_Carpocorini/Acledra_fraterna.htm. [Acesso em: 16 jul. 2013.]

Ruffinelli, A. \& Pirán, A.A. 1959. Hemípteros Heteropteros Del Uruguay. Faculdad de Agronomia de Montevideo 51: 10-11. 


\section{Agroecus scabricornis (Herrich-Schäffer, 1844)}

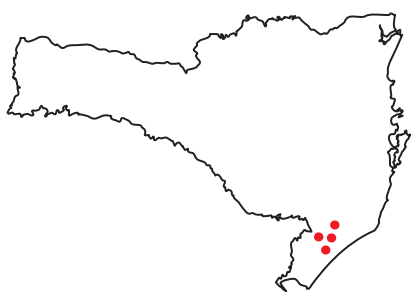

Diagnose: Coloração geral castanha. Juga ligeiramente mais longa que o clípeo. Processo anteocular pouco projetado ou ausente. Margem anterolateral do pronoto côncava, com dentículos pequenos. Ângulo umeral agudo, quase espinhoso projetado anterolateralmente (Rider \& Rolston 1987).

Tamanho dos adultos: 9,3-11,0 mm.

Metodologia de coleta: coleta manual, guarda-chuva entomológico e rede de varredura.

Locais de Coleta: Criciúma, Maracajá, Nova Veneza e Urussanga.

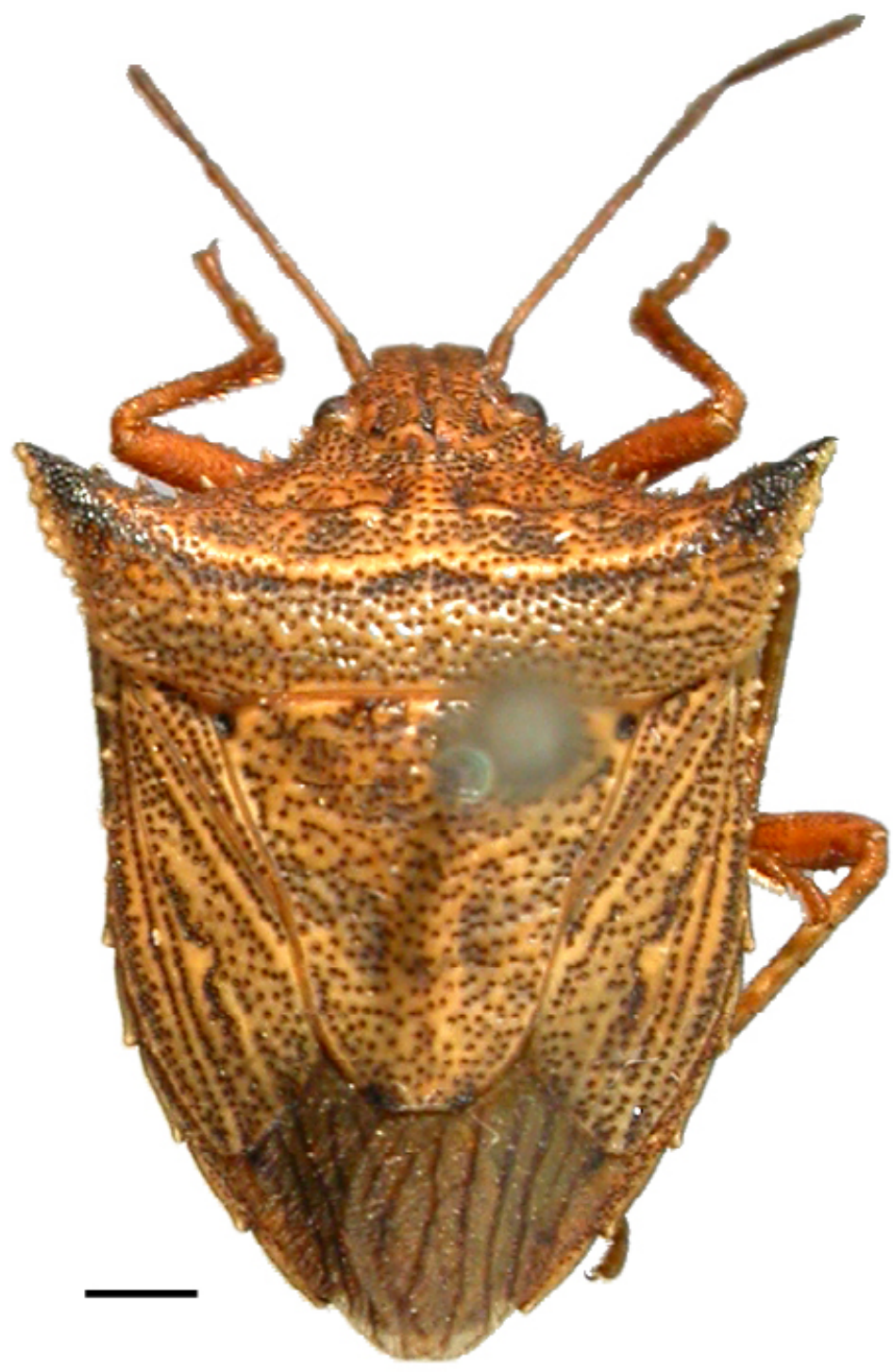

\section{Bibliografias:}

Rider, D.A. \& Rolston, L.H. 1987. Review of the genus Agroecus Dallas, with the description of a new species (Hemiptera: Petnatomidae). J. New York Entomol. Soc. 95 (3): 428-439. 


\section{Caonabo pseudoscylax (Bergroth, 1891)}

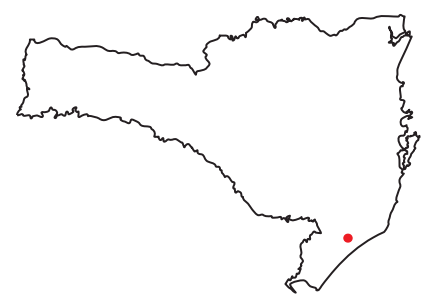

Diagnose: Coloração geral castanha; ventralmente castanho amarelado. Ângulos umerais bastante projetados, subagudo a agudo, um tanto elevados e direcionados para frente obliquamente, e negros no ápice. Margens anterolaterais do pronoto côncavas, com tubérculos nos ângulos anteriores. Espiráculos próximos a margem lateral do $2^{\circ}$ - $5^{\circ}$ esternito abdominal visível (Rolston 1974).

Tamanho dos adultos: 7,4-10,7 mm

Metodologia de coleta: coleta manual, guarda-chuva entomológico e rede de varredura

Local de Coleta: Criciúma

\begin{tabular}{|l|l|l|}
\hline Poaceae & Planta hospedeira & Nome popular \\
\hline $\begin{array}{l}\text { Panicum glutinosum } \\
\text { Sworitinomolepsis } \\
\text { glutinosa Sw. }\end{array}$ & Capim-taquara; _. \\
\hline
\end{tabular}

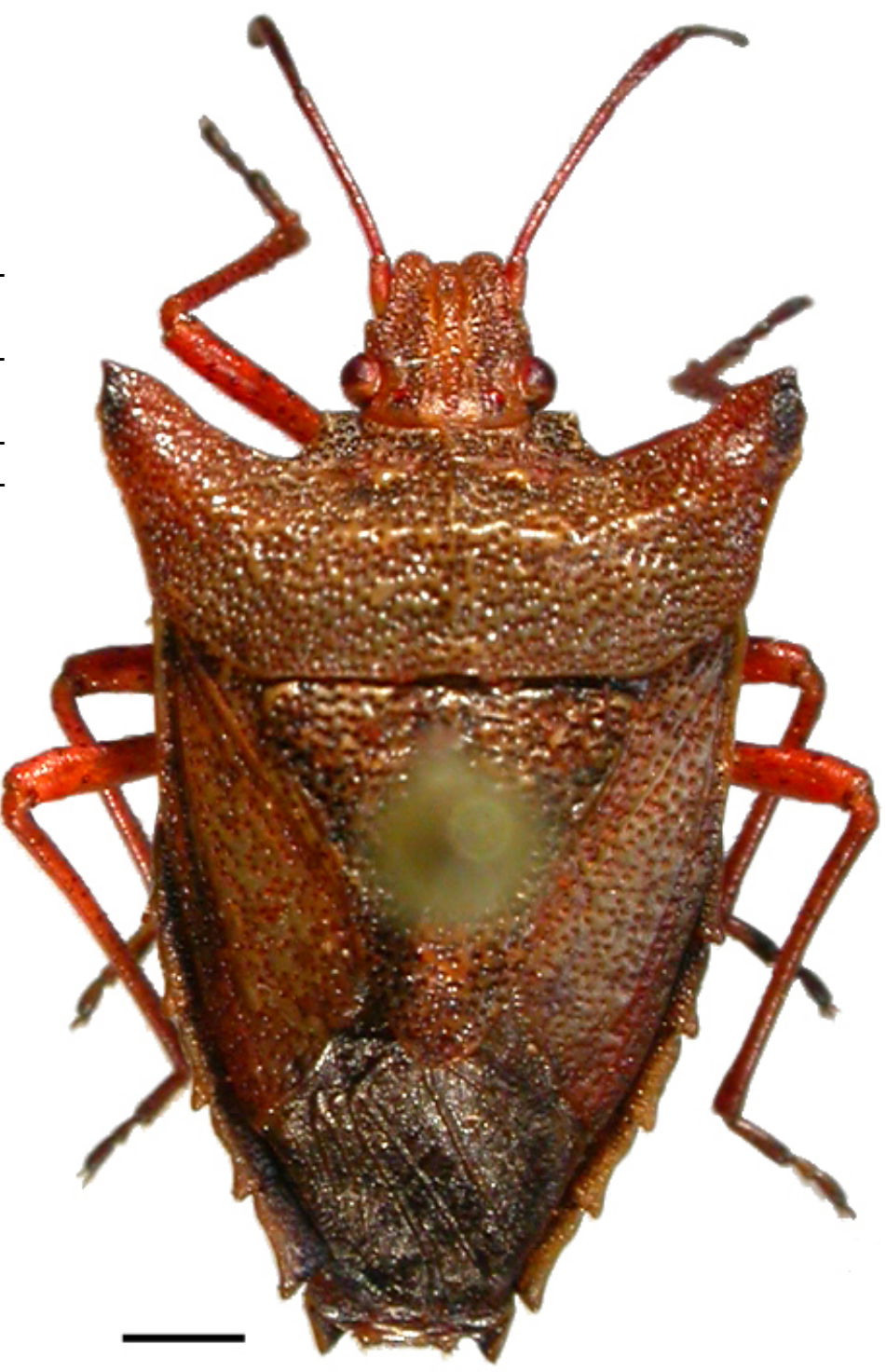

\section{Bibliografias:}

Gilio-Dias, S.M.C.; Campos, L.A. \& Bianchi, F.M. 2013. Morphology of immature of Caonabo pseudoscylax (Bergroth) (Hemiptera: Pentatomidae). Neotrop. Entomol. 42: 178-184.

Link, D. \& Grazia, J. 1987. Pentatomídeos da região central do Rio Grande do Sul (Heteroptera). An. Soc. Entomol. Bras. 16 (1):115-129.

Rolston, L.H. 1974. A new genus of Pentatomidae from South America, distinguished by the position of its spiracles (Hemiptera: Pentatomidae). J. New York Entomol. Soc. 82: 57-60. 


\section{Dichelops (D.) nigrum Bergroth, 1914}

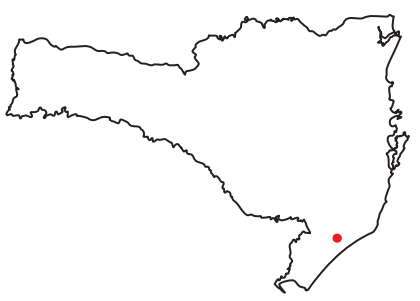

Diagnose: Coloração geral castanho-escura, alguns exemplares negros. Reflexos vermelho-ferrugíneos na cabeça, antenas e pernas; as antenas e as pernas podem ser ocres, como o conexivo. Jugas agudas e mais longas que o clípeo. Ângulos umerais desenvolvidos em espinhos longos, agudos no ápice, projetatos lateralmente além da margem do conexivo (Grazia 1978).

Tamanho dos adultos: $\sigma$ 10,7-12,2 mm; @ 11,76-11,83 mm.

Metodologia de coleta: coleta manual, guarda-chuva entomológico e rede de varredura.

Local de coleta: Criciúma.
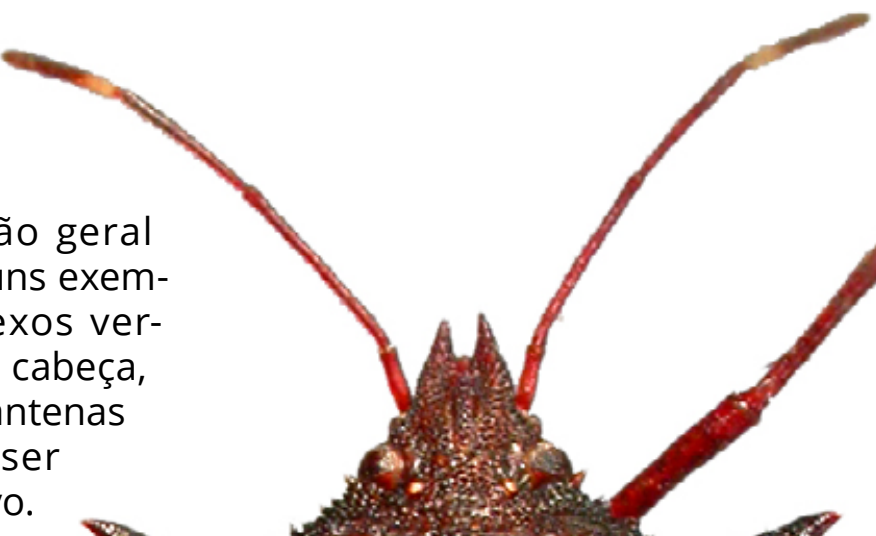

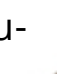

,
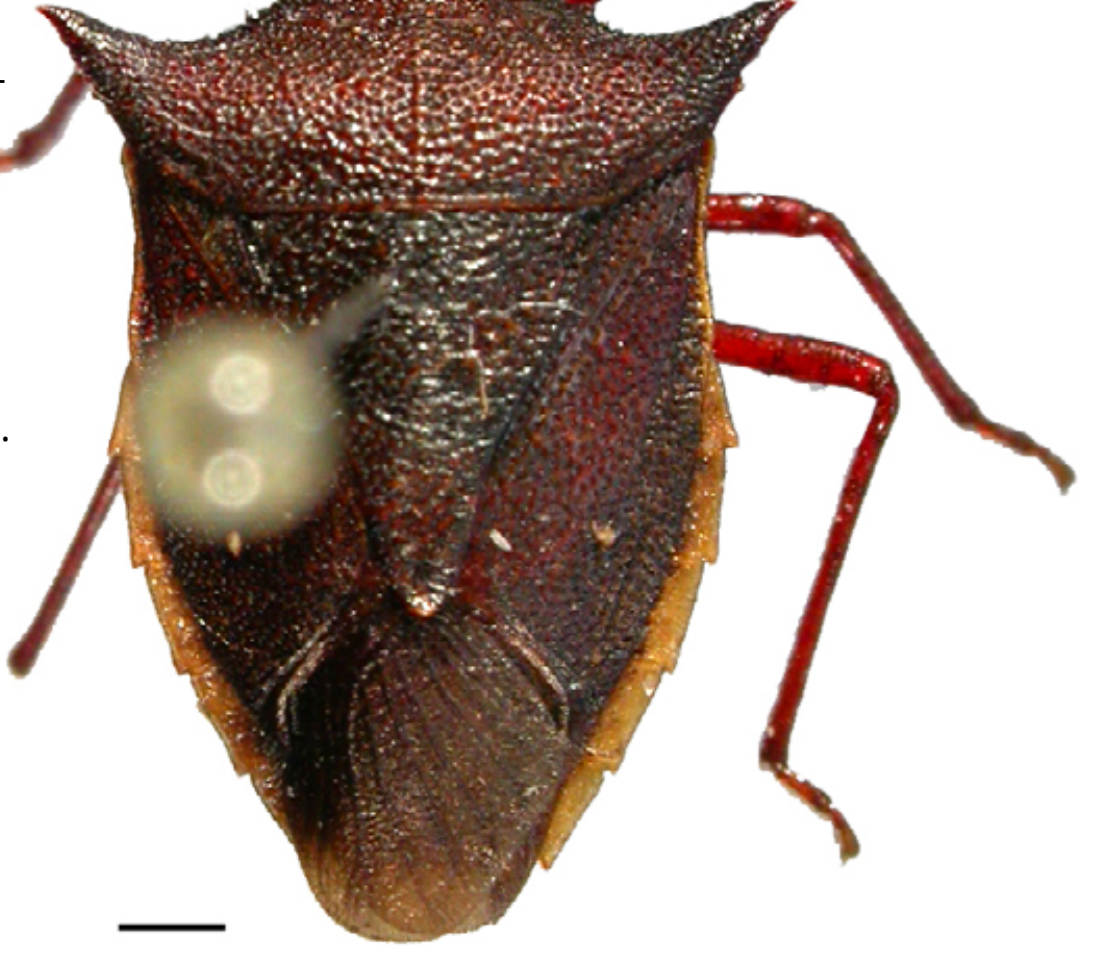

\section{Bibliografias:}

Grazia J. 1978. Revisão do gênero Dichelops Spinola, 1837 (Heteroptera, Pentatomidae, Pentatomini). Iheringia, Sér. Zool. 53: 1-119. 


\section{Dichelops (D.) furcatus (Fabricius, 1775)}

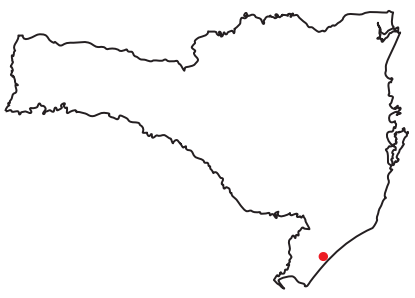

Diagnose: Coloração geral ocre, face ventral geralmente mais clara. Jugas agudas; ângulos umerais desde pouco desenvolvidos até formando longos espinhos. Pontuações negras numa linha ao longo das margens anterolaterais, desde a margem anterior até cerca do meio do pronoto (Grazia 1978).

Tamanho dos adultos: $\sigma$ 10,2-11,01 mm; Q 11,35-12,17 mm.

Metodologia de coleta: espécie com registro apenas em literatura e sem indicação de método de coleta.

Ocorrência: Araranguá.

Nome popular: Percevejo barriga-verde.

\begin{tabular}{|l|l|l|}
\hline & Planta hospedeira & $\begin{array}{l}\text { Nome } \\
\text { popular }\end{array}$ \\
\hline Asteraceae & Bidens pilosa L. & Picão \\
\hline Fabaceae & $\begin{array}{l}\text { Lotus corniculatus L.; } \\
\text { Vigna sinensis (L.) Savi; } \\
\text { Macroptilium atropurpureum } \\
\text { Urb.; Glycine max (L.) } \\
\text { Merrill; Medicago sativa } \\
\text { L.; Phaseolus vulgaris L. }\end{array}$ & $\begin{array}{l}\text { Cornichão; } \\
\text { Feijão- } \\
\text { miúdo; } \\
\text { Siratro; Soja; } \\
\text { Alfafa; Feijão }\end{array}$ \\
\hline Malvaceae & $\begin{array}{l}\text { Gossypium arboreum L. } \\
\text { Poaceae }\end{array}$ & $\begin{array}{l}\text { Triticum aestivum L. } \\
\text { Algodoeiro }\end{array}$ \\
\hline Rosaceae & Fragraria vesca L. & Trigo \\
\hline Solanaceae & $\begin{array}{l}\text { Nicotiana tabacum L.; } \\
\text { Solanum tuberosum L. }\end{array}$ & $\begin{array}{l}\text { Morangueiro } \\
\text { Batata }\end{array}$ \\
\hline
\end{tabular}

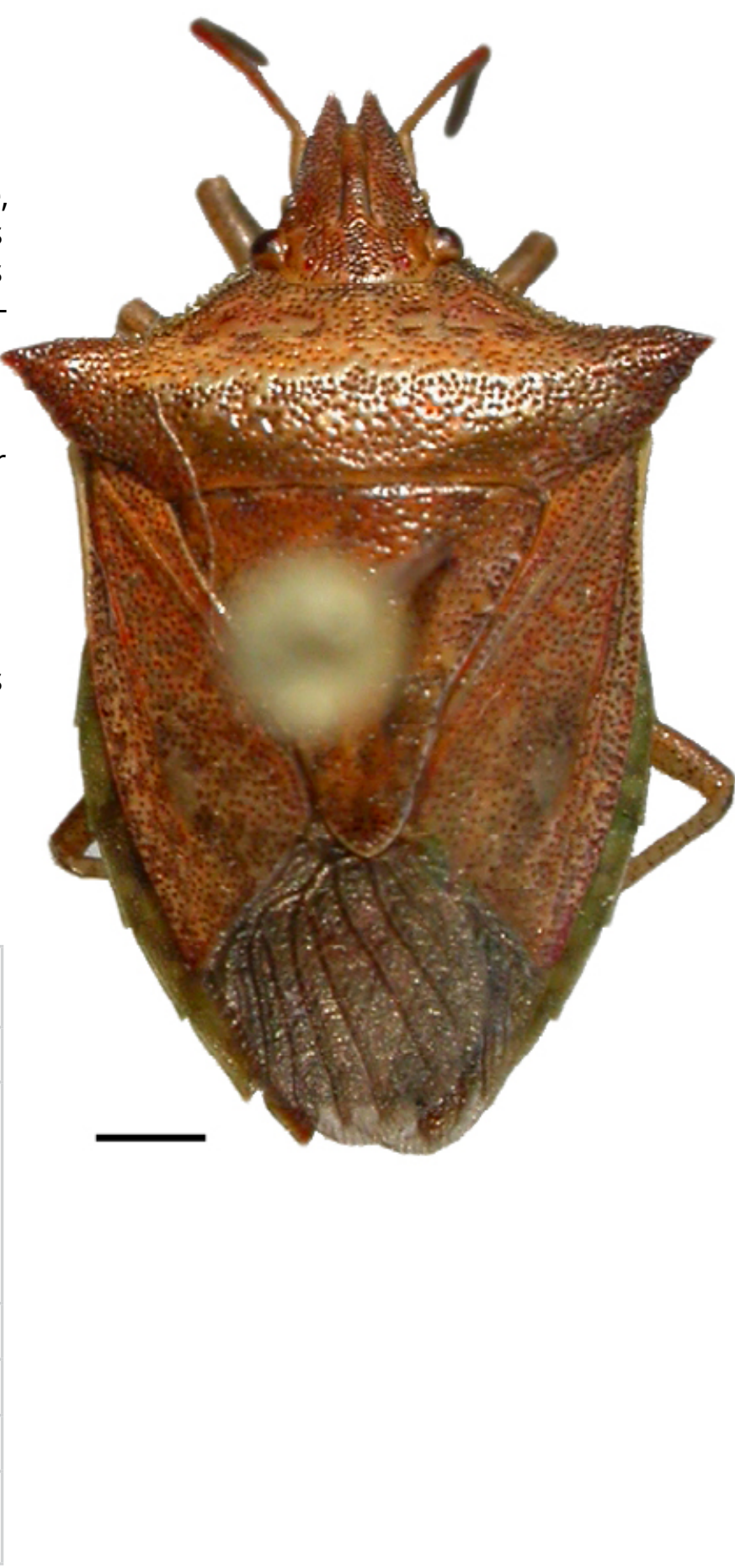

\section{Bibliografias:}

Basso, L.V.; Link, D. \& Lopes, O.J. 1974. Entomofauna de algumas solanáceas em Santa Maria, RS. Rev. Centro Ciências Rurais 4 (3): 263-270.

FMC. 2013. Percevejos.com.br. Disponível online em: http://www.percevejos.com.br/ [Acesso em: 19 dez. 2013.]

Grazia, J. 1977. Revisão dos Pentatomineos citados no Quarto Catálogo dos Insetos que Vivem nas Plantas do Brasil (Hemiptera: Pentatomidae, Pentatomini). Dusenia 10 (3): 161-174. 
Grazia, J. 1978. Revisão do gênero Dichelops Spinola, 1837 (Heteroptera, Pentatomidae, Pentatomini). Iheringia, Sér. Zool. 53: 1-119.

Lopes, O.J.; Link, D. \& Basso, L.V. 1974. Pentatomídeos de Santa Maria - Lista preliminar de plantas hospedeiras. Rev. Centro Ciências Rurais 4 (4): 317-322.

Panizzi, A.R.; McPherson, J.E.; James, D.G.; Javahery, J.M. \& McPherson, R.M. 2000. Stink Bugs (Pentatomidae) p. 421-474. In: C.W. Schaefer \& A.R. Panizzi (Org). Heteroptera of economic importance. USA, CRC Press.

Poock-da-Silva, P.; Barão, K.R. \& Grazia, J. 2013. Contributions to the knowledge of Dichelops Spinola: description of a new species of Dichelops (Diceraeus) and of the male of Dichelops (Prodichelops) divisus (Hemiptera: Heteroptera: Pentatomidae: Pentatominae: Carpocorini). Zootaxa 3609: 060-068.

Rider, D.A. 1998. Nomenclatural changes in the Pentatomoidea (Hemiptera: Heteroptera: Pentatomidae, Tessaratomidae). III. Generic level changes. Proc. Entomol. Soc. Wash. 100 (3): 504-510.

Salvadori, J.R.; Lau, D. \& Pereira, P.R.V.da S. 2009. Pragas e métodos de controle. Embrapa Trigo, Sistemas de Produção No. 4. Cultivo de Trigo. Disponível online em: http://sistemasdeproducao.cnptia. embrapa.br/FontesHTML/Trigo/CultivodeTrigo/pragas.htm [Acesso em: 19 dez. 2013.] 


\section{Dichelops (D.) phoenix Grazia, 1978}

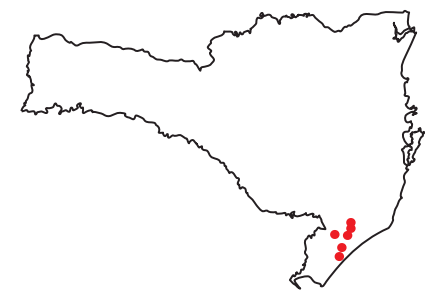

Diagnose: Coloração geral semelhante a $D i$ chelops (D.) furcatus; pronoto na metade anterior é amarelo ou ocre e na metade posterior é castanho enfuscado. Linha de pontuações negras ao longo da metade anterior das margens anterolaterais do pronoto e em torno das cicatrizes do pronoto (Grazia 1978).

Tamanho dos adultos: $\sigma^{\prime} 10,2-10,81 \mathrm{~mm}$; O 10,88-11,69 mm.

Metodologia de coleta: coleta manual, guarda-chuva entomológico e rede de varredura.

Local de coleta: Araranguá, Cocal do Sul, Criciúma, Maracajá, Nova Veneza e Urussanga.

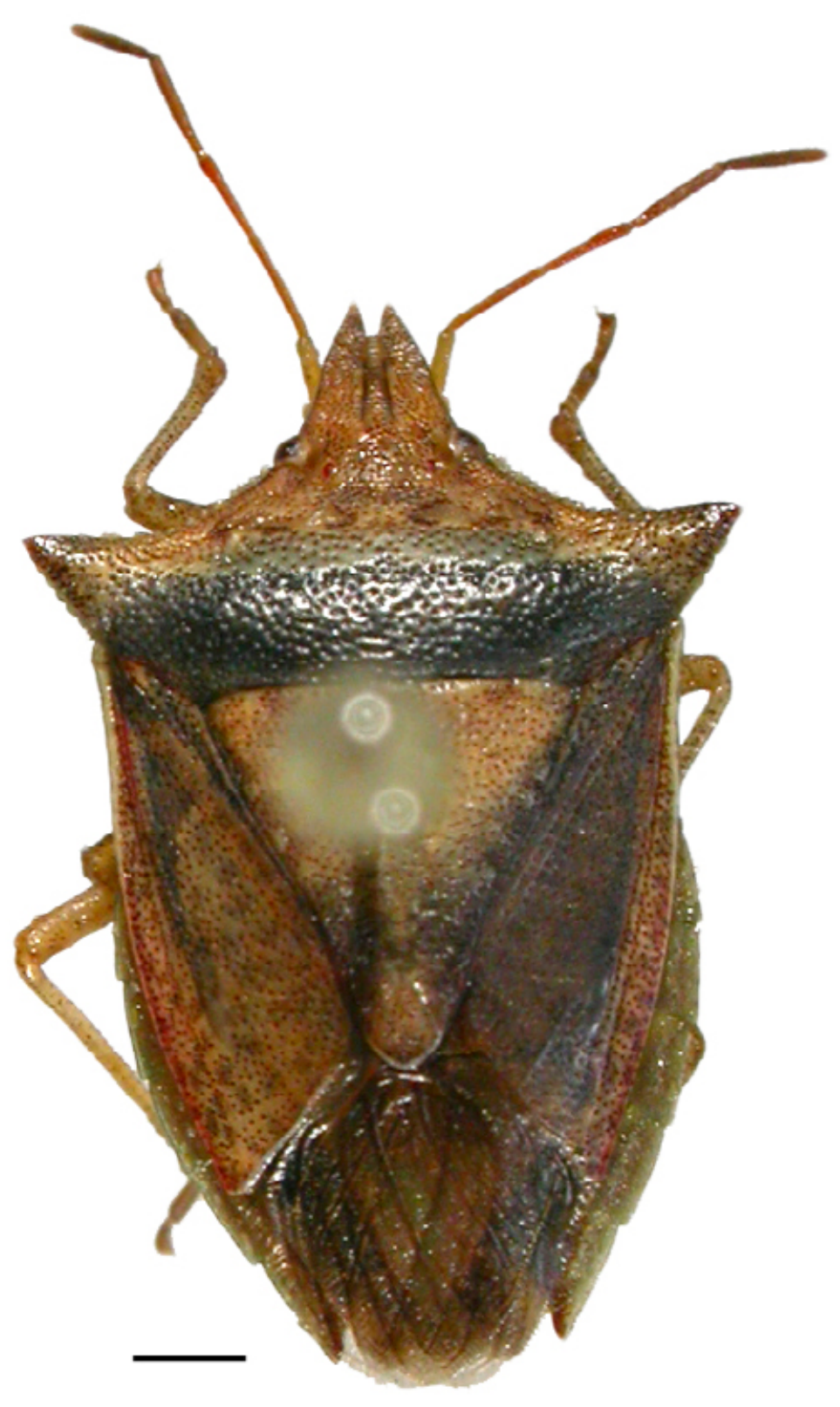

\section{Bibliografia:}

Grazia, J. 1978. Revisão do gênero Dichelops Spinola, 1837 (Heteroptera, Pentatomidae, Pentatomini). Iheringia, Sér. Zool. 53: 1-119.

Poock-da-Silva, P.; Barão, K.R. \& Grazia, J. 2013. Contributions to the knowledge of Dichelops Spinola: description of a new species of Dichelops (Diceraeus) and of the male of Dichelops (Prodichelops) divisus (Hemiptera: Heteroptera: Pentatomidae: Pentatominae: Carpocorini). Zootaxa 3609: 060-068.

Rider, D.A. 1998. Nomenclatural changes in the Pentatomoidea (Hemiptera: Heteroptera: Pentatomidae, Tessaratomidae). III. Generic level changes. Proc. Entomol. Soc. Wash. 100 (3): 504-510. 


\section{Euschistus (L.) aceratos} Berg, 1894

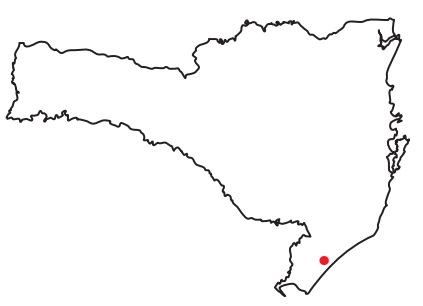

Diagnose: Coloração geral parda. Pronoto com margems ântero-laterais crenuladas; ângulos umerais obtusos, projetados lateralmente à margem do cório. Veias na membrana do hemiélitro reticuladas (Rolston 1982).

Tamanho dos adultos: 10,2-11,5 mm.

Metodologia de coleta: coleta manual, guarda-chuva entomológico e rede de varredura.

Local de coleta: Araranguá.

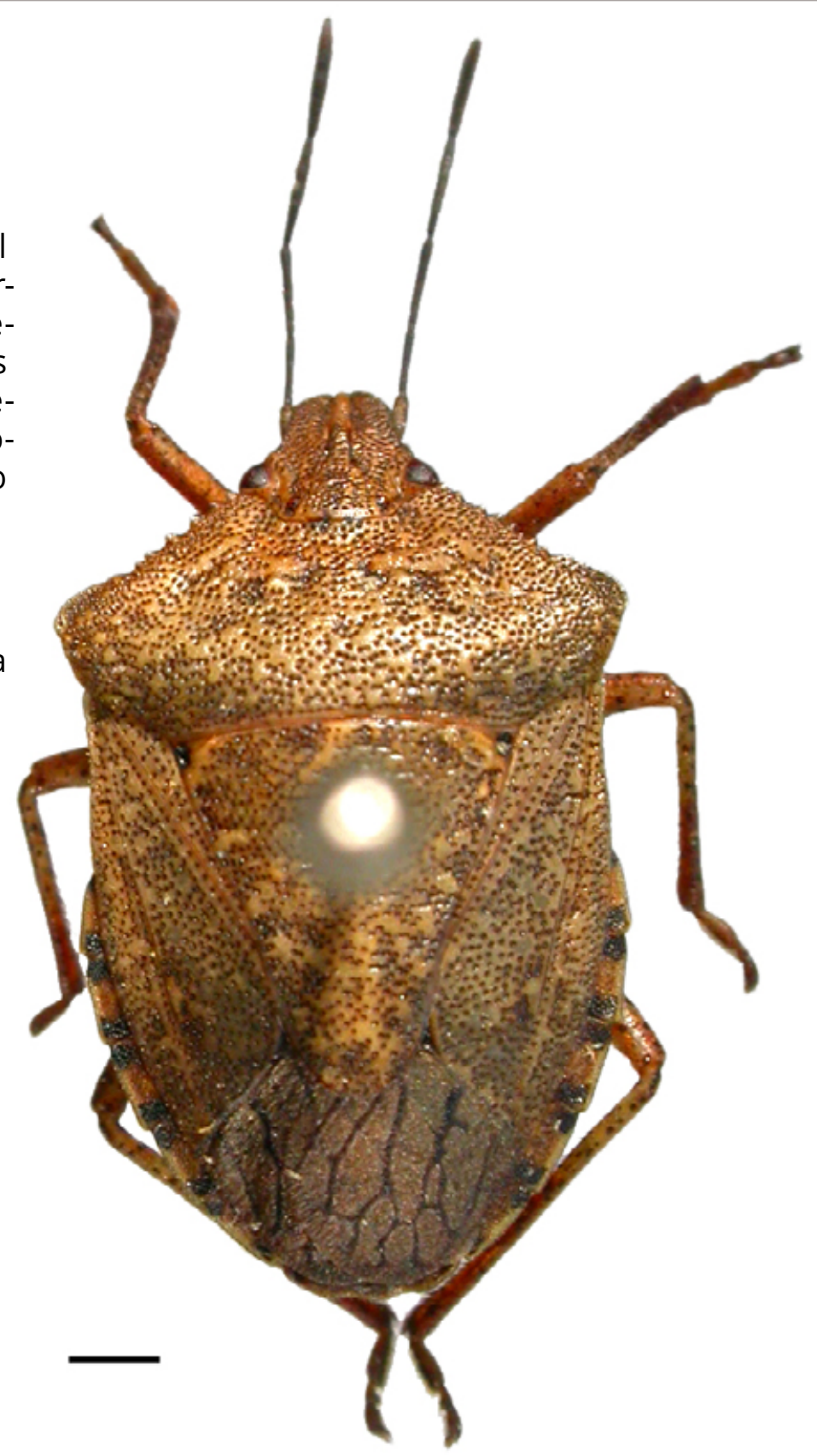

\section{Bibliografias:}

Rolston, L.H. 1982. A revision of Euschistus Dallas subgenus Lycipta Stål (Hemiptera: Pentatomidae). Proc. Entomol. Soc .Wash. 84 (2): 281-296.

Thomas, D.B. 1983. A note on the homonymy of Euschistus luridus Dallas, 1851 (Hemiptera: Pentatomidae). Proc. Entomol. Soc. Wash. 85 (1): 182.

Weiler, L.; Ferrari, A. \& Grazia, J. 2011. Contributions to the knowledge of Euschistus (Lycipta) with the description of $E$. (L.) riograndensis sp. nov. (Hemiptera: Heteroptera: Pentatomidae: Pentatominae: Carpocorini). Zootaxa 3067: 59-64. 


\section{Euschistus (L.) triangulator (Herrich-Schäffer, 1842)}

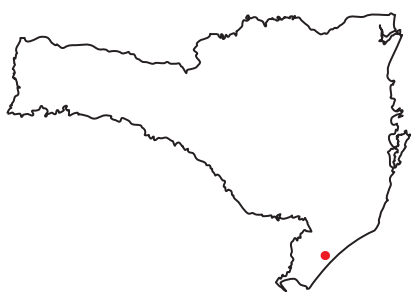

Diagnose: Coloração geral parda. Ângulos umerais em espinho, bastante projetados ântero-lateralmente. Ápice do escutelo de coloração marfim, normalmente um tanto refletido. Veias da membrana do hemiélitro reticuladas (Rolston 1982).

Tamanho dos adultos: 9,4-10,5 mm.

Metodologia de coleta: guarda-chuva entomológico e rede de varredura.

Local de coleta: Araranguá.

$=$

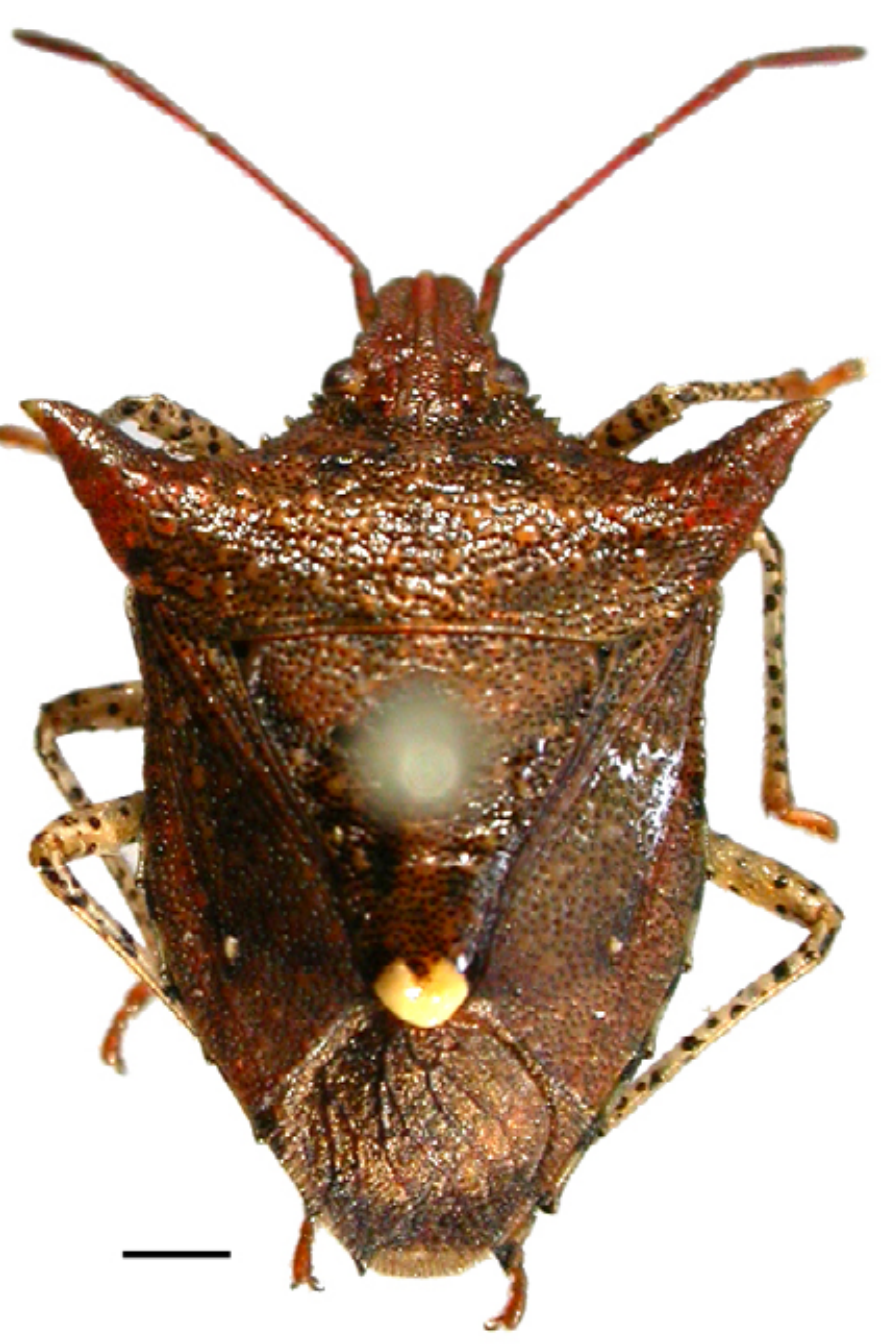

\section{Bibliografias:}

Rolston, L.H. 1982. A revision of Euschistus Dallas subgenus Lycipta Stål (Hemiptera: Pentatomidae). Proc. Entomol. Soc .Wash. 84 (2): 281-296.

Weiler, L.; Ferrari, A. \& Grazia, J. 2011. Contributions to the knowledge of Euschistus (Lycipta) with the description of $E$. (L.) riograndensis sp. nov. (Hemiptera: Heteroptera: Pentatomidae: Pentatominae: Carpocorini). Zootaxa 3067: 59-64. 


\section{Euschistus (M.) hansi Grazia, 1987}

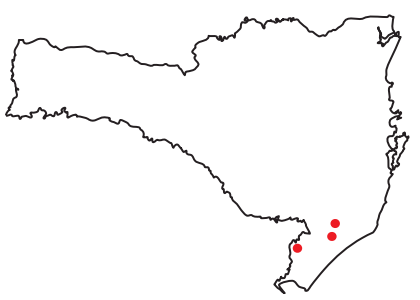

Diagnose: Coloração geral parda, ventralmente amarelado. Cabeça e porção anterior do pronoto fusco a negro com fraco tom bronze. Calosidades claras na borda posterior de cada lado da cicatriz do pronoto; ângulos umerais desenvolvidos ântero-lateralmente com ápice arredondado. Pequena mancha pálida mediana normalmente presente na base do escutelo (Rolston 1978).

Tamanho dos adultos: $8,4-10,1 \mathrm{~mm}$.

Metodologia de coleta: coleta manual, guarda-chuva entomológico e pit-fall.

Local de coleta: Criciúma, Timbé do Sul e Urussanga.

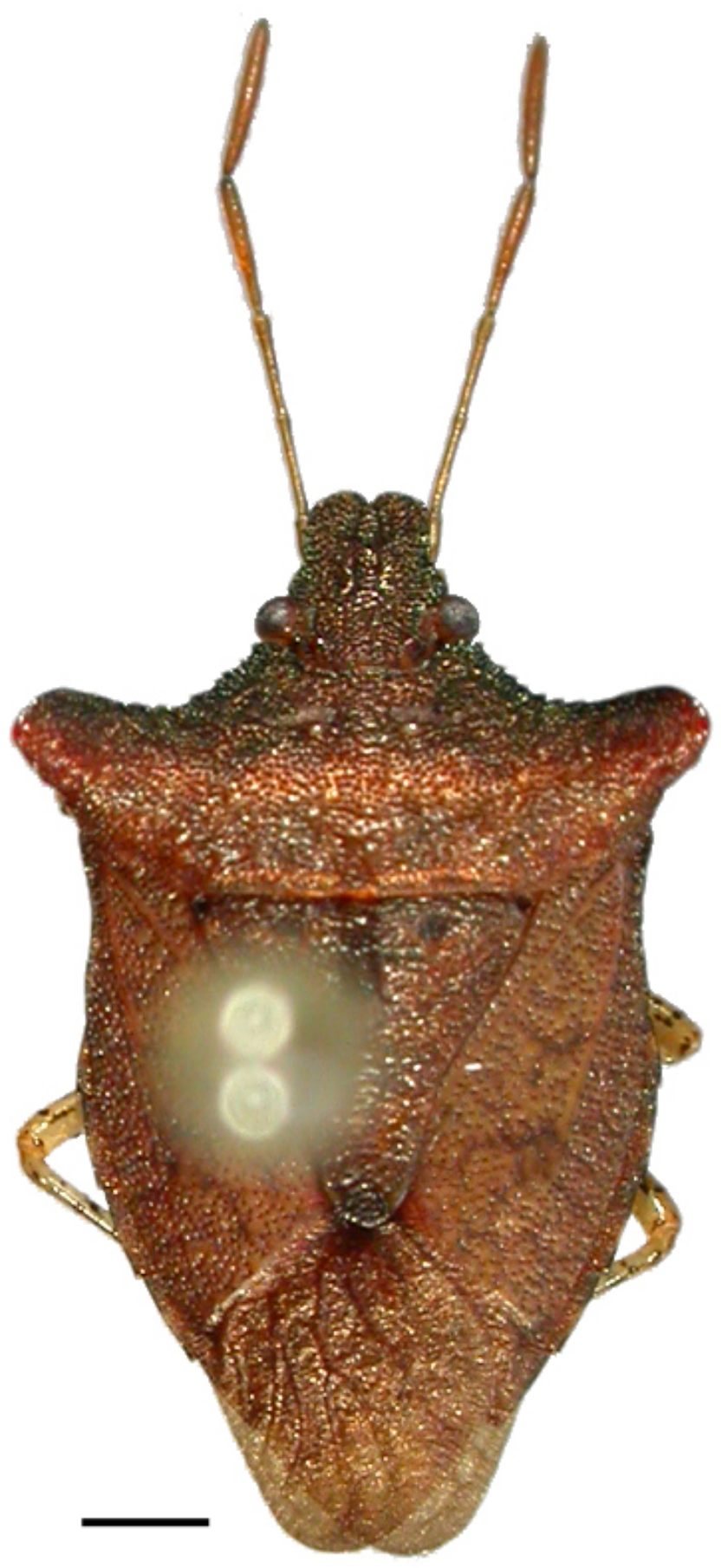

\section{Bibliografias:}

Grazia, J. 1987. Duas novas espécies de Euschistus do subgênero Mitripus Rolston, 1978 (Heteroptera, Pentatomidae, Pentatomini). Rev. Bras. entomol. 31 (1): 83-88.

Martins, F.S. \& Campos, L.A. 2006. Morfologia e biologia dos imaturos de Euschistus hansi (Hemiptera, Heteroptera, Pentatomidae). Iheringia, Sér. Zool. 96 (2): 213-218.

Rolston, L.H. 1978. A new subgenus of Euschistus (Hemiptera: Pentatomidae). J. New York Entomol. Soc. 86 (2): 102-120. 


\section{Galedanta bituberculata} Amyot \& Serville, 1843

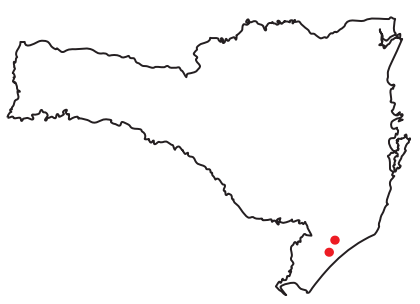

Diagnose: Coloração geral parda com manchas ferrugíneas nas pernas e conexivo. Ângulos umerais projetados lateralmente variando de arredondados a nitidamente truncados Presença de um tubérculo negro nos ângulos basais do escutelo (Grazia 1967, 1981).

Tamanho dos adultos: $18,8-19,8 \mathrm{~mm}$.

Metodologia de coleta: coleta manual, guarda-chuva entomológico.

Local de coleta: Criciúma, Maracajá.

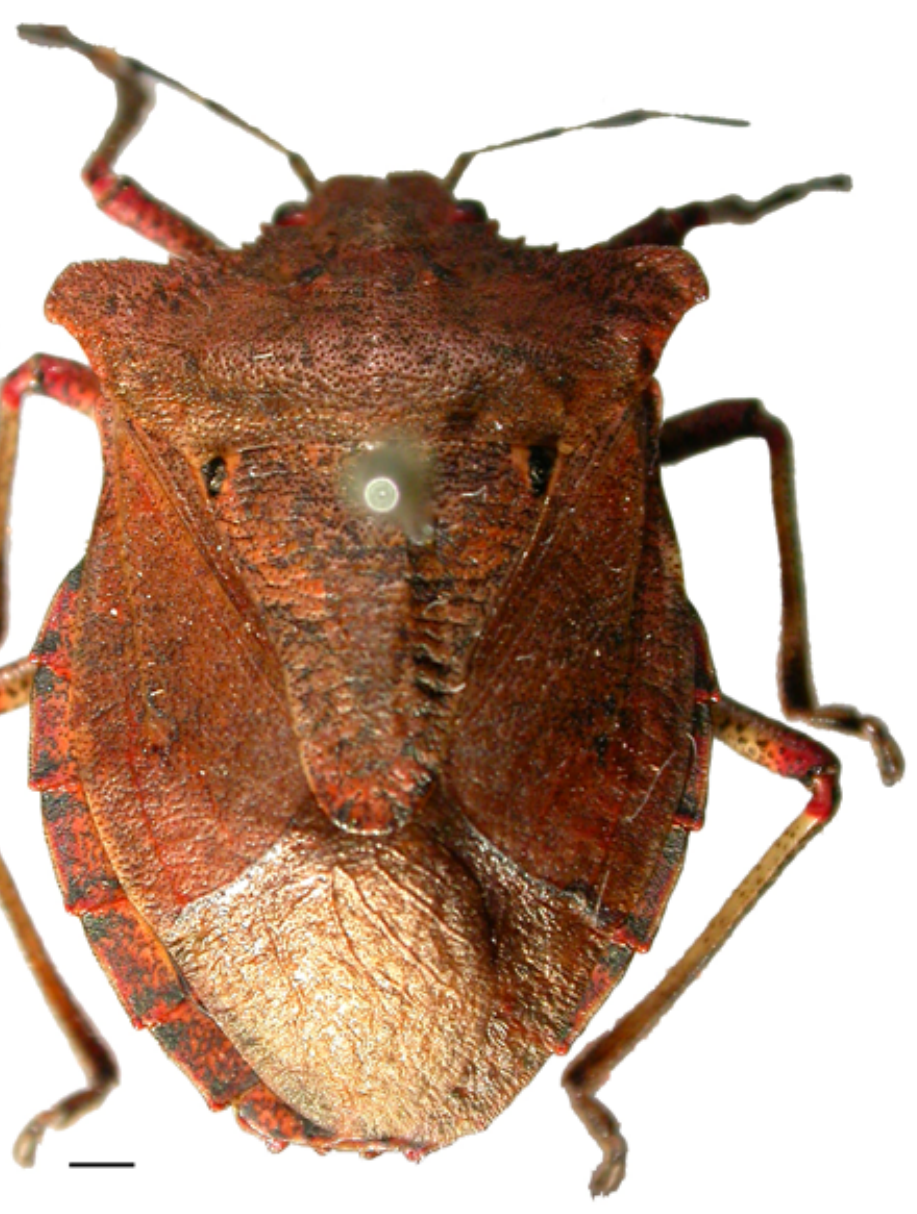

\section{Bibliografias:}

Grazia, J. 1967. Estudos sobre o gênero Galedanta Amyot \& Serville, 1843 (Hemiptera-Heteroptera, Pentatomidae). Iheringia, Sér. Zool. 35: 45-59.

Grazia, J. 1981. Novas considerações sobre Galedanta Amyot \& Serville, 1843 com a descrição de duas novas espécies (Heteroptera: Pentatomini). An. Soc. Entomol. Bras. 10 (1): 9-19. 


\section{Glyphepomis adroguensis} Berg, 1891

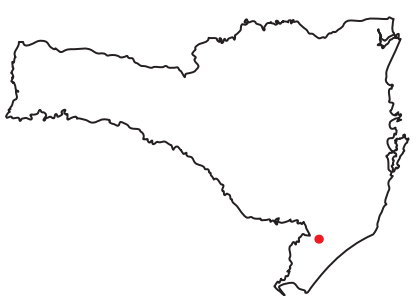

Diagnose: Coloração ocre a marrom escura. Superfície do corpo glabra. Ângulos ântero-laterais do pronoto em dentículos triangulares, deprimidos. Abdômen ventralmente com faixas laterais amplas larmente pontuadas (Campos \& Grazia 1998). ocre-amareladas, intensas e regu-

Tamanho dos adultos: $\sigma$ 5,74-7,3 mm; $@$ 6,56-7,79 Metodologia de coleta: coleta manual.

Local de coleta: Nova Veneza.

\section{Bibliografias:}

Campos, L.A. \& Grazia, J. 1998. Revisão de Glyphepomis Berg, 1891 (Heteroptera, Pentatomidae). Rev. Bras. entomol. 41 (2-4): 203-212. 


\section{Hypatropis inermis (Stål, 1872)}

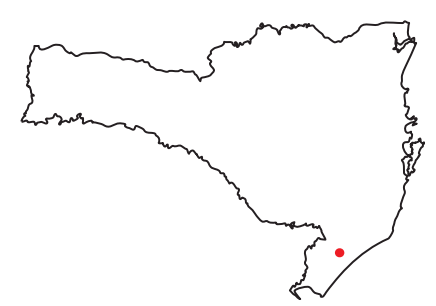

Diagnose: Coloração amarelo-pálida a castanho escura. Corpo ovalado, e convexo ventralmente. Jugas e clípeo subiguais em comprimento. Margens anterolaterais do pronoto crenuladas ou serrilhadas no terço ou metade anterior. Espiráculos negros e elípticos (Fernandes \& Grazia 1996).

Tamanho dos adultos: $\sigma 6,97-9,18 \mathrm{~mm}$; @ 7,54-9,84 mm.

Metodologia de coleta: rede de varredura.

Local de coleta: Maracajá.

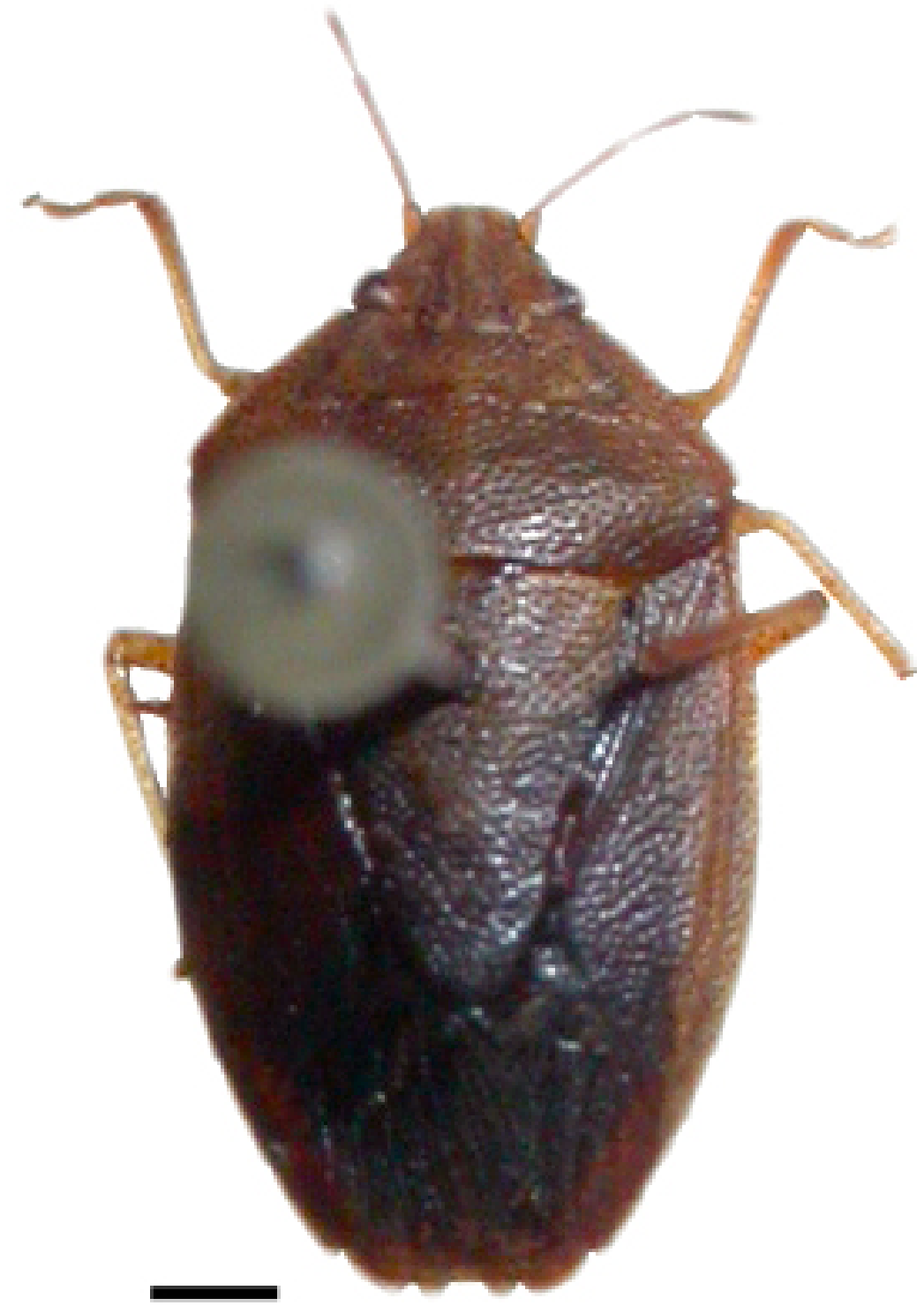

\section{Bibliografias:}

Fernandes, J.A.M. \& Grazia, J. 1996. Revisão do gênero Hypatropis Bergroth, 1891 (Heteroptera, Pentatomidae). Rev. Bras. entomol. 40 (3/4): 341-352. 


\section{Mormidea hamulata Stål, 1860}

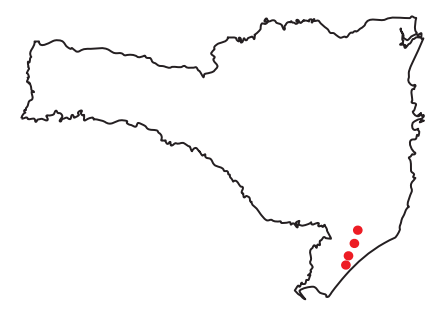

Diagnose: Dorsalmente fusco, margens basais da costa e conexivo, com frequência com uma mancha amarela pardacenta a marfim. Margens ântero-laterais do pronoto inteiramente côncavas; ângulos umerais projetados lateralmente, agudo ou subagudo no ápice. Pernas avermelhadas com pequenas manchas fuscas (Rolston 1978).

Tamanho dos adultos: 9-10,5 mm

Metodologia de coleta: coleta manual, guarda-chuva entomológico e rede de varredura.

Local de Coleta: Araranguá, Criciúma, Maracajá e Urussanga

\begin{tabular}{|l|l|l|}
\hline & Planta hospedeira & Nome popular \\
\hline Malvaceae & $\begin{array}{l}\text { Gossypium } \\
\text { arboreum L. }\end{array}$ & Algodoeiro \\
\hline
\end{tabular}

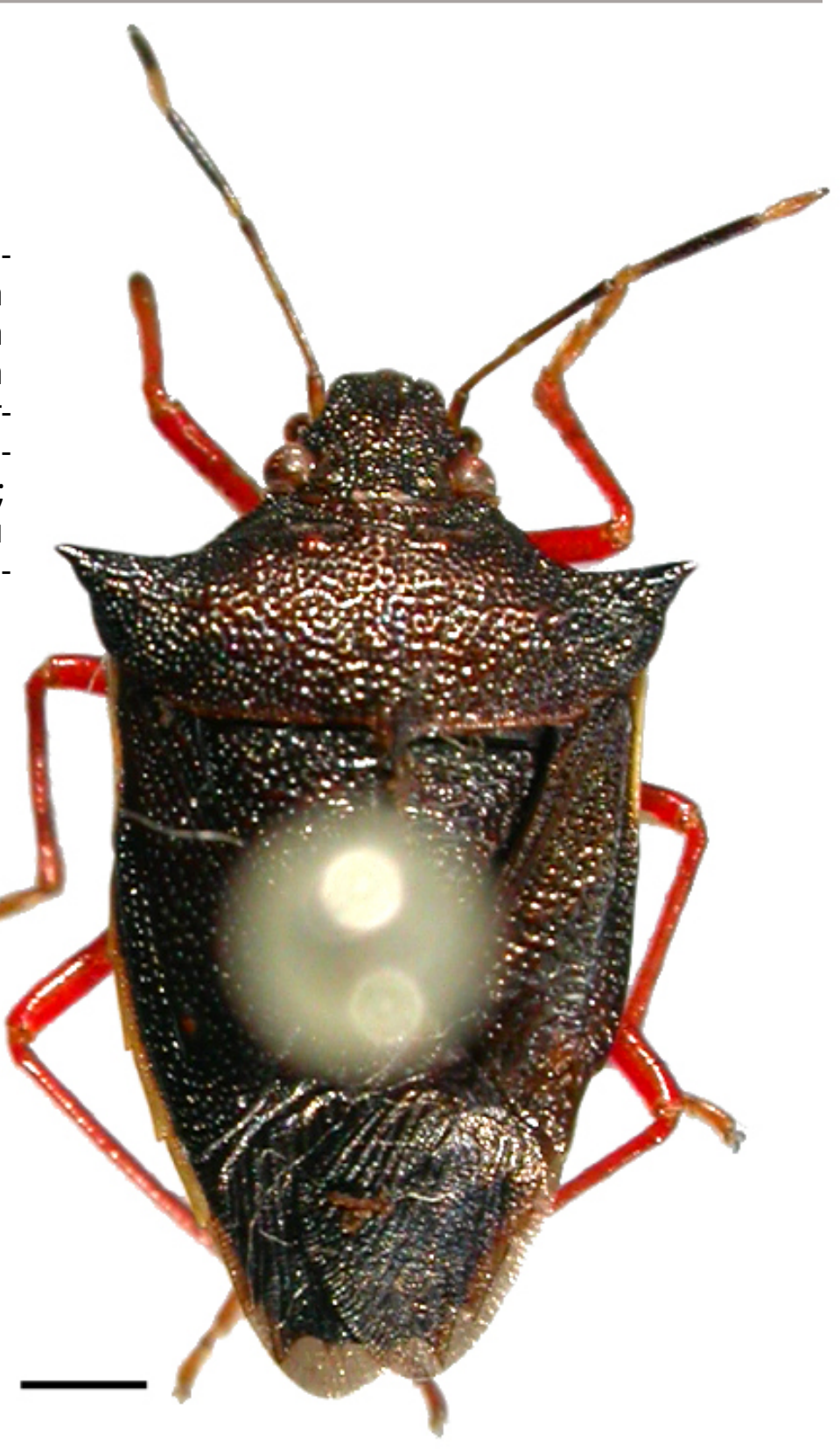

\section{Bibliografias:}

Grazia, J. 1977. Revisão dos Pentatomineos citados no Quarto Catálogo dos Insetos que Vivem nas Plantas do Brasil (Hemiptera: Pentatomidae, Pentatomini). Dusenia 10 (3): 161-174.

Rolston, L H. 1978. A revision of the genus Mormidea (Hemiptera: Pentatomidae). J. New York Entomol. Soc. 86 (3): 161-219. 


\section{Mormidea notulifera Stål, 1860}

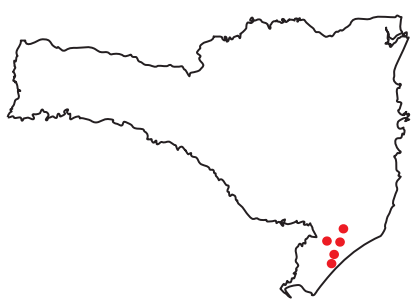

Diagnose: Castanho claro a fusco no dorso, normalmente negro nos úmeros. Ponto marfim atrás de cada cicatriz, medianamente com a base do escutelo, e no disco do cório, as vezes ausente no pronoto. Mancha calosa nos ângulos basais do escutelo estendendo-se submarginalmente ao longo do freno; ápice do escutelo marfim. Úmeros pouco projetados arredondados ou projetados lateralmente, espinhoso (Rolston 1978).

Tamanho dos adultos: 7-8,5 mm

Metodologia de coleta: coleta manual, guarda-chuva entomológico, rede de varredura e coleta de serrapilheira.

Local de Coleta: Araranguá, Criciúma, Maracajá, Nova Veneza e Urussanga.

Nome popular: percevejo-do-grão.

\begin{tabular}{|l|l|l|}
\hline & Planta hospedeira & Nome popular \\
\hline Asteraceae & Grindelia robusta Nutt. & Mal-me-quer \\
\hline Euphorbiaceae & Ricinus communis L. & Mamona \\
\hline Fabaceae & $\begin{array}{l}\text { Cassia macranthera } \\
\text { DC.; Lupinus albus L. }\end{array}$ & $\begin{array}{l}\text { Manduirana; } \\
\text { Tremoço branco }\end{array}$ \\
\hline Poaceae & $\begin{array}{l}\text { Triticum aestivum L.; Oryza } \\
\text { sativa L.; Secale cereale } \\
\text { L.; Lolium multiflorum L. }\end{array}$ & $\begin{array}{l}\text { Trigo; Arroz; } \\
\text { Centeio; Azevém }\end{array}$ \\
\hline Polygonaceae & $\begin{array}{l}\text { Polygonum acre Kunth. } \\
\text { Erva-de-bicho }\end{array}$ \\
\hline Solanaceae & Solanum gilo Raddi & jiloeiro \\
\hline
\end{tabular}

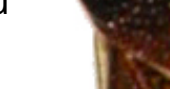

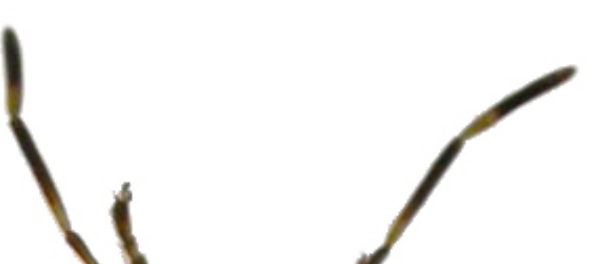

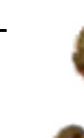

.

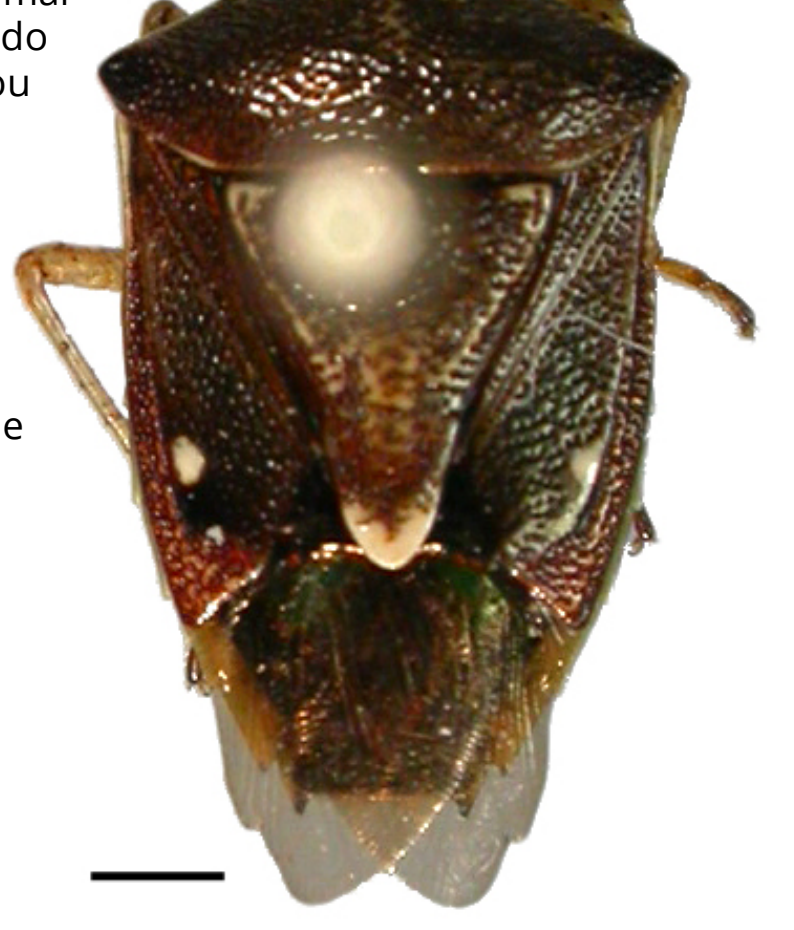

\section{Bibliografias:}

Barrigossi, J.A.F. \& Martins, J.F.da S. 2006. Pragas e métodos de controle. Embrapa Arroz e Feijão, Sistemas de Produção No. 7, Cultivo do arroz de terras altas no Estado de Mato Grosso. Disponível online em: http://sistemasdeproducao.cnptia.embrapa.br/FontesHTML/Arroz/ArrozTerrasAltasMatoGrosso/ pragas_metodos_controle.htm\#pg [Acesso em: 19 dez. 2013]

Grazia, J. 1977. Revisão dos Pentatomineos citados no Quarto Catálogo dos Insetos que Vivem nas Plantas do Brasil (Hemiptera: Pentatomidae, Pentatomini). Dusenia 10 (3): 161-174.

Link, D. \& Grazia, J. 1987. Pentatomídeos da região central do Rio Grande do Sul (Heteroptera). An. Soc. Entomol. Bras. 16 (1): 115-129.

Panizzi, A.R. 1997. Wild hosts of Pentatomids: ecological significance and role in their pest status on crops. Annu. Rev. Entomol. 42: 99-122. 
Panizzi, A.R.; McPherson, J.E.; James, D.G.; Javahery, J.M. \& McPherson, R.M. 2000. Stink Bugs (Pentatomidae) p. 421-474. In: C.W. Schaefer \& A.R. Panizzi (Org). Heteroptera of economic importance. USA, CRC Press.

Picanço, M.; Casali, V.W.D.; Leite, G.L.D. \& de Oliveira, I.R 1999. Heteropteros associados ao Solanum gilo (Raddi, 1825). Agro-Ciência 15 (1): 81-88.

Rolston, L H. 1978. A revision of the genus Mormidea (Hemiptera: Pentatomidae). J. New York Entomol. Soc. 86 (3): 161-219. 


\section{Mormidea v-luteum (Lichtenstein, 1796)}

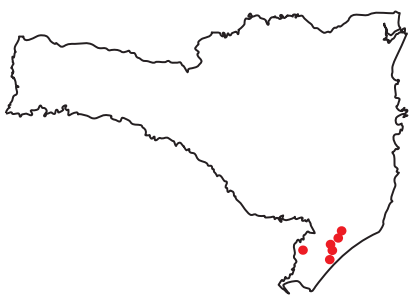

escutelo e margem da costa no cório ao longo do terço basal, marfim. Pernas castanhas com manchas negras. Úmeros pouco arredondados ou projetados em espinho. Manchas podem ser completamente ausentes ou representadas em parte (Rolston 1978).

Tamanho dos adultos: 7,3-8,9 mm

* Fotos ilustrando a variação de padrões de coloração.

Metodologia de coleta: coleta manual, guarda-chuva entomológico, rede de varredura e armadilha luminosa.

Local de Coleta: Araranguá, Cocal do Sul, Criciúma, ForquiIhinha, Maracajá, Timbé do Sul e Urussanga.

Nome popular: percevejo-do-grão.

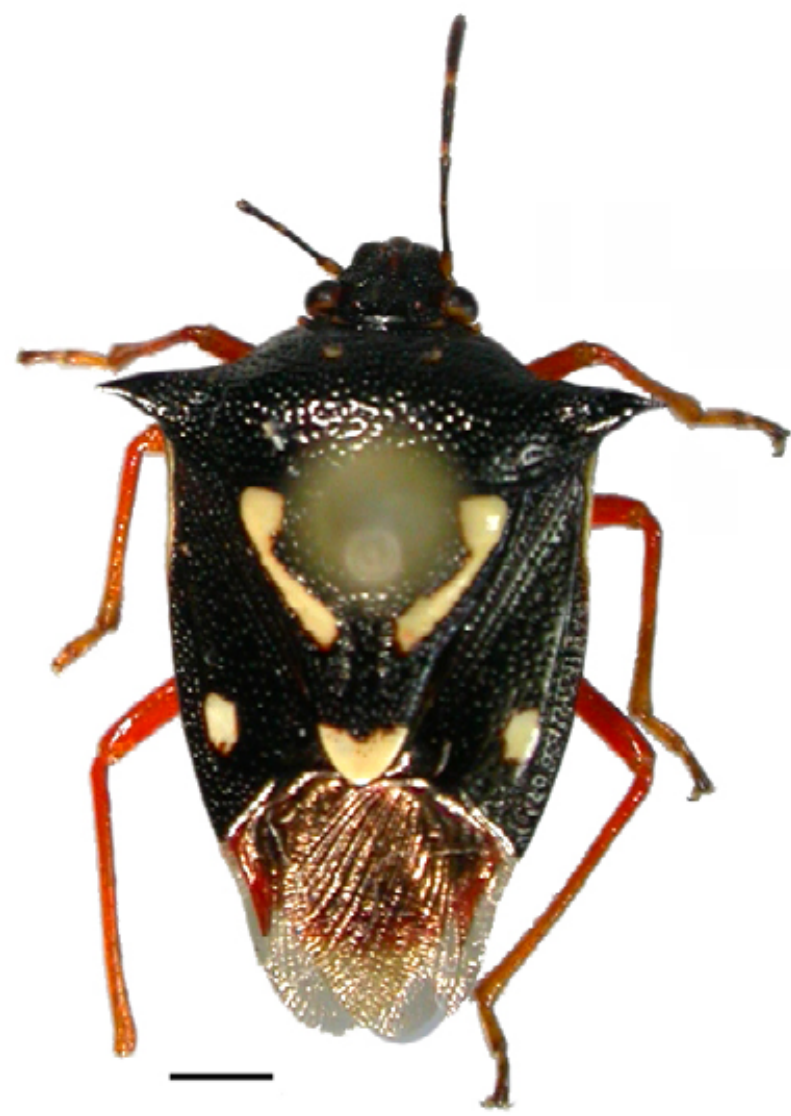

manchas marfim no cório, outra mediana na base do escutelo, normalmente uma junto a cada cicatriz do pronoto; em cada lado do escutelo gulo basal e estendendo-se submargi-

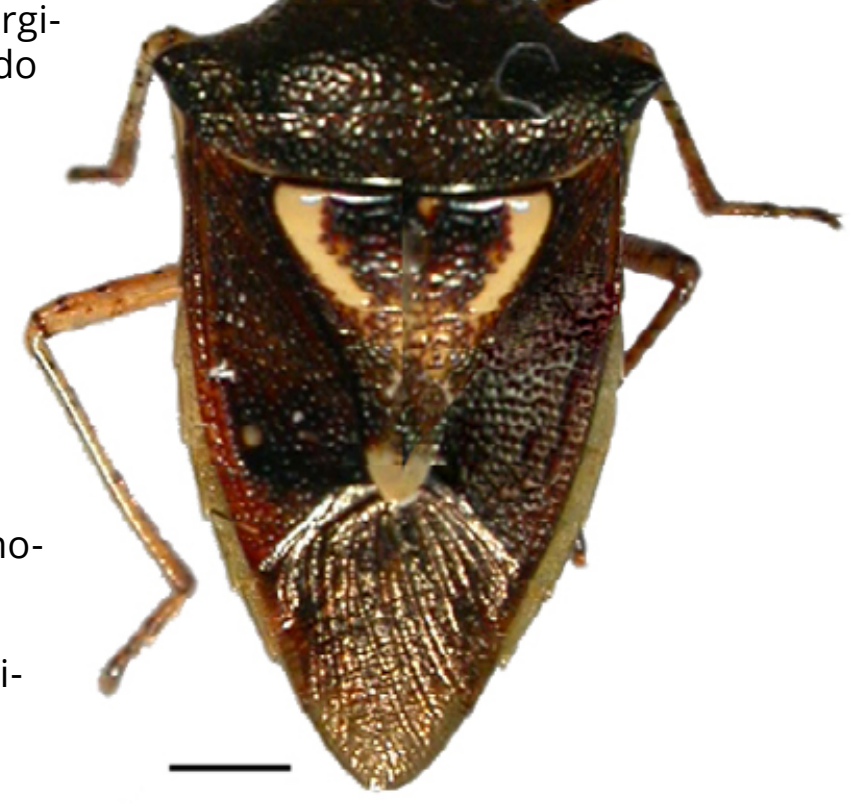




\begin{tabular}{|l|l|l|}
\hline & Planta hospedeira & Nome popular \\
\hline Brassicaceae & Brassica napus L. var. oleifera Meitzg. & Colza \\
\hline Fabaceae & Glycine max (L.) Merrill; Lupinus albus L. & Soja; Tremoço-branco \\
\hline Poaceae & $\begin{array}{l}\text { Phallaris canariensis L.; Oryza sativa L.; Echinochloa cruzgali } \\
\text { (L.) Beauv. var. crusgalli; Paspalum urvillei Steud.; Panicum } \\
\text { sanguinale (L.) Scop.; Triticum aestivum L.; Zea mays L.; } \\
\text { Lolium multiflorum L.; Panicum grumosum Nees; }\end{array}$ & $\begin{array}{l}\text { Alpiste; Arroz; Capim-arroz; } \\
\text { Forquilhão; Milhã; Trigo; } \\
\text { Milho; Azevém; Canevão; }\end{array}$ \\
\hline Polygonaceae & Polygonum acre Kunth. & Erva-de-bicho \\
\hline Solanaceae & Lycopersicum esculentum Mill.; Nicotiana tabacum L. & Tomate; Fumo \\
\hline
\end{tabular}

\section{Bibliografias:}

Barrigossi, J.A.F. \& Martins, J.F.da S. 2006. Pragas e métodos de controle. Embrapa Arroz e Feijão, Sistemas de Produção No. 7, Cultivo do arroz de terras altas no Estado de Mato Grosso. Disponível online em: http://sistemasdeproducao.cnptia.embrapa.br/FontesHTML/Arroz/ArrozTerrasAltasMatoGrosso/ pragas_metodos_controle.htm\#pg [Acesso em: 19 dez. 2013]

Grazia, J. 1977. Revisão dos Pentatomineos citados no Quarto Catálogo dos Insetos que Vivem nas Plantas do Brasil (Hemiptera: Pentatomidae, Pentatomini). Dusenia, 10 (3): 161-174.

Link, D. \& Grazia, J. 1987. Pentatomídeos da região central do Rio Grande do Sul (Heteroptera). An. Soc. Entomol. Bras. 16 (1): 115-129.

Lopes, O.J.; Link, D. \& Basso, L.V. 1974. Pentatomídeos de Santa Maria - Lista preliminar de plantas hospedeiras. Rev. Centro Ciências Rurais, 4 (4): 317-322.

Panizzi, A.R.; McPherson, J.E.; James, D.G.; Javahery, J.M. \& McPherson, R.M. 2000. Stink Bugs (Pentatomidae) p. 421-474. In: C.W. Schaefer \& A.R. Panizzi (Org). Heteroptera of economic importance. USA, CRC Press.

Rolston, L H. 1978. A revision of the genus Mormidea (Hemiptera: Pentatomidae). J. New York Entomol. Soc. 86 (3): 161-219. 


\section{Oebalus poecilus (Dallas, 1851)}

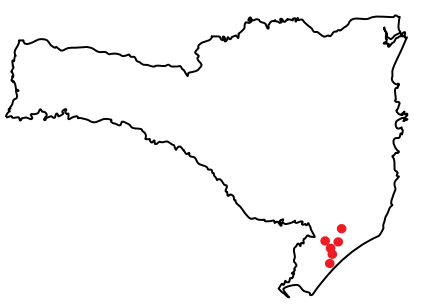

Diagnose: Forma oval alongada. Coloração ferrugínea a castanho escuro dorsalmente. Nas formas escuras, máculas calosas marfim na declividade do pronoto de cada lado da linha mediana. Escutelo com ampla área calosa amarela de cada lado da metade basal e no ápice. Mancha retangular marfim no disco do cório. Nas formas claras menor desenvolvimento dessas áreas com manchas. Pronoto declivoso anteriormente aos ângulos umerais, estes desenvolvidos em espinho com variação na intensidade deste desenvolvimento (Sailer 1944).

Tamanho dos adultos: $\sigma$ 6,9-8,3 mm; $९$ 7,4-9,5 mm

Fotos: forma escura (acima) e clara (abaixo).

Metodologia de coleta: coleta manual, guarda-chuva entomológico, rede de varredura e coleta de serrapilheira.

Local de coleta: Araranguá, Criciúma, Forquilhinha, Maracajá, Nova Veneza e Urussanga.

Nomes populares: Percevejo-do-grão, percevejo-do-arroz, percevejo-pequeno-do-arroz, percevejo-do-grão-do-arroz, percevejo-da-panícula.

\begin{tabular}{|c|c|c|}
\hline & Planta hospedeira & Nome popular \\
\hline Brassicaceae & $\begin{array}{l}\text { Brassica napus L. var. } \\
\text { oleifera Meitzg. }\end{array}$ & Colza \\
\hline Fabaceae & $\begin{array}{l}\text { Glycine max (L.) Merrill; } \\
\text { Lupinus albus L.; Phaseolus } \\
\text { vulgaris L.; Lupinus Iuteus L. }\end{array}$ & $\begin{array}{l}\text { Soja; Tremoço- } \\
\text { branco; Feijão; } \\
\text { Tremoço-amarelo }\end{array}$ \\
\hline Malvaceae & Gossypium arboreum L. & Algodoeiro \\
\hline Poaceae & $\begin{array}{l}\text { Oryza sativa L.; Lolium } \\
\text { multiflorum L.; Echinochloa } \\
\text { cruzgalli (L.) Beauv. var. } \\
\text { cruzgalli; Paspalum urvillei } \\
\text { Steud.; Panicum sanguinale } \\
\text { (L.) Scop.; Triticum aestivum } \\
\text { L.; Zea mays L.; Avena sativa } \\
\text { L.; Hordeum vulgare L.; }\end{array}$ & $\begin{array}{l}\text { Arroz; Azevém; } \\
\text { Capim-arroz; } \\
\text { Forquilhão; } \\
\text { Milhã; Trigo; } \\
\text { Milho; Aveia; } \\
\text { Cevada; }\end{array}$ \\
\hline Polygonaceae & Polygonum acre Kunth. & Erva-de-bicho \\
\hline Solanaceae & $\begin{array}{l}\text { Solanum sisymbrifolium } \\
\text { Lam.; Solanum incarceratum } \\
\text { Ruiz \& Pav.; Solanum balbisii } \\
\text { Dunal; Capsicum annum L. }\end{array}$ & $\begin{array}{l}\text { Joá; _i _i } \\
\text { Pimentão }\end{array}$ \\
\hline
\end{tabular}
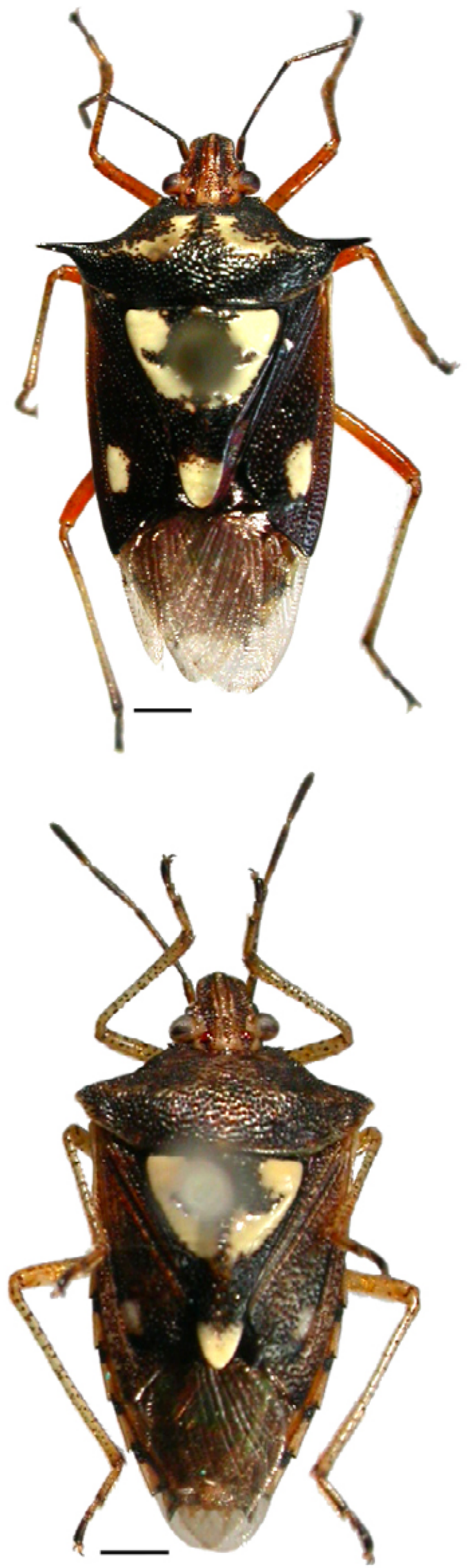


\section{Bibliografias:}

Barrigossi, J.A.F. \& Martins, J.F.da S. 2006. Pragas e métodos de controle. Embrapa Arroz e Feijão, Sistemas de Produção No. 7, Cultivo do arroz de terras altas no Estado de Mato Grosso. Disponível online em: http://sistemasdeproducao.cnptia.embrapa.br/FontesHTML/Arroz/ArrozTerrasAltasMatoGrosso/ pragas_metodos_controle.htm\#pg [Acesso em: 19 dez. 2013]

Ferreira, E.; Barrigossi, J.A.F. \& Vieira, N.R.de A. 2001. Percevejos das paniculas do arroz: fauna Heteroptera associada ao arroz. Santo Antonio de Goiás, GO. Embrapa Arroz e Feijão. 52p (Embrapa Arroz e Feijão. Circular técnica On-lin, 43). Disponível online em: http://ainfo.cnptia.embrapa.br/digital/ bitstream/item/59106/1/Circ-43.pdf [Acesso em: 20 dez. 2013.]

Grazia, J. 1977. Revisão dos Pentatomineos citados no Quarto Catálogo dos Insetos que Vivem nas Plantas do Brasil (Hemiptera: Pentatomidae, Pentatomini). Dusenia 10 (3): 161-174.

Link, D. \& Grazia, J. 1987. Pentatomídeos da região central do Rio Grande do Sul (Heteroptera). An. Soc. Entomol. Bras. 16 (1): 115-129.

Lopes, O.J.; Link, D. \& Basso, L.V. 1974. Pentatomídeos de Santa Maria - Lista preliminar de plantas hospedeiras. Rev. Centro Ciências Rurais, 4 (4): 317-322.

Panizzi, A.R.; McPherson, J.E.; James, D.G.; Javahery, J.M. \& McPherson, R.M. 2000. Stink Bugs (Pentatomidae) p. 421-474. In: C.W. Schaefer \& A.R. Panizzi (Org). Heteroptera of economic importance. USA, CRC Press.

Sailer, R.I. 1944. The genus Solubea (Heteroptera: Pentatomidae). Proc. Entomol. Soc. Wash. 46 (5): 105-127. 


\section{Oebalus ypsilongriseus} (De Geer, 1773)

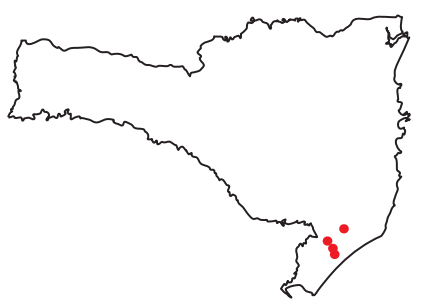

Diagnose: Corpo alongado e estreito. Coloração geral amarelo palha. Pronoto com pequenas pontuações redondas amarelas; ângulos umerais em espinhos negros direcionados para fora e ligeiramente para frente. Escutelo com calosidades amarelas marcadas ao longo da metade basal e no ápice. Forma hibernante com menor desenvolvimento das máculas e espinhos umerais (Oebalus grisescens, sensu Sailer 1944).

Tamanho dos adultos: $\sigma^{\prime \prime} 8-8,75 \mathrm{~mm} ; ~ \bigcirc 8,5-10 \mathrm{~mm}$.

Fotos: forma normal (acima) e forma hibernante (abaixo).

Metodologia de coleta: coleta manual, guarda-chuva entomológico, rede de varredura, armadilha luminosa e coleta de serrapilheira.

Local de coleta: Forquilhinha, Maracajá, Nova Veneza e Urussanga.

Nomes populares: Percevejo-do-grão, percevejo-do-grão-do-arroz, percevejo-da-panícula.

\begin{tabular}{|c|c|c|}
\hline & Planta hospedeira & Nome popular \\
\hline Apiaceae & $\begin{array}{l}\text { Foeniculum vulgare Mill. } \\
\text { var. capillaceum (Gilibi.) }\end{array}$ & Funcho \\
\hline Fabaceae & $\begin{array}{l}\text { Glycine wightii (W. } \\
\text { \& A.) Verdec. }\end{array}$ & Soja-perene \\
\hline Malvaceae & Gossypium arboreum L. & Algodoeiro \\
\hline Poaceae & $\begin{array}{l}\text { Oryza sativa L.; Avena } \\
\text { sativa L.; Lolium } \\
\text { multiflorum L.; Lolium } \\
\text { perene L.; Echinochloa } \\
\text { cruzgalli (L.) Beauv. var. } \\
\text { cruzgalli; Cynodon dactylon } \\
\text { (L.) Pers; Holcus lanatus } \\
\text { L.; Hordeum vulgare L.; } \\
\text { Paspalum urvillei Steud.; } \\
\text { Panicum maximum Jacq.; } \\
\text { Panicum sanguinale (L.) } \\
\text { Scop.; Paspalum notatum } \\
\text { Fl.; Triticum aestivum } \\
\text { L.; Secale cereale L.; }\end{array}$ & $\begin{array}{l}\text { Arroz; Aveia; } \\
\text { Azevém; } \\
\text { Azevém-perene; } \\
\text { Capim-arroz; } \\
\text { Capim-bermuda; } \\
\text { Capim-lanudo; } \\
\text { Cevada; } \\
\text { Forquilhão; } \\
\text { "Gatton } \\
\text { panic" "Green } \\
\text { panic"; Milhã; } \\
\text { Pensacola; Trigo; } \\
\text { Centeio; Arroz- } \\
\text { vermelho }\end{array}$ \\
\hline Polygonaceae & Polygonum acre Kunth. & Erva-de-bicho \\
\hline
\end{tabular}

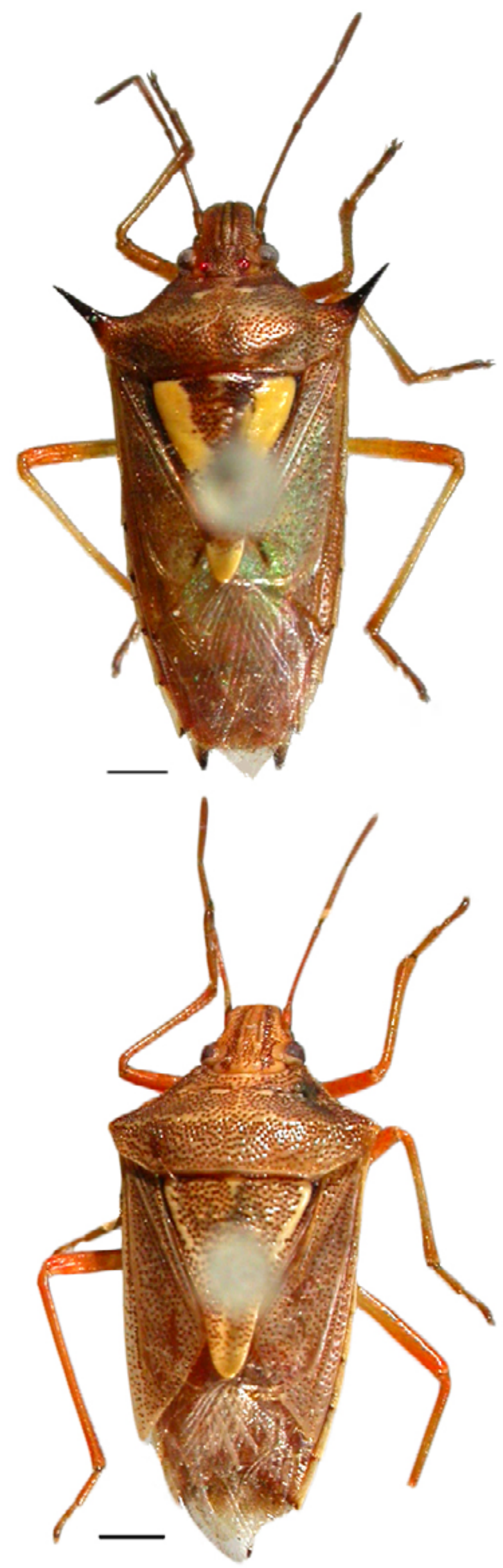




\section{Bibliografias:}

Barrigossi, J.A.F. \& Martins, J.F.da S. 2006. Pragas e métodos de controle. Embrapa Arroz e Feijão, Sistemas de Produção No. 7, Cultivo do arroz de terras altas no Estado de Mato Grosso. Disponível online em: http://sistemasdeproducao.cnptia.embrapa.br/FontesHTML/Arroz/ArrozTerrasAltasMatoGrosso/ pragas_metodos_controle.htm\#pg [Acesso em: 19 dez. 2013]

Ferreira, E.; Barrigossi, J.A.F. \& Vieira, N.R.de A. 2001. Percevejos das paniculas do arroz: fauna Heteroptera associada ao arroz. Santo Antonio de Goiás, GO. Embrapa Arroz e Feijão. 52p (Embrapa Arroz e Feijão. Circular técnica On-lin, 43). Disponível online em: http://ainfo.cnptia.embrapa.br/digital/ bitstream/item/59106/1/Circ-43.pdf [Acesso em: 20 dez. 2013.]

Grazia, J. 1977. Revisão dos Pentatomineos citados no Quarto Catálogo dos Insetos que Vivem nas Plantas do Brasil (Hemiptera: Pentatomidae, Pentatomini). Dusenia 10 (3): 161-174.

Link, D. \& Grazia, J. 1987. Pentatomídeos da região central do Rio Grande do Sul (Heteroptera). An. Soc. Entomol. Bras. 16 (1): 115-129.

Lopes, O.J.; Link, D. \& Basso, L.V. 1974. Pentatomídeos de Santa Maria - Lista preliminar de plantas hospedeiras. Rev. Centro Ciências Rurais, 4 (4): 317-322.

Panizzi, A.R.; McPherson, J.E.; James, D.G.; Javahery, J.M. \& McPherson, R.M. 2000. Stink Bugs (Pentatomidae) p. 421-474. In: C.W. Schaefer \& A.R. Panizzi (Org). Heteroptera of economic importance. USA, CRC Press.

Sailer, R.I. 1944. The genus Solubea (Heteroptera: Pentatomidae). Proc. Entomol. Soc. Wash. 46 (5): 105-127.

Vecchio, M. C. Del, J. Grazia, and G. S. Albuquerque. 1994. Dimorfismo sazonal em Oebalus ypsilongriseus (De Geer, 1773) (Hemiptera, Pentatomidae) e uma nova sinonímia. Revista Bras. entomol. 38 (1):101-108. 


\section{Paramecocephala australis Frey-da-Silva \& Grazia, 2002}

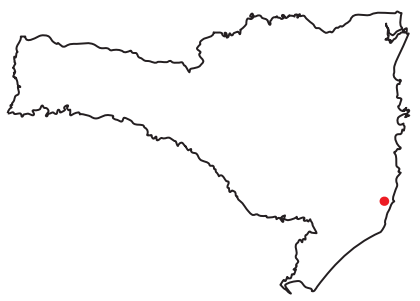

Diagnose: Coloração geral castanho-avermelhada; ventralmente castanho-escura a negra. Pontuações negras concentradas sobre as jugas e delineando as margens ântero e póstero-laterais do pronoto. Pronoto declivoso anteriormente aos ângulos umerais. Pode apresentar áreas subcalosas amareladas na base do escutelo. Cório com mancha calosa esbranquiçada a amarelada no ápice da veia radial (Frey-da-Silva et al. 2002).

Tamanho dos adultos: $\sigma 12,2-14,7 \mathrm{~mm} ;$ @ 12,53-15,87 mm

Metodologia de coleta: espécie com registro apenas em literatura e sem indicação de método de coleta.

Ocorrência: Imbituba.

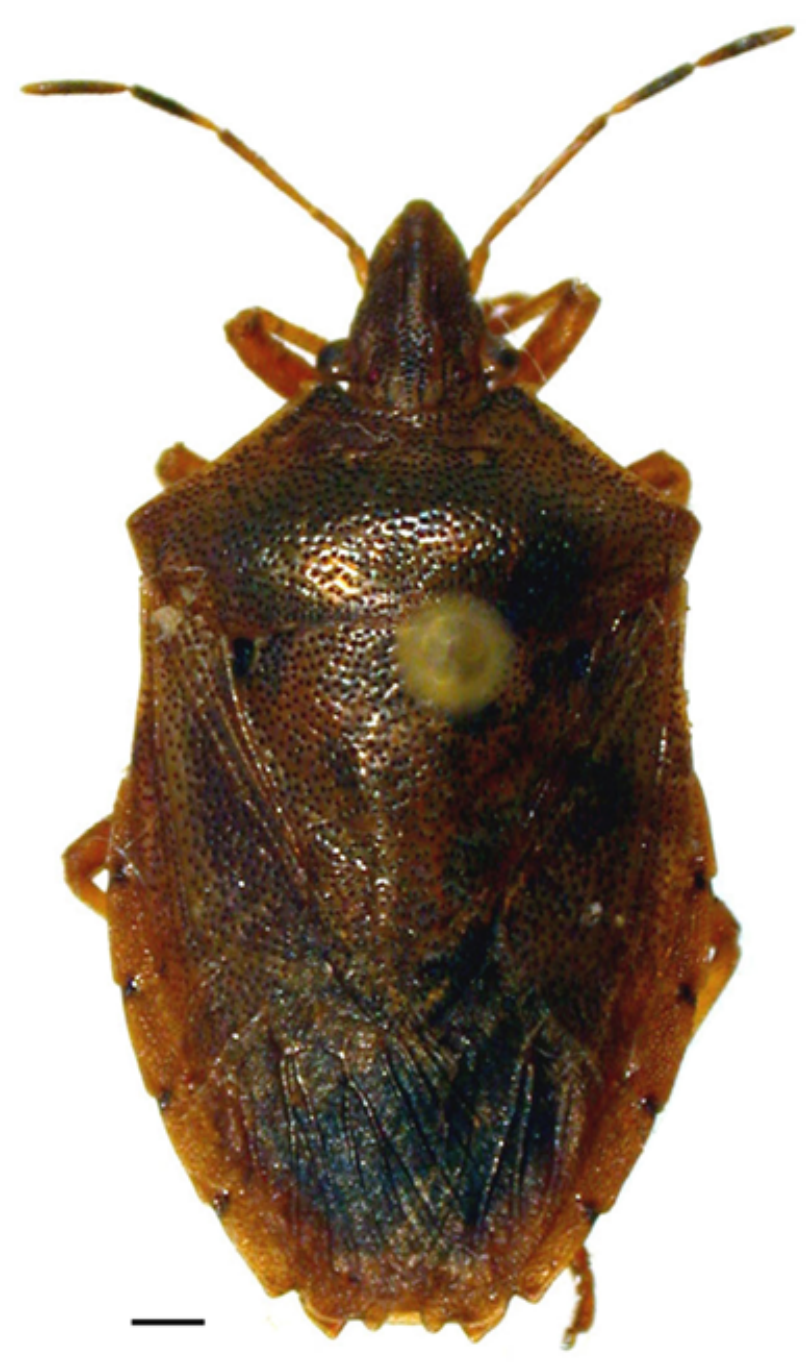

\section{Bibliografias:}

Frey-da-Silva, A.; Grazia, J. \& Fernandes, J.A.M. 2002. Revisão do gênero Paramecocephala Benvegnú, 1968 (Heteroptera, Pentatomidae). Rev. Bras. entomol. 46(2): 209-225. 


\section{Proxys albopunctulatus (Palisot de Beauvois, 1805)}

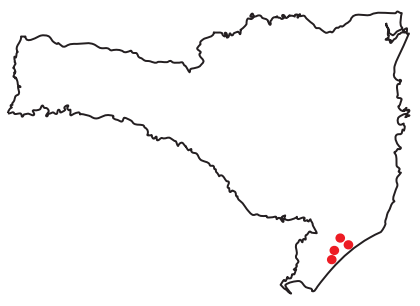

Diagnose: Margens ventrais da búcula amarelo claro, especialmente anterior e posteriormente. Pro e meso fêmures desprovidos de banda negra apical (Rider 2008).

Indivíduos dorsalmente negros com máculas marfim no canto interno das cicatrizes do pronoto e no ápice do escutelo. Ângulos umerais desenvolvidos em projeção aguda. Pernas claras com manchas negras. Jugas mais curtas que o clípeo, este com ápice agudo.

Tamanho dos adultos: 9,9-11,2 mm.

Metodologia de coleta: coleta manual, rede de varredura.

Local de Coleta: Araranguá, Criciúma, Içara e Maracajá.

\begin{tabular}{|c|c|c|}
\hline & Planta hospedeira & Nome popular \\
\hline Apiaceae & $\begin{array}{l}\text { Foeniculum vulgare Mill. } \\
\text { var. capillaceum (Gilibi.) }\end{array}$ & Funcho \\
\hline Curcubitaceae & Sechium edule Swartz & Chuchuzeiro \\
\hline Fabaceae & $\begin{array}{l}\text { Lotus corniculatus L.; } \\
\text { Phaseolus vulgaris L.; } \\
\text { Lens culinarie Medik.; } \\
\text { Lotononis bainesii } \\
\text { Baker.; Glycine max } \\
\text { (L.) Merrill; Trifolium } \\
\text { repene L.; Medicago } \\
\text { polymorpha L. }\end{array}$ & $\begin{array}{l}\text { Cornichão; } \\
\text { Feijão; Lentilha; } \\
\text { Lotononis; } \\
\text { Soja; Trevo } \\
\text { branco; Trevo- } \\
\text { de-carretilha }\end{array}$ \\
\hline Phytolaccaceae & Phytolacca dioica L. & Umbu \\
\hline Rosaceae & Fragraria vesca L. & Morangueiro \\
\hline
\end{tabular}
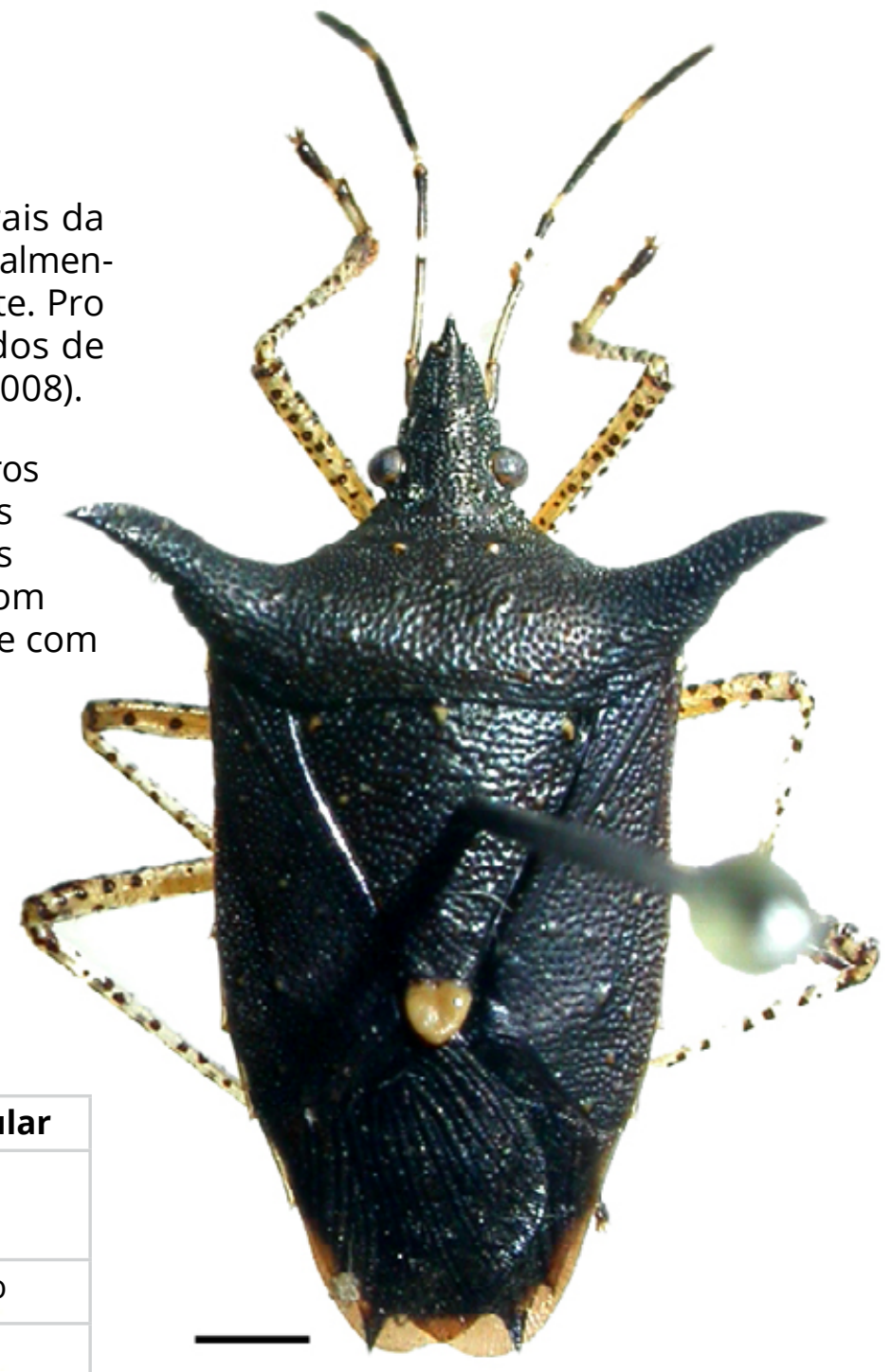

\section{Bibliografias:}

Grazia, J. 1977. Revisão dos Pentatomineos citados no Quarto Catálogo dos Insetos que Vivem nas Plantas do Brasil (Hemiptera: Pentatomidae, Pentatomini). Dusenia 10 (3): 161-174.

Lopes, O.J.; Link, D. \& Basso, L.V. 1974. Pentatomídeos de Santa Maria - Lista preliminar de plantas hospedeiras. Rev. Centro Ciências Rurais 4 (4): 317-322.

Rider, D.A. (2008). Pentatomoidea Home Page. North Dakota: North Dakota State University. Disponível on line em: http://www.ndsu.nodak.edu/ndsu/rider/Pentatomoidea/index.htm [Acesso em: 23 set. 2008] 


\section{Sibaria armata} (Dallas, 1851)

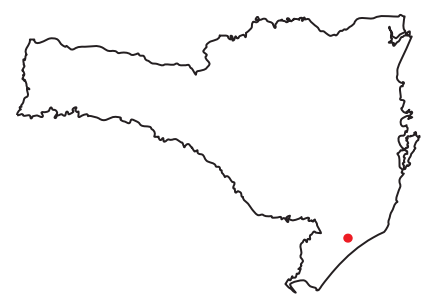

Diagnose: Coloração geral negra; pernas claras com manchas castanhas. Olhos largos, juntos quase se igualam a distância interocular. Ângulos umerais desenvolvidos em espinho. Superfície anterior do fêmur armada com um par de espinhos e um par de tubérculos na base dos espinhos; estes com frequência menores nos fêmures medianos e posteriores, o último armado somente com um par de tubérculos pré-apicais (Rolston 1975).

Tamanho dos adultos: $9,6 \mathrm{~mm}$.

Metodologia de coleta: guarda-chuva entomológico.

Local de Coleta: Criciúma.

\begin{tabular}{|l|l|l|}
\hline & Planta hospedeira & Nome popular \\
\hline Malvaceae & Gossypium arboreum L. & Algodoeiro \\
\hline
\end{tabular}

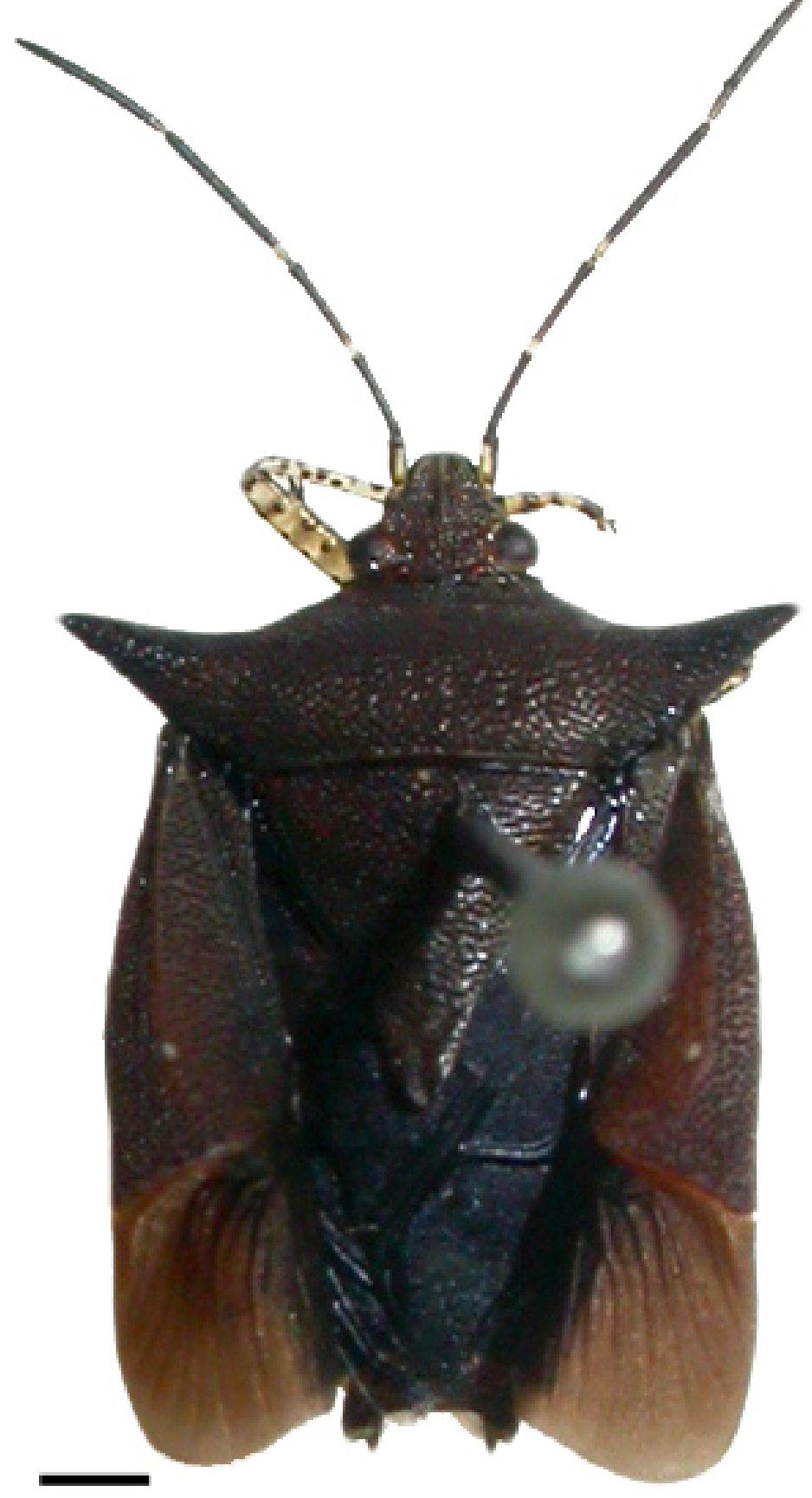

\section{Bibliografias:}

Grazia, J. 1977. Revisão dos Pentatomineos citados no Quarto Catálogo dos Insetos que Vivem nas Plantas do Brasil (Hemiptera: Pentatomidae, Pentatomini). Dusenia 10 (3): 161-174.

Rolston, L.H. 1975. A new species and review of Sibaria (Hemiptera: Pentatomidae). J. New York Entomol. Soc. 83: 218-225. 


\section{Tibraca exigua Fernandes \& Grazia, 1998}

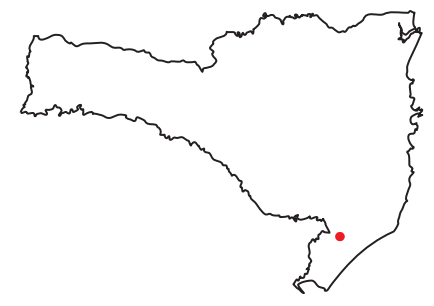

Diagnose: Coloração geral castanho escuro com pernas vermelhas a vermelho escuro. Margens laterais do pronoto destituídas de pontuações ou raramente pontuadas na metade posterior. Peritrema tão longo quanto ou levemente mais longo que o ostíolo (Fernandes \& Grazia 1998).

Tamanho dos adultos: 9-12 $\mathrm{mm}$.

Metodologia de coleta: coleta manual.

Local de Coleta: Nova Veneza.

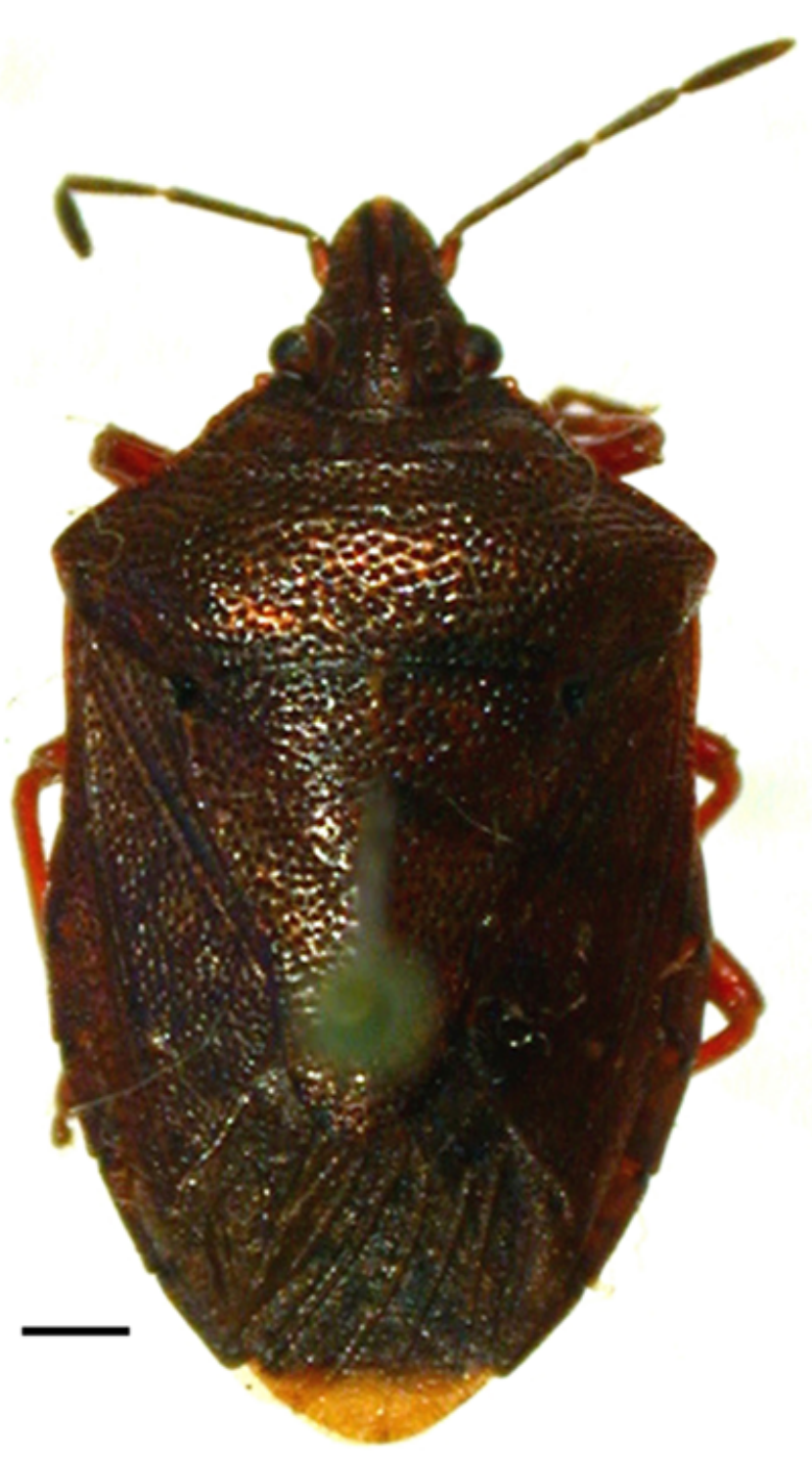

\section{Bibliografias:}

Fernandes, J.A.M. \& Grazia, J. 1998. Revision of the genus Tibraca Stål (Heteroptera, Pentatomidae, Pentatominae). Rev. Bras. Zool. 15 (4): 1049-1060. 


\section{Tibraca limbativentris}

\section{Stål, 1860}

Diagnose: Coloração geral castanha; pernas concolores com o corpo. Margens laterais do pronoto destituídas de pontuações ou raramente pontuadas na metade posterior. Peritrema duas ou três vezes mais larga que a abertura do ostíolo (Fernandes \& Grazia 1998).

Tamanho dos adultos: $13-16 \mathrm{~mm}$.

Metodologia de coleta: coleta manual e rede de varredura.

Local de Coleta: Forquilhinha e Nova Veneza.

Nomes Populares: Percevejo-do-colmo, percevejo-grande-do-arroz.

\begin{tabular}{|c|c|c|}
\hline & Planta hospedeira & Nome popular \\
\hline Fabaceae & Glycine max (L.) Merrill & Soja \\
\hline Poaceae & $\begin{array}{l}\text { Oryza sativa L.; Lolium } \\
\text { multiflorum L.; Triticum aestivum } \\
\text { L.; Echinochloa cruzgalli } \\
\text { (L.) Beauv. var. cruzgalli; } \\
\text { Paspalum urvillei Steud. }\end{array}$ & $\begin{array}{l}\text { Arroz; } \\
\text { Azevém; Trigo; } \\
\text { Capim-arroz; } \\
\text { Forquilhão }\end{array}$ \\
\hline Solanaceae & Lycopersicum esculentum Mill. & Tomate \\
\hline
\end{tabular}

\section{Bibliografias:}

Barrigossi, J.A.F. \& Martins, J.F.da S. 2006. Pragas e métodos de controle. Embrapa Arroz e Feijão, Sistemas de Produção No. 7, Cultivo do arroz de terras altas no Estado de Mato Grosso. Disponível online em: http://sistemasdeproducao.cnptia.embrapa.br/FontesHTML/Arroz/ArrozTerrasAltasMatoGrosso/ pragas_metodos_controle.htm\#pg [Acesso em: 19 dez. 2013]

Ferreira, E.; Barrigossi, J.A.F. \& Vieira, N.R.de A. 2001. Percevejos das paniculas do arroz: fauna Heteroptera associada ao arroz. Santo Antonio de Goiás, GO. Embrapa Arroz e Feijão. 52p (Embrapa Arroz e Feijão. Circular técnica On-lin, 43). Disponível online em: http://ainfo.cnptia.embrapa.br/digital/ bitstream/item/59106/1/Circ-43.pdf [Acesso em: 20 dez. 2013.]

Grazia, J. 1977. Revisão dos Pentatomineos citados no Quarto Catálogo dos Insetos que Vivem nas Plantas do Brasil (Hemiptera: Pentatomidae, Pentatomini). Dusenia 10 (3): 161-174.

Link, D. \& Grazia, J. 1987. Pentatomídeos da região central do Rio Grande do Sul (Heteroptera). An. Soc. Entomol. Bras. 16 (1): 115-129.

Lopes, O.J.; Link, D. \& Basso, L.V. 1974. Pentatomídeos de Santa Maria - Lista preliminar de plantas hospedeiras. Rev. Centro Ciências Rurais 4 (4): 317-322.

Panizzi, A.R. 1997. Wild hosts of Pentatomids: ecological significance and role in their pest status on crops. Annu. Rev. Entomol. 42: 99-122.

Fernandes, J.A.M. \& Grazia, J. 1998. Revision of the genus Tibraca Stål (Heteroptera, Pentatomidae, Pentatominae). Rev. Bras. Zool. 15 (4): 1049-1060. 


\section{Catacanthini}

Arocera (Euopta) spectabilis (Drury, 1782) 


\section{Arocera (E.) spectabilis (Drury, 1782)}

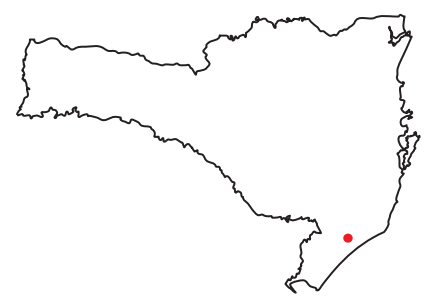

Diagnose: Ápice da cabeça alaranjado-vermelho; base negra. Margem anterior do pronoto negra exceto pelo amarelo mediano. Áreas negras na margem anterior do pronoto normalmente se estendendo sobre as margens anterolaterais, formando manchas negras nos úmeros. Mancha negra mediana no disco posterior do pronoto, se estendendo até a base do escutelo. Banda negra larga cortando transversalmente o cório e o escutelo, algumas vezes dividida na mediana do escutelo por linha amarela (Rider 1992).

Tamanho dos adultos: $14,5 \mathrm{~mm}$.

Metodologia de coleta: coleta manual.

Local de Coleta: Criciúma.

\begin{tabular}{|l|l|}
\hline & Planta hospedeira \\
\hline Asteraceae & Chicorium indivia L. \\
\hline
\end{tabular}

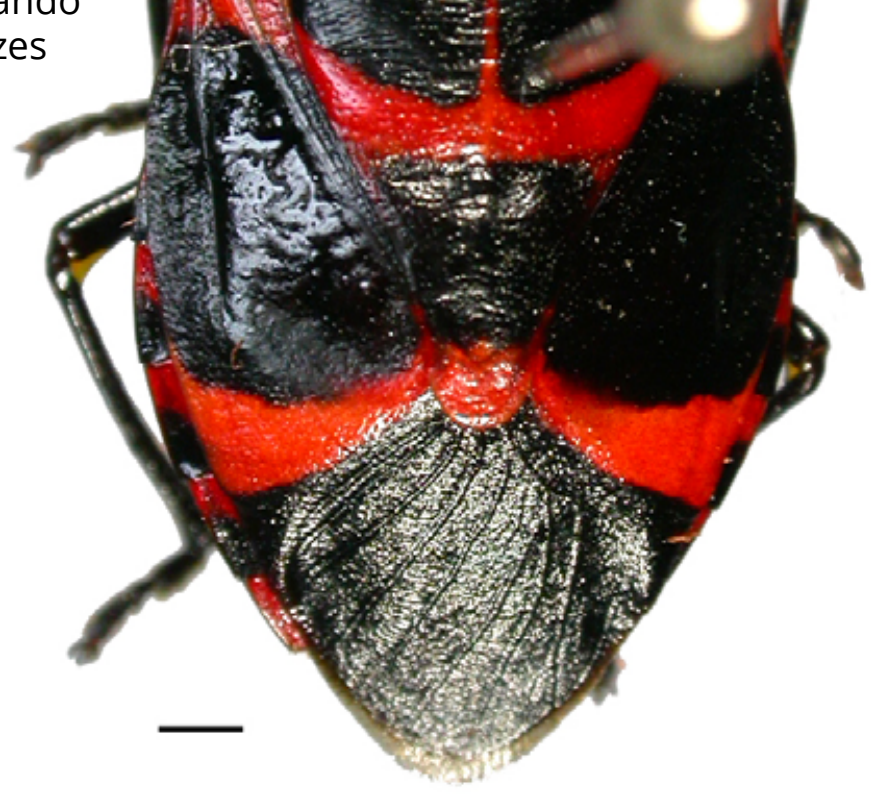

\section{Bibliografias:}

Grazia, J. 1977. Revisão dos Pentatomineos citados no Quarto Catálogo dos Insetos que Vivem nas plantas do Brasil (Hemiptera: Pentatomidae, Pentatomini). Dusenia 10 (3): 161-174.

McDonald, F.J.D. 1984. Revision of Arocera Spinola (Heteroptera: Pentatomidae). J. New York Entomol. Soc. 92 (2): 97-120.

Rider, D.A. 1992. Revision of Arocera Spinola, with the description of two new species (Heteroptera: Pentatomidae). J. New York Entomol. Soc. 100 (1): 99-136. 


\section{Chlorocorini}

Arvelius albopunctatus (DeGeer, 1773)

Arvelius latus Breddin, 1909

Chlorocoris (Chlorocoris) tau Spinola, 1837

Chloropepla vigens (Stål, 1860)

Loxa deducta Walker, 1867

Loxa virescens Amyot \& Serville, 1843

Loxa viridis (Palisot de Beauvois, 1805)

Mayrinia curvidens (Mayr, 1864)

* É comum os percevejos desse grupo alterarem a coloração quando secos, ganhando, geralmente, tons alaranjados. 


\section{Arvelius albopunctatus (DeGeer, 1773)}

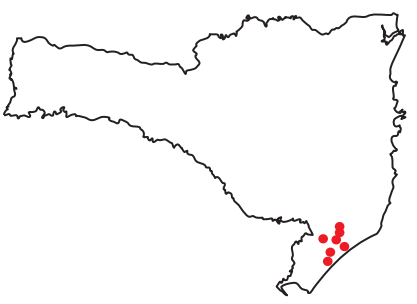

Diagnose: Coloração geral amarelo esverdeado nos exemplares vivos e amarelo palha nos exemplares montados. Jugas mais longas que o clípeo. Bordo anterior do pronoto dentado e o anterolateral variando de quase reto a amplamente côncavo. Espinhos umerais muito variáveis quanto ao tamanho e largura, porém maioria longos e delgados (Brailovsky 1981)

Tamanho dos adultos: $\sigma$ 13,8-15 mm; १ 13,8-16,2 mm.

Metodologia de coleta: coleta manual guarda-chuva entomológico e rede de varredura.

Local de Coleta: Araranguá, Cocal do Sul, Criciúma, Içara, Maracajá, Nova Veneza e Urussanga.

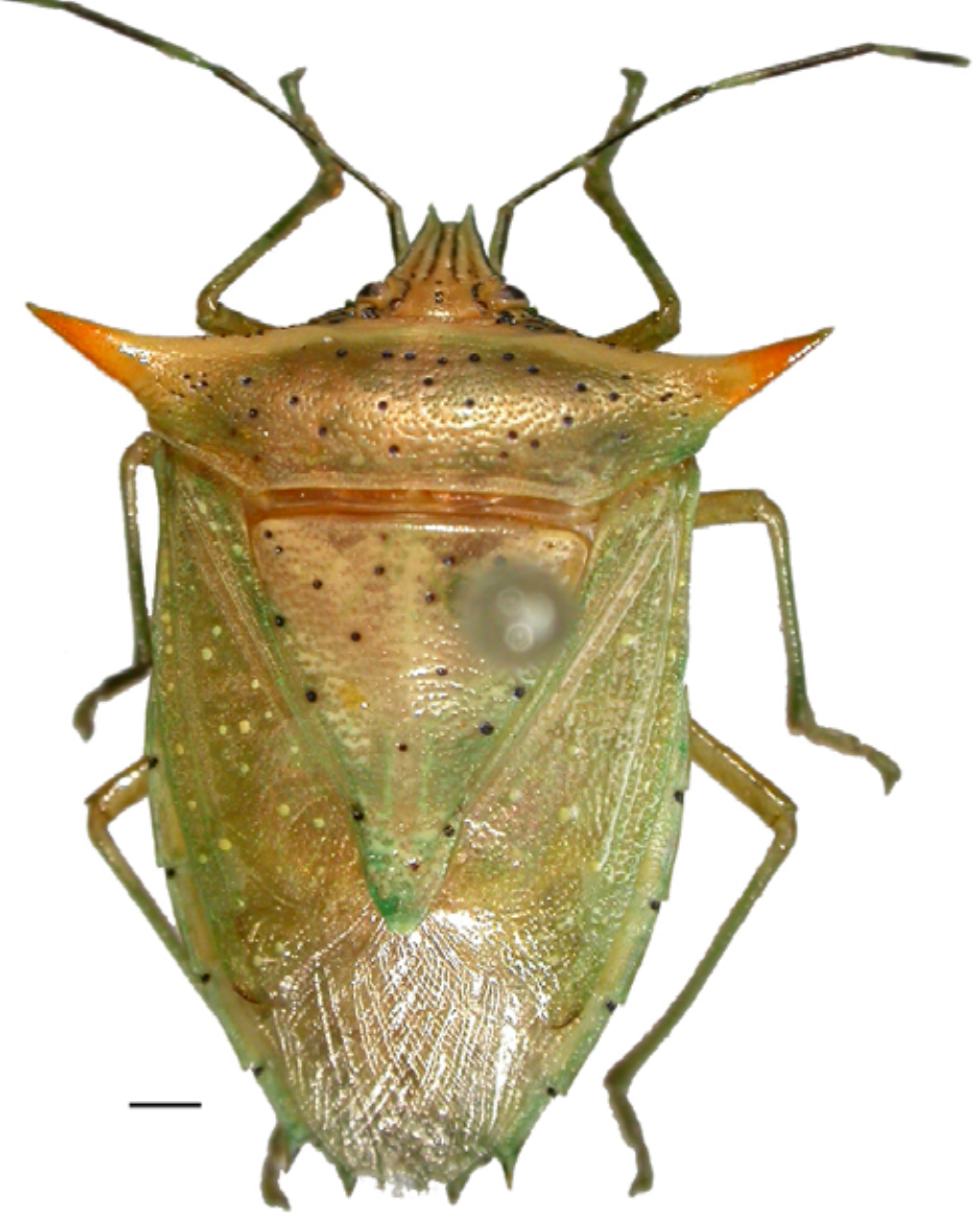

\begin{tabular}{|l|l|l|}
\hline \multicolumn{1}{|c|}{ Planta hospedeira } & Nome popular \\
\hline Asteraceae & Helianthus annuus L. & Girassol \\
\hline Fabaceae & Phaseolus vulgaris L.; Glycine max (L.) Merrill & Feijão; Soja \\
\hline Malvaceae & Hibiscus esculentus L. & Quiabo \\
\hline Poaceae & Triticum aestivum L. & Trigo \\
\hline Solanaceae & $\begin{array}{l}\text { Solanum variabile Mart.; S. flagellare Sendtn.; S. aculeatissimum } \\
\text { Jacq.; S. gracile Dunal; S. tuberosum L.; Lycopersicum } \\
\text { esculentum Mill.; S. sisymbrifolium Lam.; S. melongena L.; } \\
\text { Capsicum annum L.; S. ciliatum Lam.; S. auriculatum Aiton; } \\
\text { S. gilo Raddi; S. palinacanthum Dunal; S. paniculatum L. }\end{array}$ & $\begin{array}{l}\text {-i_i_i_; Batata; Tomate; Joá; } \\
\text { Berinjela; Pimentão; _; _; } \\
\text { Jiloeiro; Joá-bagudo; Jurubeba }\end{array}$ \\
\hline
\end{tabular}

\section{Bibliografias:}

Basso, L.V.; Link, D. \& Lopes, O.J. 1974. Entomofauna de algumas solanáceas em Santa Maria, RS. Rev. Centro Ciências Rurais 4 (3): 263-270.

Bertels, A. 1962. Relação de insetos encontrados sobre plantas hospedeiras da família Solanaceae. Iheringia, Sér. Zool. 25: 2-11. 
Brailovsky, H. 1981. Revisión del gênero Arvelius Spinola (Hemiptera-Heteroptera-Pentatomidae-Pentatomini). An. Inst. Biol. Univ. Nal. Autón. de Méx. Ser. Zool. [1980], 51 (1): 239-298.

Grazia, J. 1977. Revisão dos Pentatomineos citados no Quarto Catálogo dos Insetos que Vivem nas Plantas do Brasil (Hemiptera: Pentatomidae, Pentatomini). Dusenia 10 (3): 161-174.

Link, D. \& Grazia, J. 1987. Pentatomídeos da região central do Rio Grande do Sul (Heteroptera). An. Soc. Entomol. Bras. 16 (1): 115-129.

Lopes, O.J.; Link, D. \& Basso, L.V. 1974. Pentatomídeos de Santa Maria - Lista preliminar de plantas hospedeiras. Rev. Centro Ciências Rurais 4 (4): 317-322.

Panizzi, A.R. 1997. Wild hosts of Pentatomids: ecological significance and role in their pest status on crops. Annu. Rev. Entomol. 42: 99-122.

Panizzi, A.R.; McPherson, J.E.; James, D.G.; Javahery, J.M. \& McPherson, R.M. 2000. Stink Bugs (Pentatomidae) p. 421-474. In: C.W. Schaefer \& A.R. Panizzi (Org). Heteroptera of Economic Importance. USA, CRC Press. 


\section{Arvelius latus Breddin, 1909}

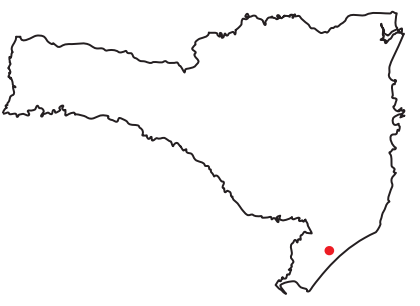

Diagnose: Coloração geral alaranjado rosado. Jugas com ápice robusto mais longas que o clípeo, este encoberto parcialmente pelas jugas visto de cima. Margem anterolateral do pronoto curva; espinhos umerais longos e robustos (Brailovsky 1981).

Tamanho dos adultos: $\sigma$ 16,2 mm; $@ 16,8 \mathrm{~mm}$.

Metodologia de coleta: coleta manual e guarda-chuva entomológico.

Local de Coleta: Maracajá.

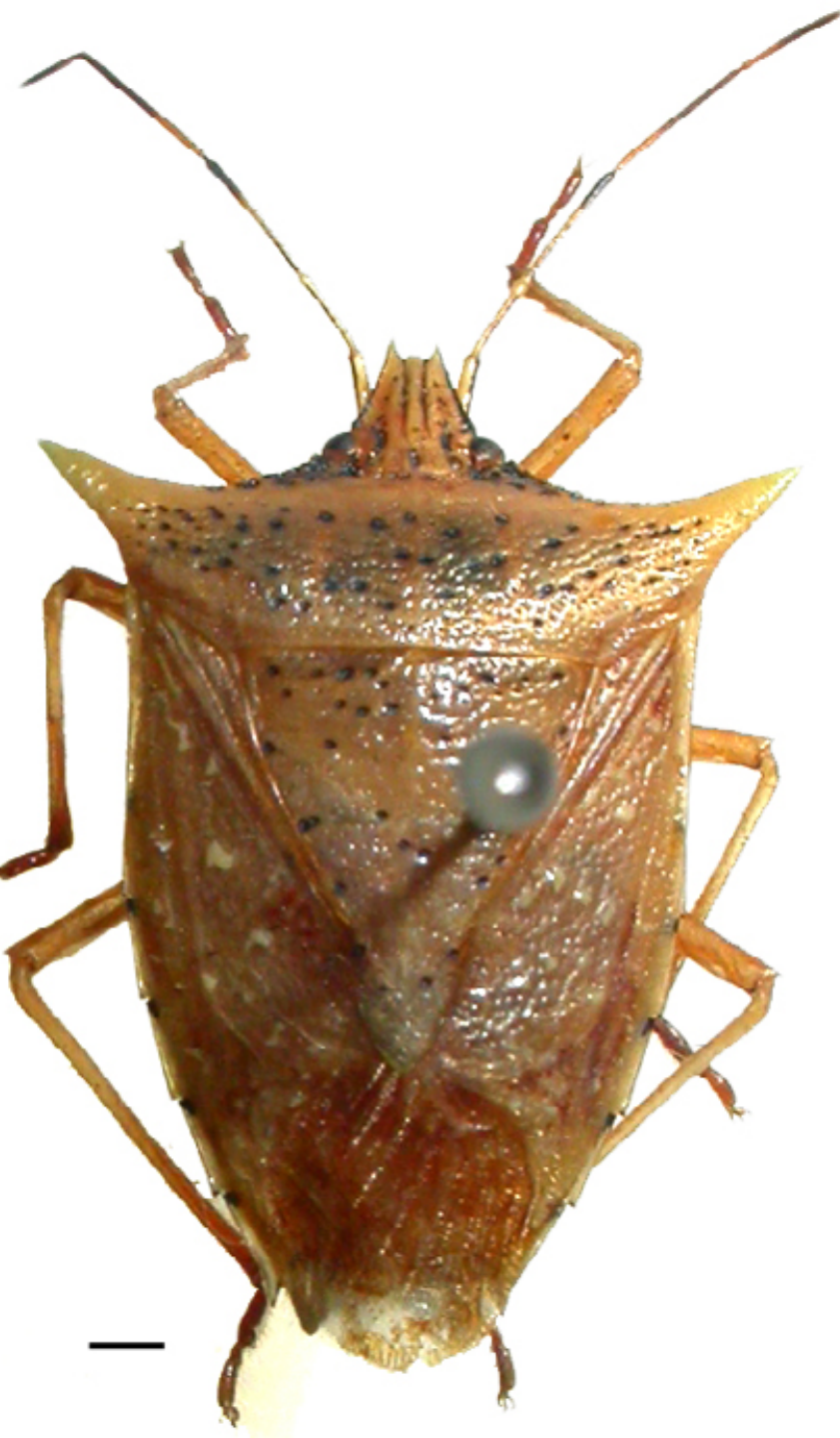

\section{Bibliografias:}

Brailovsky, H. 1981. Revisión del gênero Arvelius Spinola (Hemiptera-Heteroptera-Pentatomidae-Pentatomini). An. Inst. Biol. Univ. Nal. Autón. de Méx. Ser. Zool. [1980], 51 (1): 239-298. 


\section{Chlorocoris (C.) tau Spinola, 1837}

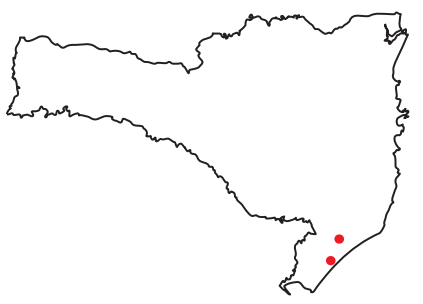

Diagnose: Corpo oval e achatado. Coloração geral verde ou amarelo. Pronoto com mancha pálida subcalosa entre os úmeros, outra bisseccionando o pronoto e o escutelo longitudinalmente, as duas formando um T marcando o dorso. Pontuações no dorso concolores com a superfície, mas cada uma areolada com um fino círculo rosa ou vermelho. Borda da margem posterior do conexivo preta (Thomas 1985).

Tamanho dos adultos: 19,2-19,2 mm.

Metodologia de coleta: coleta manual.

Local de Coleta: Araranguá, Criciúma.

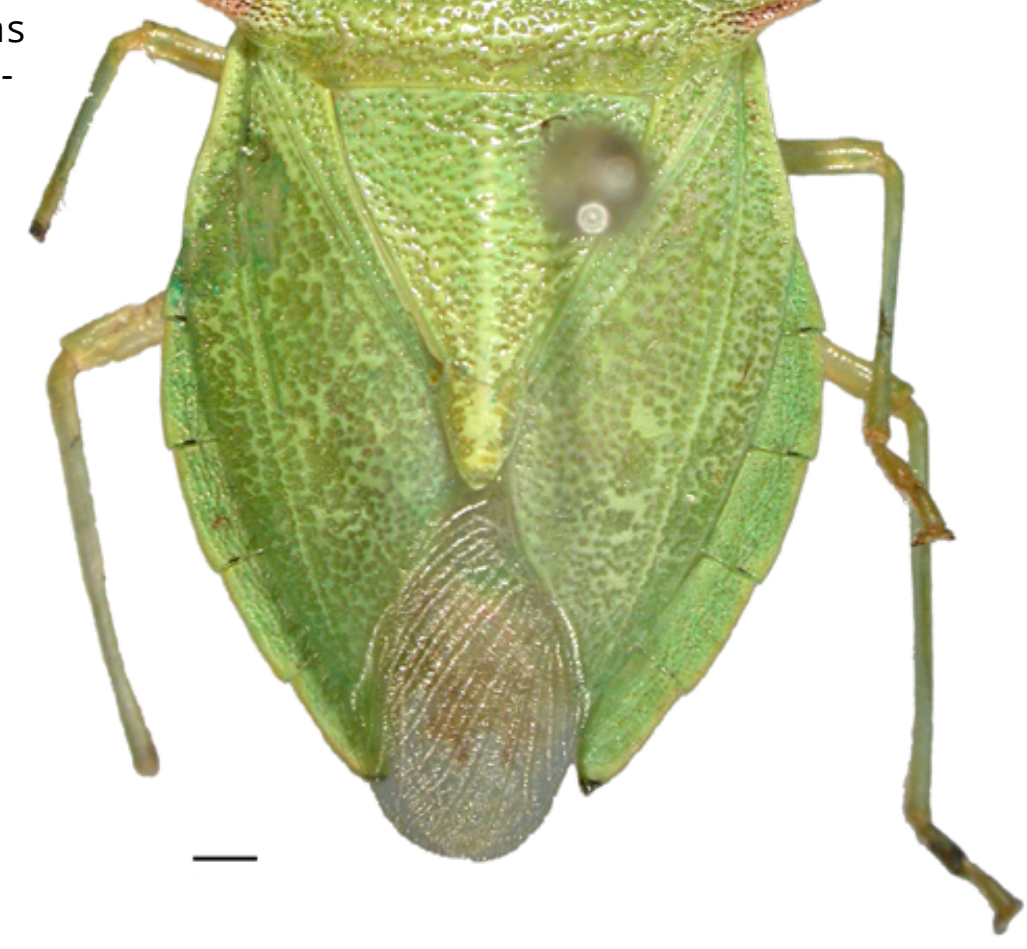

\section{Bibiliografias:}

Thomas, D.B. 1985. Revision of the genus Chlorocoris Spinola (Hemiptera: Pentatomidae). Ann. Entomol. Soc. Am. 78 (5): 674-690. 


\section{Chloropepla vigens (Stål, 1860)}

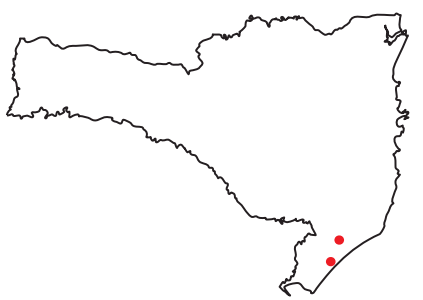

Diagnose: Coloração geral verde. Ângulos umerais do pronoto expandidos lateralmente, prolongados em espinhos de orientação lateral. Jugas ultrapassando consideravelmente o clípeo; margem interna do ápice das jugas divergente diante do clípeo resultando um recorte em "V". Hemiélitros cobrindo totalmente o conexivo, com mancha marfim no ápice da veia radial (Grazia 1968).

Tamanho dos adultos: 11,9-13,1 mm.

Metodologia de coleta: coleta manual.

Local de Coleta: Araranguá e Criciúma.

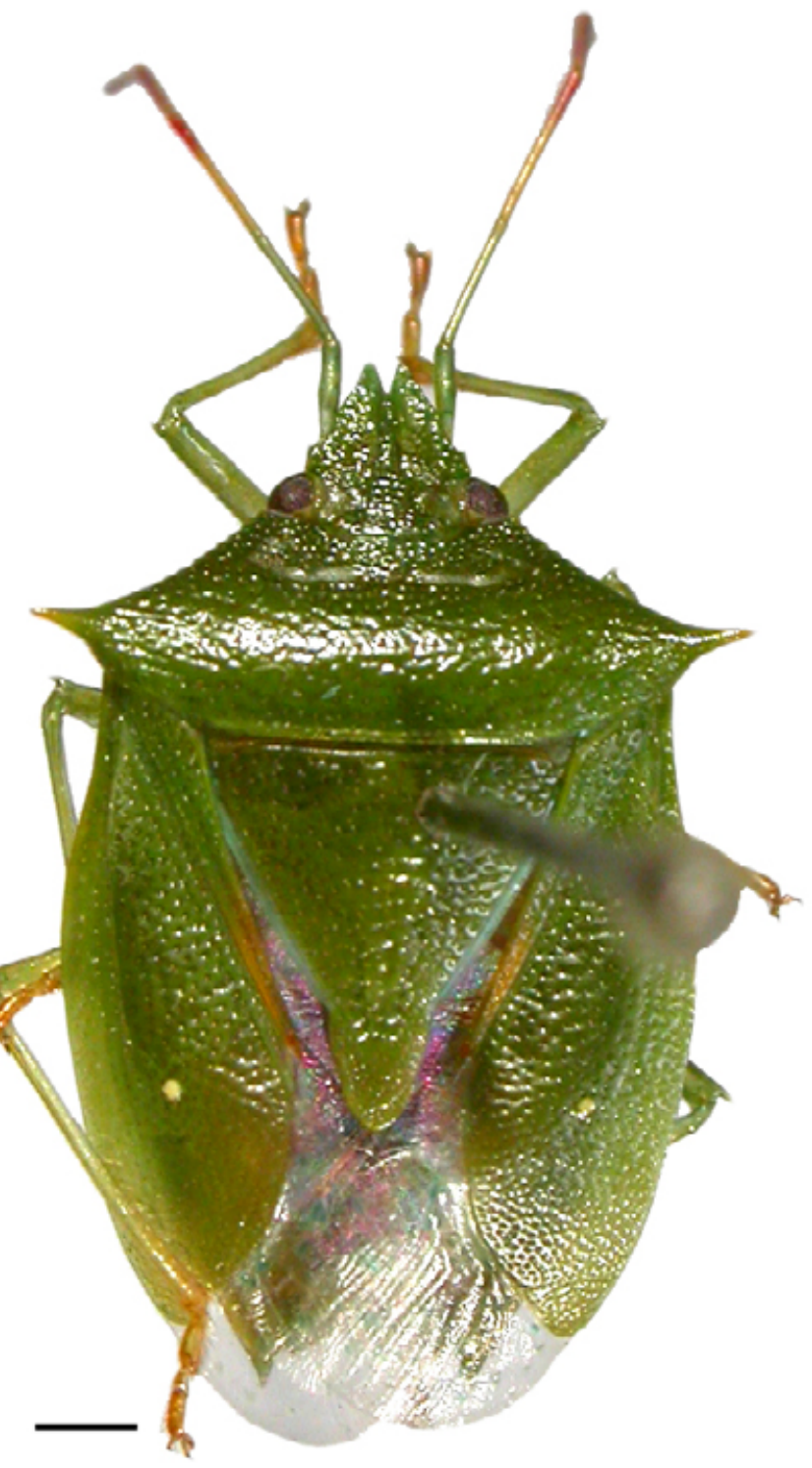

\section{Bibliografias:}

Grazia, J. 1968. Sobre o gênero "Chloropepla" Stål, 1867, com a descrição de uma nova espécie (Hemiptera, Pentatomidae, Pentatominae). Rev. Bras. Biol. 28 (2): 193-206.

Greve, C.; Schwertner, C.F. \& Grazia, J. 2013. Cladistic analysis and synopsis of Chloropepla Stål (Hemiptera: Heteroptera: Pentatomidae) with the description of three new species. Insect Systematics and Evolution 44: 1-43. 


\section{Loxa deducta} Walker, 1867

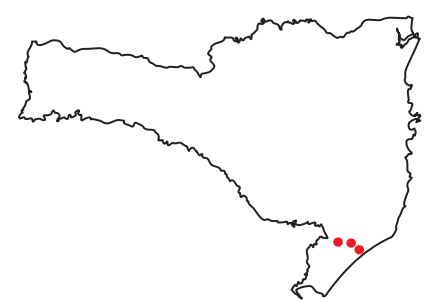

Diagnose: Coloração geral verde. Jugas com densas pontuações vermelhas nas margens mediana e lateral, estas de vez em quando concolores na faixa mediana. Clípeo com a banda mediana normalmente pontuada de vermelho até aproximadamente a metade basal. Margem ântero-lateral do pronoto serrilhada; ângulos umerais desenvolvidos em espinhos elevados e projetados lateralmente. Cório com numerosos calos pálidos e dispersos (Eger 1978).

Tamanho dos adultos: $\sigma$ 13,3-16,3 mm; Metodologia de coleta: coleta manual e rede de varredura.

Local de Coleta: Criciúma, Içara, e Nova Veneza.

\begin{tabular}{|c|c|c|}
\hline & Planta hospedeira & Nome popular \\
\hline Anarcadiaceae & $\begin{array}{l}\text { Lythraea brasiliensis } \\
\text { March.; Schinus molle L. }\end{array}$ & $\begin{array}{l}\text { Aroeira-cinzenta; } \\
\text { Aroeira-mansa }\end{array}$ \\
\hline Euphorbiaceae & $\begin{array}{l}\text { Sebastiania klotzschiana } \\
\text { (Müll. Arg.) }\end{array}$ & Branquinho \\
\hline Fabaceae & $\begin{array}{l}\text { Glycine max (L.) Merrill; } \\
\text { Bauhinia candicans } \\
\text { Benth.; Tipuana } \\
\text { tipu (Benth.) DC. }\end{array}$ & $\begin{array}{l}\text { Soja; Pata-de- } \\
\text { vaca; Tipa }\end{array}$ \\
\hline Oleaceae & Ligustrum lucidium (Ait.) & Ligustro \\
\hline Solanaceae & $\begin{array}{l}\text { Solanum } \\
\text { sisymbrifolium Lam. }\end{array}$ & Joá \\
\hline
\end{tabular}
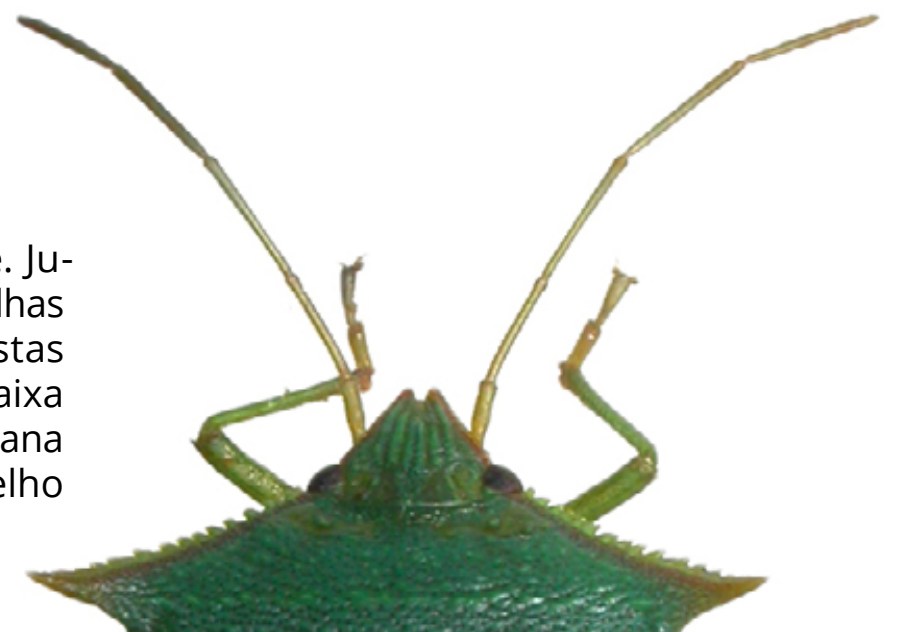


\section{Loxa virescens} Amyot \& Serville, 1843

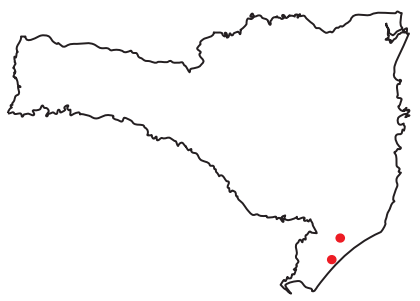

Diagnose: Coloração geral verde. Pronoto normalmente com linha transversal de rugas pálidas entre os ângulos umerais; espinhos umerais normalmente mais claros que o disco do pronoto, raramente vermelho; margens ântero-laterais crenuladas. Cório normalmente com mancha discóide pálida, sendo esta de vez em quando concolor e obscura ou totalmente ausente (Eger 1978).

Tamanho dos adultos: $\sigma$ 18,7-21,4 mm; @ 19,2-24,7 mm. Metodologia de coleta: coleta manual e rede de varredura.

Local de Coleta: Araranguá e Criciúma.

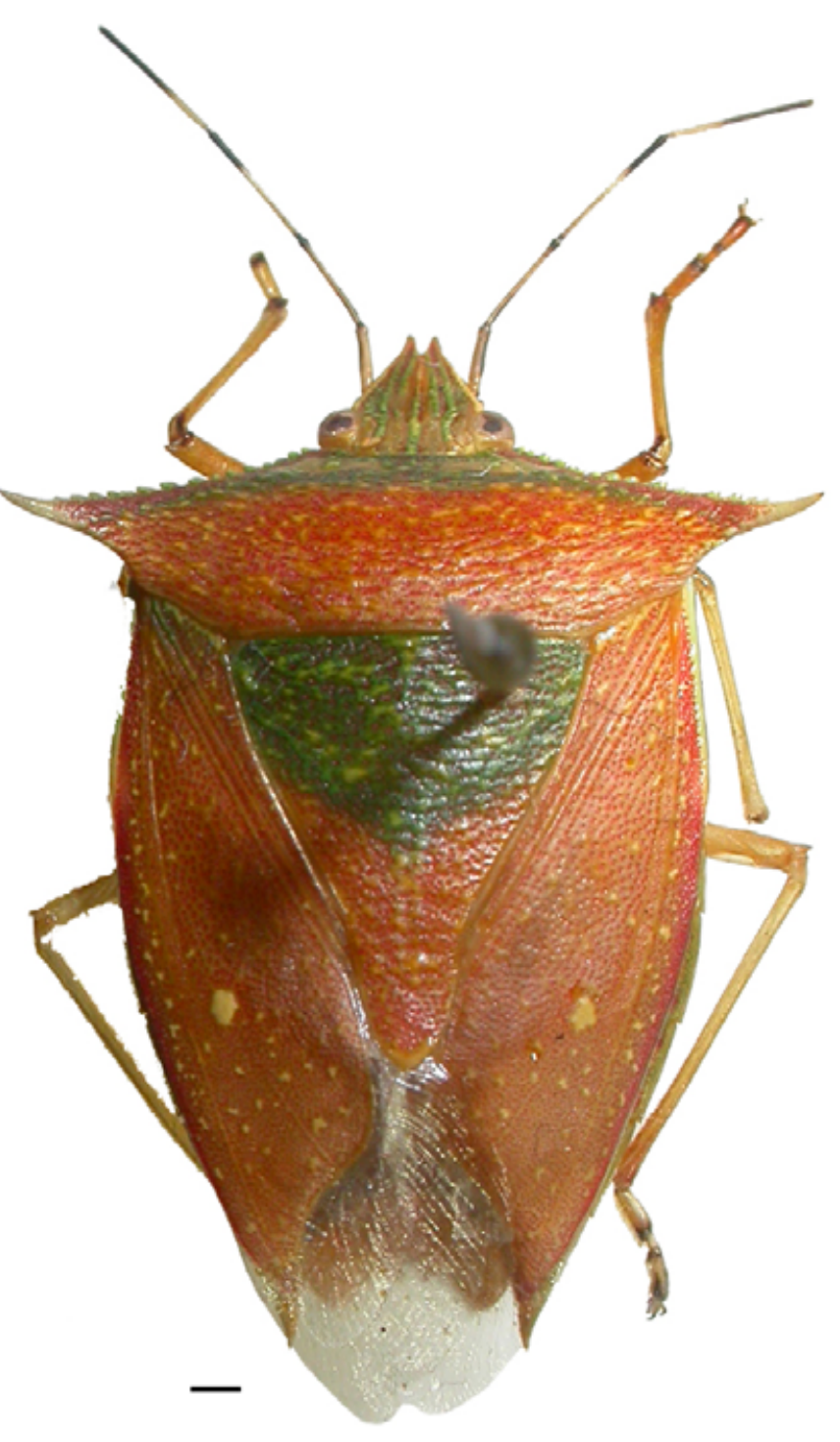

\section{Bibliografias:}

Eger, J.E. 1978. Revision of the genus Loxa (Hemiptera: Pentatomidae). J. New York Entomol. Soc. 86 (3): 224-259. 


\section{Loxa viridis}

\section{(Palisot de Beauvois, 1805)}

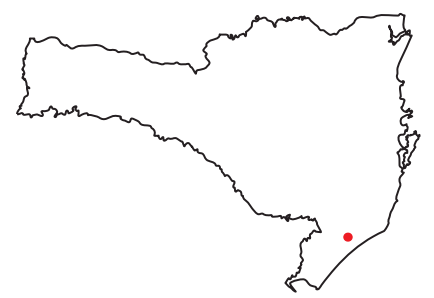

Diagnose: Coloração geral verde. Margens laterais das jugas de coloração geralmente mais clara que o disco da cabeça. Margens anterolaterais do pronoto serriIhadas, normalmente mais claras que o disco do pronoto; ângulos umerais bastante projetados com espinhos agudos, moderadamente a bastante elevados, direcionados lateralmente ou anterolateralmente, concolores com as margens anterolaterais ou vermelho. Mancha pálida no ápice da veia radial (Eger 1978).

Tamanho dos adultos: $\sigma \times 18,3-25,5 \mathrm{~mm}$; $18,9-25,3 \mathrm{~mm}$.

Metodologia de coleta: coleta manual e guarda-chuva entomológico.

Local de Coleta: Criciúma.

\section{Bibliografias:}

Eger, J.E. 1978. Revision of the genus Loxa (Hemiptera: Pentatomidae). J. New York Entomol. Soc. 86 (3): 224-259. 


\section{Mayrinia curvidens (Mayr, 1864)}

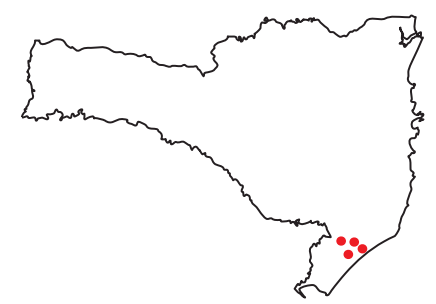

Diagnose: Coloração geral verde. Margens das jugas quase totalmente convexas uniformemente. Espinhos umerais de coloração negra, pontiagudos e dirigidos para frente. Conexivo imaculado, total ou parcialmente coberto pelos hemiélitros (Grazia-Vieira 1972).

Tamanho dos adultos: $\bigcirc$ " 11-11,8 mm; $९$ 11,4-14 mm.

Metodologia de coleta: coleta manual, guarda-chuva entomológico e rede de varredura.

Local de Coleta: Criciúma, Içara, Maracajá e Nova Veneza.

\begin{tabular}{|l|l|l|}
\hline & Planta hospedeira & Nome popular \\
\hline Fabaceae & Glycine max (L.) Merr. & Soja \\
\hline Poaceae & Oryza sativa L. & Arroz \\
\hline
\end{tabular}

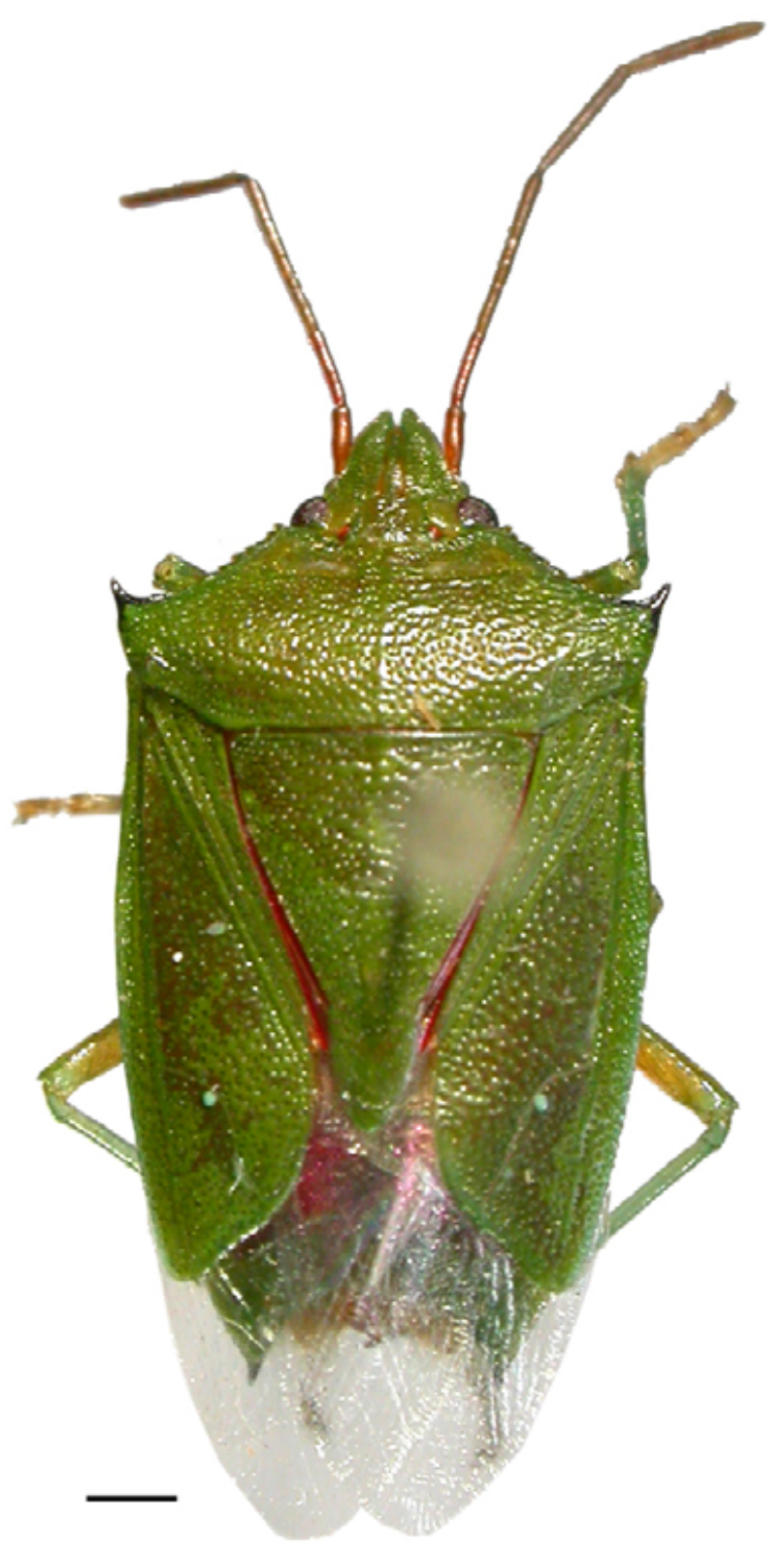

\section{Bibliografias:}

Grazia-Vieira, J. 1972. O gênero Mayrinia Horvath, 1925 (Heteroptera, Pentatomidae, Pentatomini). Rev. Per. Entom. 15 (1): 117-124.

Lopes, O.J.; Link, D. \& Basso, L.V. 1974. Pentatomídeos de Santa Maria - Lista preliminar de plantas hospedeiras. Rev. Centro Ciências Rurais 4 (4): 317-322. 
Nezarini

Chinavia difficilis (Stål, 1860)

Chinavia nigrodorsata (Breddin, 1901)

Chinavia obstinata (Stål, 1860)

Chinavia pengue (Rolston, 1983)

Chinavia runaspis (Dallas, 1851)

Nezara viridula (Linnaeus, 1758) 


\section{Chinavia difficillis} (Stål, 1860)

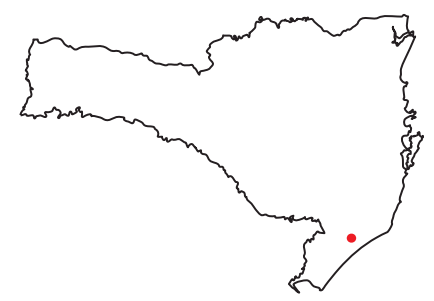

Diagnose: Coloração geral verde a verde-clara; cicatrizes do pronoto, ângulos basais do escutelo sem manchas negras; e ângulos póstero-laterais do conexivo podendo apresentar manchas negras. Espinho abdominal no máximo alcançando as mesocoxas. Espiráculos escuros. Antenas verdes (Schwertner \& Grazia 2007; Campos et al. 2012).

Tamanho dos adultos: 12-15 $\mathrm{mm}$.

Metodologia de coleta: guarda-chuva entomológico.

Local de Coleta: Criciúma.

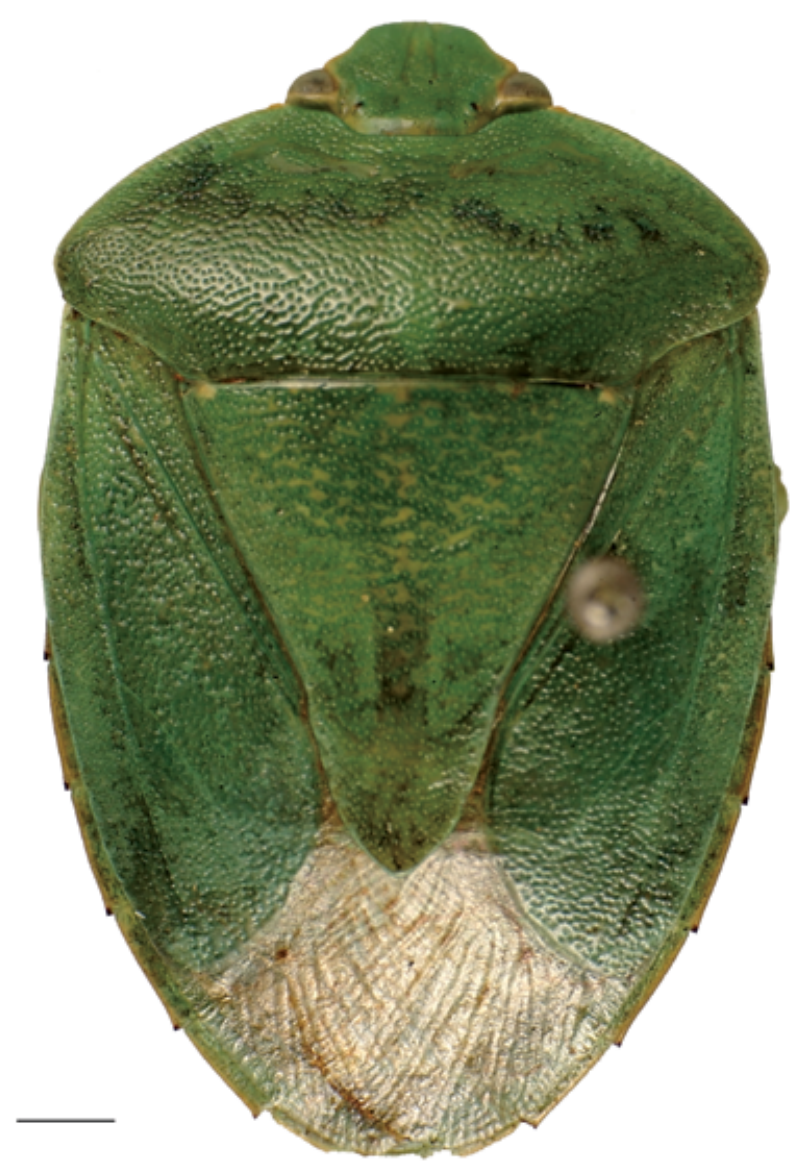

\section{Bibliografias:}

Schwertner, C.F. \& Grazia, J. 2007. O gênero Chinavia Orian (Hemiptera, Pentatomidae, Pentatominae) no Brasil, com chave pictórica para os adultos. Rev. Bras. entomol. 51 (4): 416-435.

Campos, L.A.; Bianchi, F.M. \& Garbelotto, T.A. 2012. On the genus Chinavia Orian: Additions to the description of three species (Hemiptera: Pentatomidae). Neotrop. Entomol. 41: 163-167. 


\section{Chinavia nigrodorsata (Breddin, 1901)}

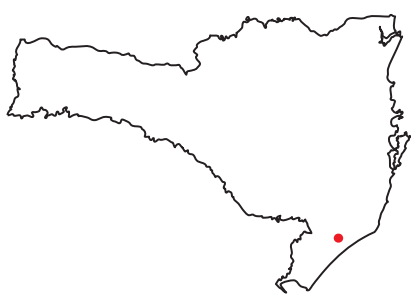

Diagnose: Coloração geral verde, com margens das jugas, pronoto, terço basal do hemiélitro e conexivo de coloração avermelhada. Ângulos umerais, geralmente desenvolvidos em espinho; cicatrizes do pronoto e ângulos basais do escutelo sem manchas negras; manchas negras no conexivo junto aos ângulos póstero-laterais presentes; espiráculos escuros e calo junto aos espiráculos presente (Schwertner \& Grazia 2007).

Tamanho dos adultos: $11-13 \mathrm{~mm}$.

Metodologia de coleta: coleta manual

Local de Coleta: Criciúma

\begin{tabular}{|c|c|c|}
\hline & Planta hospedeira & Nome popular \\
\hline Aizoaceae & $\begin{array}{l}\text { Tetragonia expansa Murray; } \\
\text { Tetragonia tetragonioides }\end{array}$ & Espinafre; _ \\
\hline Apiaceae & $\begin{array}{l}\text { Foeniculum vulgare Mill. } \\
\text { var. capillaceum (Gilibi.) }\end{array}$ & Funcho \\
\hline Asteraceae & $\begin{array}{l}\text { Cynara scolymus L.; } \\
\text { Helianthus annuus L. }\end{array}$ & $\begin{array}{l}\text { Alcachofra; } \\
\text { Girassol }\end{array}$ \\
\hline Brassicaceae & $\begin{array}{l}\text { Brassica napus L. var. oleifera } \\
\text { Meitzg.; Brassica oleracea } \\
\text { L. var. acephala DC. }\end{array}$ & $\begin{array}{l}\text { Colza; Couve- } \\
\text { comum }\end{array}$ \\
\hline Fabaceae & $\begin{array}{l}\text { Aeschynomene rudis Benth.; } \\
\text { Glycine max (L.) Merrill; Lupinus } \\
\text { albus L.; Pisum sativum L.; } \\
\text { Phaseolus vulgaris L.; Lupinus } \\
\text { angustifolius L.; Lens culinarie } \\
\text { Medik.; Mimosa invisa Mart. }\end{array}$ & $\begin{array}{l}\text { Anjiquinho; } \\
\text { Soja; Tremoço- } \\
\text { branco; Ervilha; } \\
\text { Feijoeiro; } \\
\text { Tremoço-azul; } \\
\text { Lentilha;_. }\end{array}$ \\
\hline Linaceae & Linum usitatissimum L. & Linho \\
\hline Malvaceae & Hibiscus esculentus L. & Quiabeiro \\
\hline Poaceae & Oryza sativa L.; Triticum aestivum L. & Arroz; Trigo \\
\hline Solanaceae & $\begin{array}{l}\text { Nicotiana tabacum L.; Solanum } \\
\text { sisymbrifolium Lam. }\end{array}$ & Fumo; Joá \\
\hline
\end{tabular}

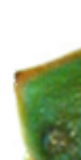




\section{Chinavia obstinata} (Stål, 1860)

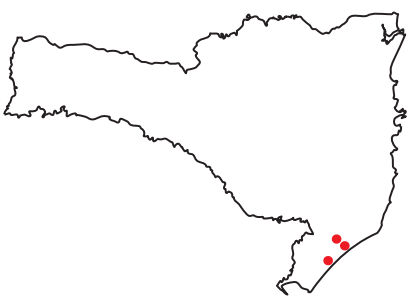

Diagnose: Corpo ovalado. Coloração geral verde-clara a verde-escura. Cicatrizes do pronoto imaculadas, com um par de manchas nos ângulos internos ou dois pares de manchas nos ângulos internos e externos. Ângulos basais do escutelo imaculados ou negros. Conexivo imaculado ou com amplas manchas negras junto aos ângulos póstero-laterais. Espinho abdominal ultrapassando as mesocoxas; espiráculos claros ou negros (Schwertner \& Grazia, 2007; Campos et al. 2012).

Tamanho dos adultos: $11-15 \mathrm{~mm}$.

Metodologia de coleta: coleta manual, guarda-chuva entomológico e rede de varredura.

Local de Coleta: Araranguá, Criciúma e Içara.

\begin{tabular}{|l|l|l|}
\hline & $\begin{array}{l}\text { Planta } \\
\text { hospedeira }\end{array}$ & Nome popular \\
\hline Fabaceae & $\begin{array}{l}\text { Glycine max } \\
\text { (L.) Merrill }\end{array}$ & Soja \\
\hline Passifloraceae & $\begin{array}{l}\text { Passiflora } \\
\text { edulis Sims }\end{array}$ & $\begin{array}{l}\text { Maracujá- } \\
\text { amarelo }\end{array}$ \\
\hline
\end{tabular}

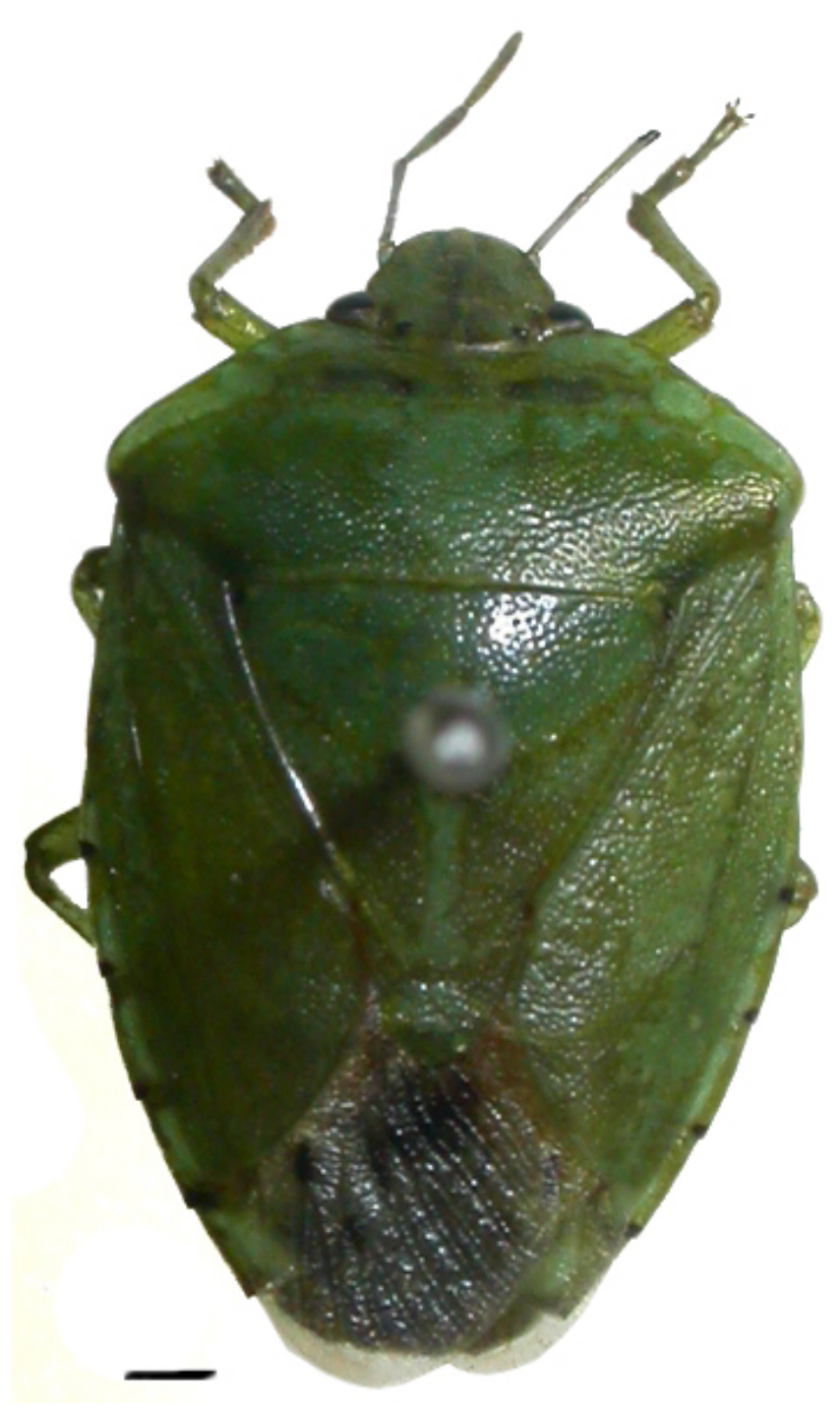

\section{Bibliografias:}

Schwertner, C.F. \& Grazia, J. 2007. O gênero Chinavia Orian (Hemiptera, Pentatomidae, Pentatominae) no Brasil, com chave pictórica para os adultos. Rev. Bras. entomol. 51 (4): 416-435.

Campos, L.A.; Bianchi, F.M. \& Garbelotto, T.A. 2012. On the genus Chinavia Orian: Additions to the description of three species (Hemiptera: Pentatomidae). Neotrop. Entomol. 41: 163-167. 


\section{Chinavia pengue (Rolston, 1983)}

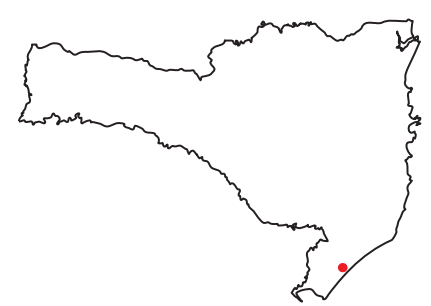

Diagnose: Coloração geral verde a verde clara. Margens das jugas, pronoto, terço basal do hemiélitro e conexivo de coloração vermelha a vermelho-alaranjada. Ângulos basais do escutelo imaculados. Presença de pequenas máculas amareladas na face dorsal do corpo. Manchas negras junto às margens posteriores do conexivo atingindo pelo menos a metade da largura deste (Schwertner \& Grazia, 2007).

Tamanho dos adultos: 11-13 mm.

Metodologia de coleta: guarda-chuva entomológico.

Local de Coleta: Araranguá.

\begin{tabular}{|l|l|l|}
\hline & Planta hospedeira & Nome popular \\
\hline Aquifoliaceae & $\begin{array}{l}\text { Ilex paraguariensis } \\
\text { A. St. Hil }\end{array}$ & Erva-mate \\
\hline Brassicaceae & $\begin{array}{l}\text { Brassica napus L. } \\
\text { var. oleifera Meitzg. }\end{array}$ & colza \\
\hline Fabaceae & $\begin{array}{l}\text { Glycine max (L.) } \\
\text { Merrill; Lupinus } \\
\text { albus L.; Crotalária } \\
\text { pallida Aiton }\end{array}$ & $\begin{array}{l}\text { Soja; termoço- } \\
\text { branco; - }\end{array}$ \\
\hline Malvaceae & $\begin{array}{l}\text { Gossypium } \\
\text { arboreum L. }\end{array}$ & algodoeiro \\
\hline
\end{tabular}

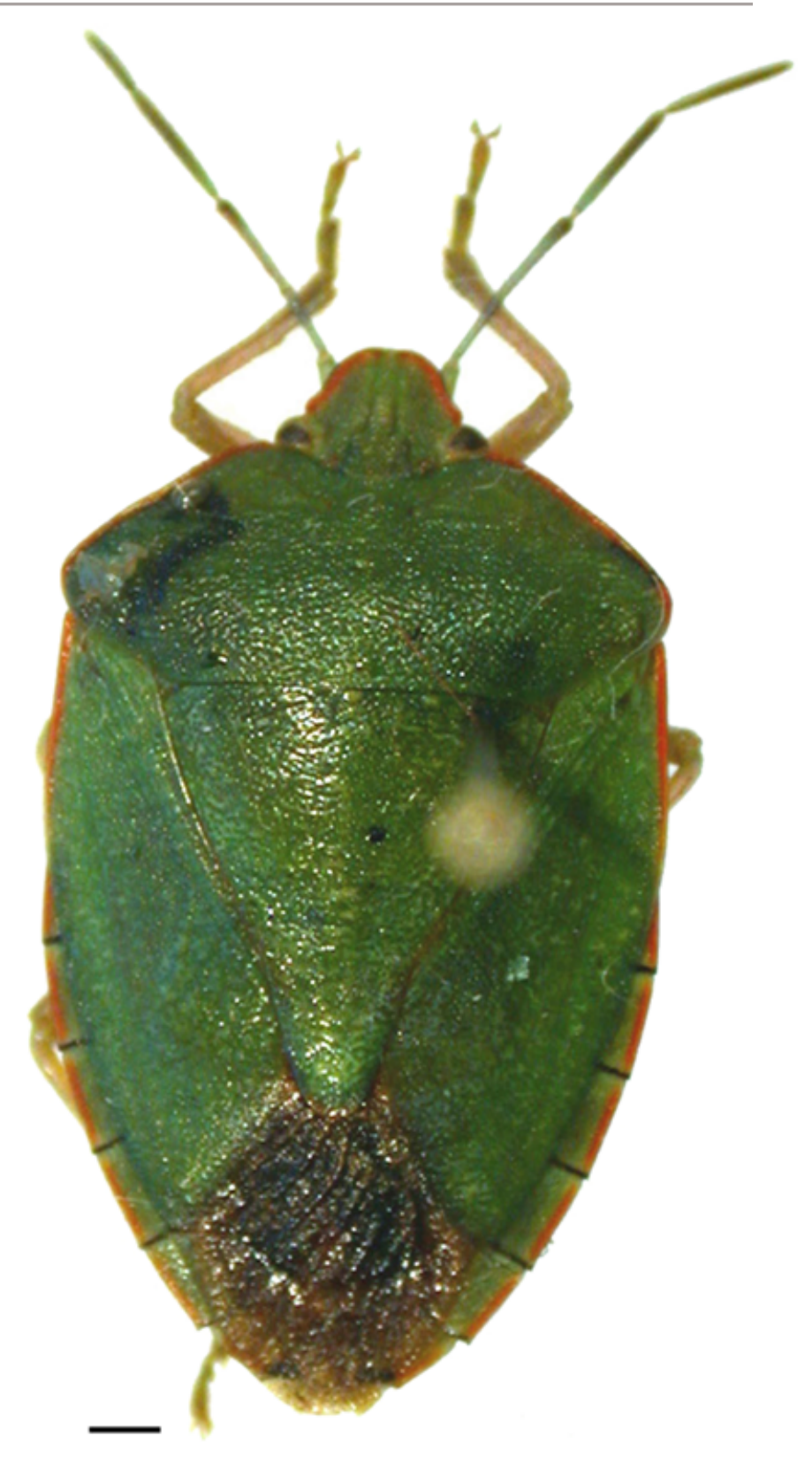

\section{Bibliografias:}

Link, D. \& Grazia, J. 1987. Pentatomídeos da região central do Rio Grande do Sul (Heteroptera). An.

Soc. Entomol. Bras. 16 (1): 115-129.

Schwertner, C.F. \& Grazia, J. 2007. O gênero Chinavia Orian (Hemiptera, Pentatomidae, Pentatominae) no Brasil, com chave pictórica para os adultos. Rev. Bras. entomol. 51 (4): 416-435. 


\section{Chinavia runaspis} (Dallas, 1851)

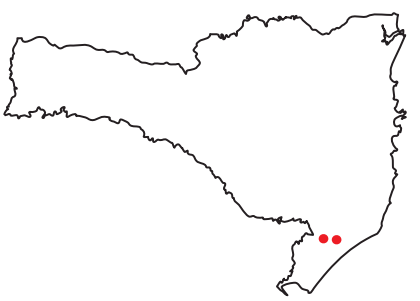

noto e ângulos basais do escutelo sem manchas negras. Margens anterior e posterior do conexivo com amplas manchas negras, ultrapassando a metade da largura destes; espiráculos verdes (Schwertner \& Grazia, 2007).

Tamanho dos adultos: $15-19 \mathrm{~mm}$.

Metodologia de coleta: coleta manual e rede de varredura.

Local de Coleta: Criciúma e Nova Veneza.

\begin{tabular}{|l|l|l|}
\hline & Planta hospedeira & Nome popular \\
\hline Arecaceae & Elaeis sp. & Dendê \\
\hline Oleaceae & Ligustrum lucidium (Ait.) & Ligustro \\
\hline
\end{tabular}

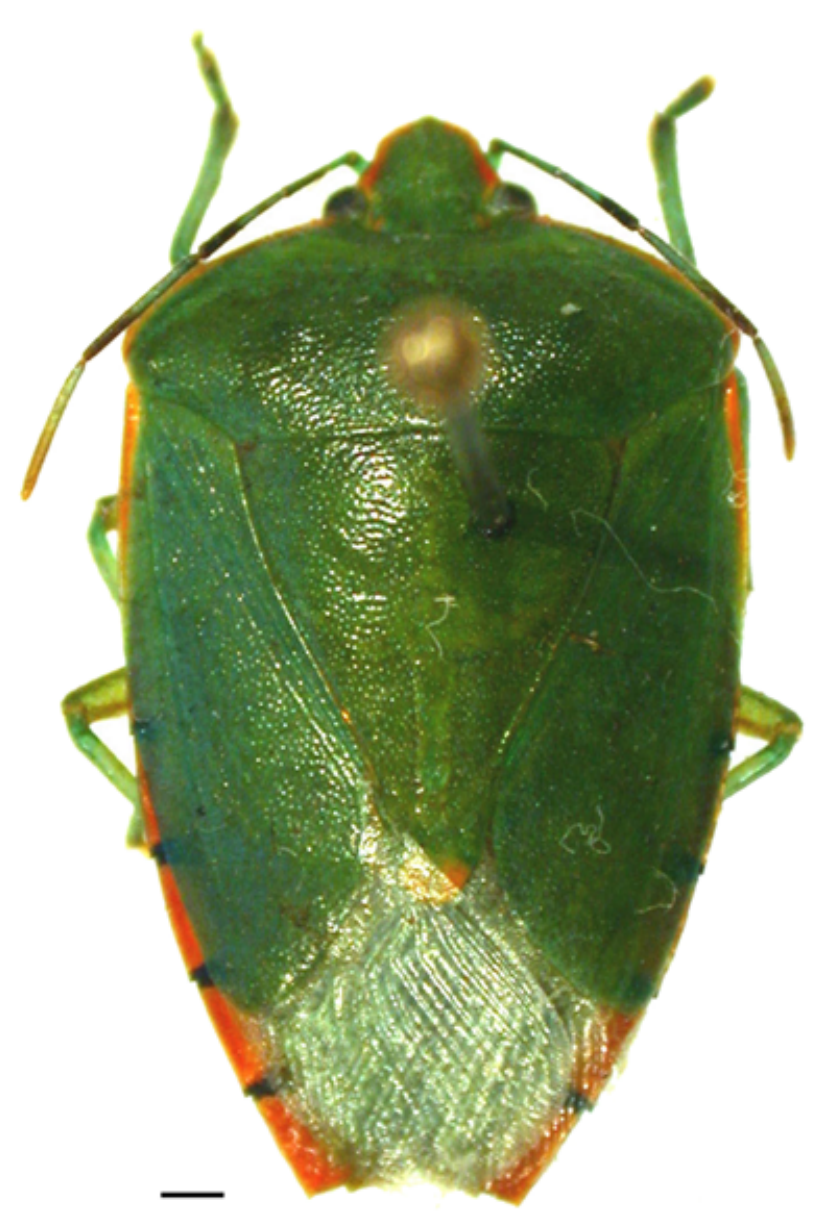

\section{Bibliografias:}

Schwertner, C.F. \& Grazia, J. 2007. O gênero Chinavia Orian (Hemiptera, Pentatomidae, Pentatominae) no Brasil, com chave pictórica para os adultos. Rev. Bras. entomol. 51 (4): 416-435. 


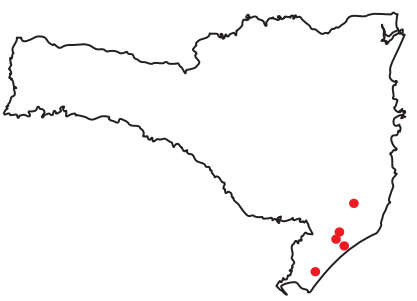

Diagnose: Coloração geral variando de completamente verde a completamente amarelo. Alguns indivíduos de coloração geral verdeamarelado e outros com a margem anterior do pronoto e da cabeça amarelas (Vivan \& Panizzi 2002). Espinho abdominal livre; ângulos umerais não desenvolvidos.

Tamanho dos adultos: $10 \mathrm{~mm}$ ou mais.

*Fotos mostrando alguns dos diferentes padrões de coloração.

Metodologia de coleta: coleta manual e rede de varredura.

Local de Coleta: Braço do Norte, Cocal do Sul, Criciúma, Içara e Sombrio.

Nomes Populares: Percevejo-verde, percevejo-da-soja, percevejo-verde-da-soja.

\begin{tabular}{|c|c|c|}
\hline & Planta hospedeira & Nome popular \\
\hline Anarcadiaceae & Schinus molle L. & Aroeira-mansa; \\
\hline Asteraceae & $\begin{array}{l}\text { Cynara scolymus L.; Bidens } \\
\text { pilosa L.; Helianthus annuus } \\
\text { L.; Lactuca sativa L.; }\end{array}$ & $\begin{array}{l}\text { Alcachofra; Picão; } \\
\text { Girassol; Alface; }\end{array}$ \\
\hline Apiaceae & $\begin{array}{l}\text { Foeniculum vulgare Mill. } \\
\text { var. capillaceum (Gilibi.) }\end{array}$ & Funcho \\
\hline Brassicaceae & $\begin{array}{l}\text { Brassica oleracea var. acephala; } \\
\text { Brassica alba (L.) Boiss.; Raphanus } \\
\text { raphanistrum L.; Brassica oleracea } \\
\text { L. var. capitata L.; Brassica } \\
\text { oleracea L. var. botrytis L. subv. } \\
\text { asparagoides DC.; Brassica } \\
\text { napus L. var. oleifera Meitzg.; } \\
\text { Brassica oleracea L. var. botrytis } \\
\text { L. subv. cauliflora (Gars.) DC.; } \\
\text { Brassica napus L.; Raphanus } \\
\text { sativus L. var. radicula Pers.; }\end{array}$ & $\begin{array}{l}\text { Couve-comum; } \\
\text { Mostarda; Nabiça; } \\
\text { Repolho; Brocoli; } \\
\text { Colza; Couve-flor; } \\
\text { Nabo; Rabanete; }\end{array}$ \\
\hline Curcubitaceae & Sechium edule Swartz & Chuchu \\
\hline Fabaceae & $\begin{array}{l}\text { Medicago sativa L.; Lotus } \\
\text { corniculatus L.; Pieum sativum } \\
\text { L.; Phaseolus calcaratus Roxbg.; } \\
\text { Vigna sinensis (L.) Savi; Phaseolus } \\
\text { vulgaris L.; Lens Culinarie Medik.; } \\
\text { Lotononis bainesii Baker.; } \\
\text { Macroptilium atropurpureum } \\
\text { Urb.; Glycine max (L.) Merrill ; } \\
\text { Glycine wightii (W. \& A.) Verdec.; } \\
\text { Lupinus luteus L.; Lupinus } \\
\text { angustifolius L.; Lupinus albus L.; }\end{array}$ & $\begin{array}{l}\text { Alfafa; Cornichão; } \\
\text { Ervilha; } \\
\text { Feijão-arroz; } \\
\text { Feijão-miúdo; } \\
\text { Feijão;Lentilha; } \\
\text { Lotononis; Siratro; } \\
\text { Soja; Soja-perene; } \\
\text { Tremoço-amarelo; } \\
\text { Tremoço-azul; } \\
\text { Tremoço-branco; }\end{array}$ \\
\hline
\end{tabular}

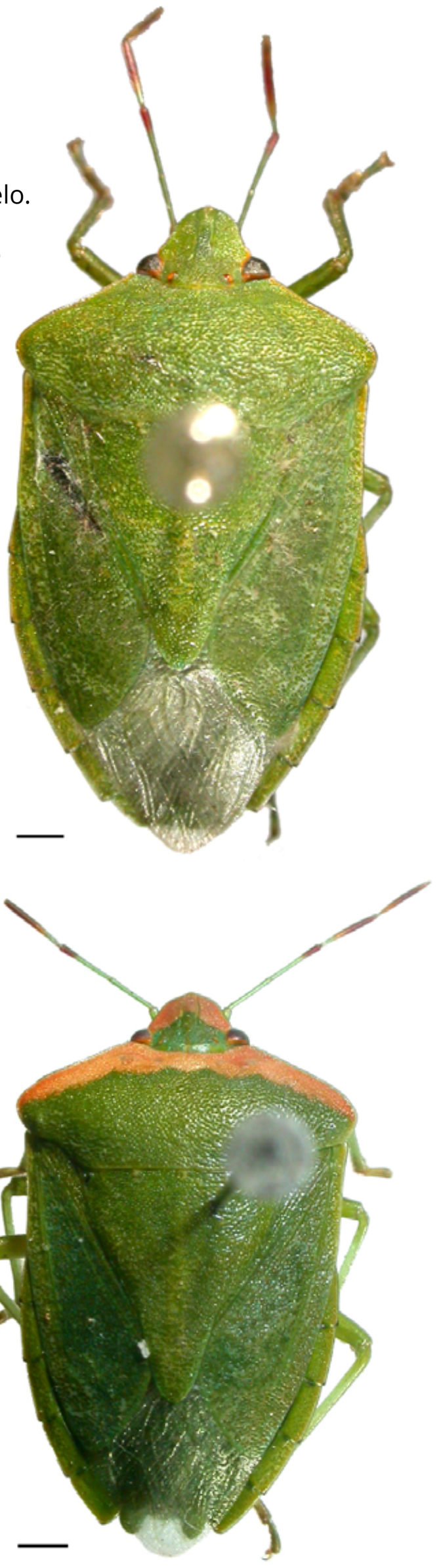




\begin{tabular}{|c|c|c|}
\hline Liliaceae & Asparagus officinale L.; & Aspargo \\
\hline Linaceae & Linum usitatissimum L.; & Linho \\
\hline Malvaceae & $\begin{array}{l}\text { Sida sp.; Hibiscus esculentus } \\
\text { L.; Hibiscus rosa-sinensis L. }\end{array}$ & $\begin{array}{l}\text { Guaxuma; } \\
\text { Quiabo; Mimo- } \\
\text { de-Vênus; }\end{array}$ \\
\hline Meliaceae & Cedrella fissilis Vell.; & Cedro \\
\hline Oleaceae & Ligustrum Iucidium (Ait.) & Ligustro \\
\hline Poaceae & $\begin{array}{l}\text { Oryza sativa L.; Avena sativa L.; } \\
\text { Zea mays L.; Sorghum vulgare L.; } \\
\text { Triticum aestivum L.; Brachiaria } \\
\text { plantaginea (Link) Hitchc.; Zea } \\
\text { mays L. var. rugosa Bonafous; }\end{array}$ & $\begin{array}{l}\text { Arroz; Aveia; } \\
\text { Milho; Sorgo; } \\
\text { Trigo; Papuã; } \\
\text { Milho-doce; }\end{array}$ \\
\hline Rosaceae & Prunus persica (L.) Batsch; & Pessegueiro \\
\hline Rutaceae & Citrus sinensis (L.) Osbeck & Laranjeira \\
\hline Solanaceae & $\begin{array}{l}\text { Solanum variabile Mart.; } \\
\text { S. sisymbrifolium Lam.; S. } \\
\text { incarceratum Ruiz \& Pav.; S. } \\
\text { balbisii Dunal; S. tuberosum } \\
\text { L.; Lycopersicum esculentum } \\
\text { Mill.; Nicotiana tabacum L.; } \\
\text { S. melongena L.; S. nigrum } \\
\text { L.; Capisicum annum L.; } \\
\text { S. americanum Mill.; }\end{array}$ & $\begin{array}{l}\text { _iJoá; _; _; } \\
\text { Batata; Tomate; } \\
\text { Fumo; Berinjela; } \\
\text { MaPretinha; } \\
\text { Pimentão; } \\
\text { MaPreta }\end{array}$ \\
\hline
\end{tabular}

\section{Bibliografias:}

Basso, L.V.; Link, D. \& Lopes, O.J. 1974. Entomofauna de algumas solanáceas em Santa Maria, RS. Rev. Centro Ciências Rurais 4 (3): 263-270.

Bertels, A. 1962. Relação de insetos encontrados sobre plantas hospedeiras da família Solanaceae. Iheringia, Sér. Zool. 25: 2-11.

Corrêa-Ferreira, B.S. \& Panizzi, A.R. 1999. Percevejos da soja e seu manejo. Londrina, PR. Embrapa-CNPSo. 45p. (Embrapa-CNPSo. Circular Tecnica, 24). Disponível online em: http://ag20.cnptia.embrapa. br/Repositorio/circTec24_000ge7ag4ne02wx5ok0ylax2l2xuj1ts.pdf [Acesso em: 20 dez. 2013.]

FMC. 2013. Percevejos.com.br. Disponível online em: http://www.percevejos.com.br/ [Acesso em: 19 dez. 2013.]

Grazia, J. 1977. Revisão dos Pentatomineos citados no Quarto Catálogo dos Insetos que Vivem nas Plantas do Brasil (Hemiptera: Pentatomidae, Pentatomini). Dusenia 10 (3): 161-174.

Link, D. \& Grazia, J. 1987. Pentatomídeos da região central do Rio Grande do Sul (Heteroptera). An. Soc. Entomol. Bras. 16 (1): 115-129.

Lopes, O.J.; Link, D. \& Basso, L.V. 1974. Pentatomídeos de Santa Maria - Lista preliminar de plantas hospedeiras. Rev. Centro Ciências Rurais 4 (4): 317-322.

Malaguido, A.B. \& Panizzi, A.R. 1998. Pentatomofauna associated with sunflower in Northern Paraná state, Brazil. An. Soc. Entomol. Bras. 27 (3): 473-475. 
Panizzi, A.R. 1997. Wild hosts of Pentatomids: ecological significance and role in their pest status on crops. Annu. Rev. Entomol. 42: 99-122.

Panizzi, A.R.; McPherson, J.E.; James, D.G.; Javahery, J.M. \& McPherson, R.M. 2000. Stink Bugs (Pentatomidae) p. 421-474. In: C.W. Schaefer \& A.R. Panizzi (Org). Heteroptera of economic importance. USA, CRC Press.

Salvadori, J.R.; Lau, D. \& Pereira, P.R.V.da S. 2009. Pragas e métodos de controle. Embrapa Trigo, Sistemas de Produção No. 4. Cultivo de Trigo. Disponível online em: http://sistemasdeproducao.cnptia. embrapa.br/FontesHTML/Trigo/CultivodeTrigo/pragas.htm [Acesso em: 19 dez. 2013.]

Schwertner, C.F. 2005. Filogenia e classificação dos percevejos-verdes do grupo Nezara Amyot \& Serville (Hemiptera, Pentatomidae, Pentatominae). 253 f. Tese. (Doutorado em Biologia Animal). Área de concentração: Biologia comparada - Universidade Federal do Rio Grande do Sul, Porto Alegre.

Vivan, L.M. \& Panizzi, A.R. 2002. Two new morphs of the southern greem stink bug, Nezara viridula (L.) (Heteroptera: Pentatomidae), in Brazil. Neotrop. Entomol. 31 (1): 475-476. 


\section{Pentatomini}

Banasa maculata Campos \& Garbelotto, 2010

Banasa sulcata Thomas, 1990

Janeirona stali (Kormilev, 1956)

Myota aerea (Herrich-Schäffer, 1841)

Pallantia macula (Dallas, 1851)

Pellaea stictica (Dallas, 1851)

Serdia indistincta Fortes \& Grazia, 2005

Serdia maxima Fortes \& Grazia, 2005

Stictochilus tripunctatus Bergroth, 1918 


\section{Banasa maculata}

Campos \& Garbelotto, 2010

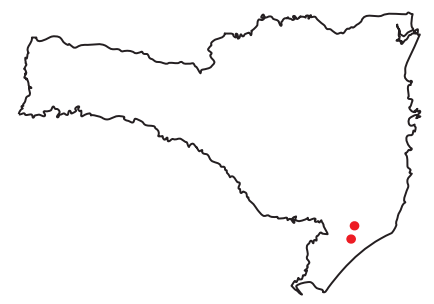

Diagnose: Castanho esverdeado dorsalmente. Cabeça variando de castanho claro a cobre. Mácula larga e irregular na metade anterior do pronoto, entre os ângulos umerais, geralmente marfim, algumas vezes concolor e inconspícua; porção posterior do pronoto e disco do escutelo esverdeados em indivíduos vivos. Lobo pós-frenal do escutelo com manchas claras, ápice marfim. Manchas claras no cório. Coloração ventral marfim (Campos et al. 2010).

Tamanho dos adultos: $\sigma$ 6.90-8.25 mm; † 7.14-9.18 mm.

Metodologia de coleta: guarda-chuva entomológico e armadilha luminosa.

Local de Coleta: Criciúma e Urussanga.

\begin{tabular}{|l|l|l|}
\hline & $\begin{array}{l}\text { Planta } \\
\text { hospedeira }\end{array}$ & $\begin{array}{l}\text { Nome } \\
\text { popular }\end{array}$ \\
\hline Melastomataceae & Miconia sellowiana & \\
\hline
\end{tabular}

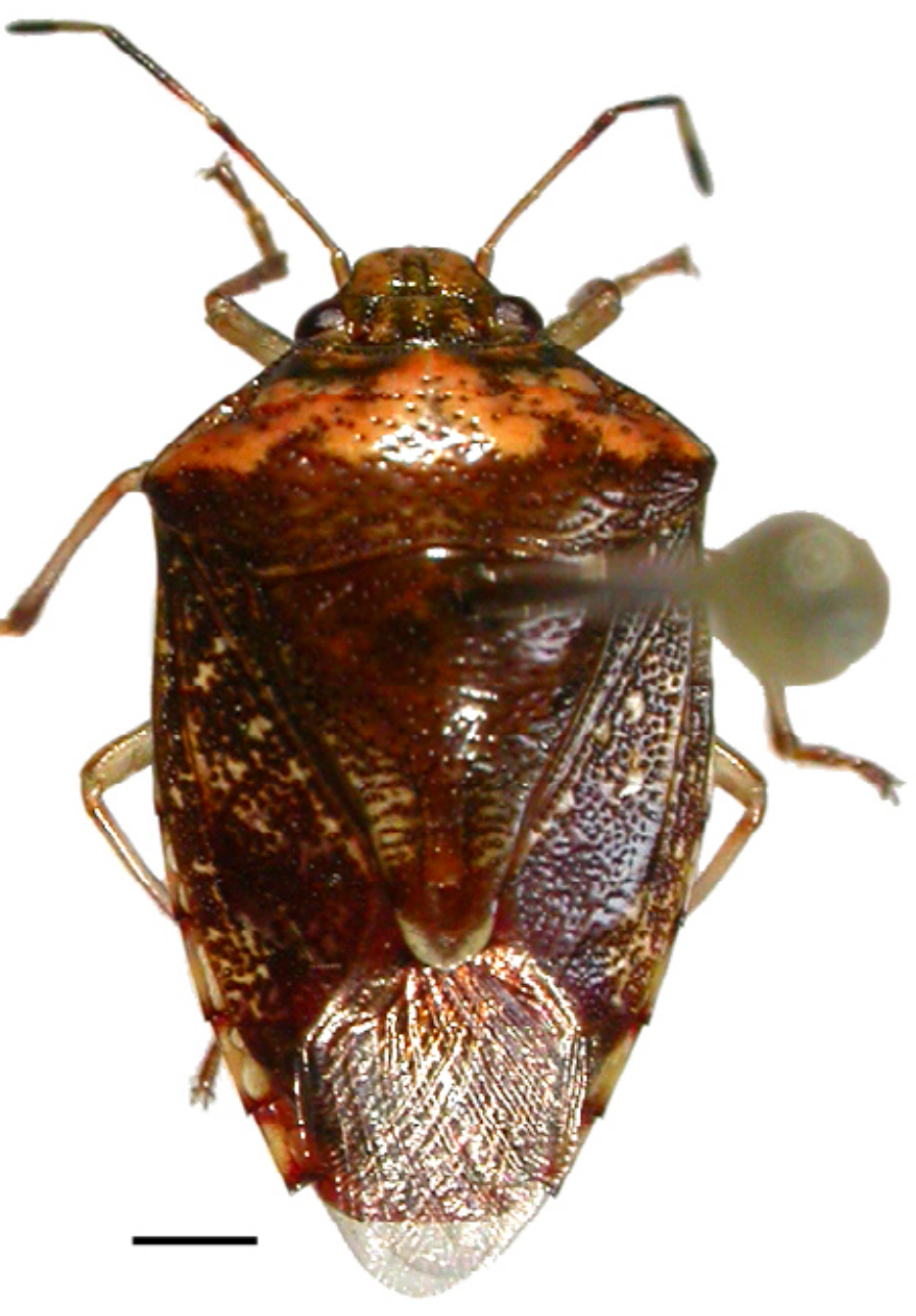

\section{Bibliografias:}

Campos, L.A.; Grazia, J.; Garbelotto, T.A.; Bianchi, F.M. \& Lanzarini, N.C. 2010. A new South American species of Banasa Stål (Hemiptera: Heteroptera: Pentatomidae: Pentatominae): from egg to adult. Zootaxa 2559: 47-57. 


\section{Banasa sulcata Thomas, 1990}

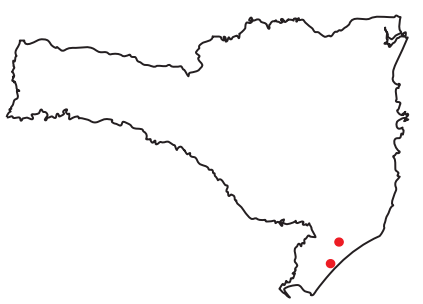

Diagnose: Corpo alongado, oval. Dorsalmente verde amarelado misturado com vermelho; ventralmente amarelo. Pontuações castanho avermelhadas, densas, uniformemente distribuídas. Carena linear de cada lado conectando os úmeros com as cicatrizes (Thomas \& Yonke 1990).

Tamanho dos adultos: $10-11,5 \mathrm{~mm}$.

Metodologia de coleta: coleta manual e guarda-chuva entomológico.

Local de Coleta: Araranguá e Criciúma.

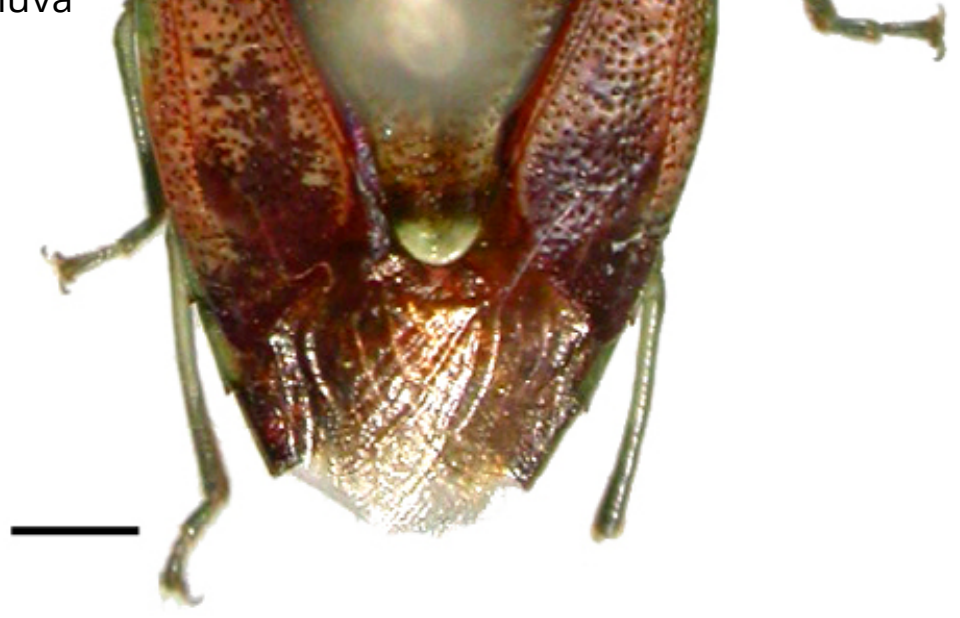

\section{Bibliografias:}

Thomas, D.B. \& Yonke, T.R. 1990. Review of the genus Banasa (Hemiptera: Pentatomidae) in South America. Ann Entomol Soc Am 83 (4): 657-688. 


\section{Janeirona stali (Kormilev, 1956)}

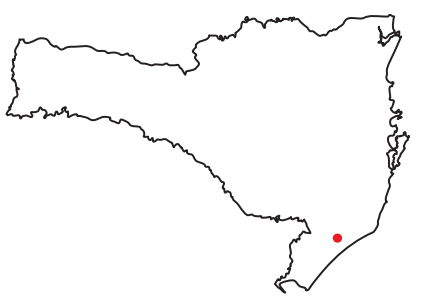

Diagnose: Coloração castanho escu$\mathrm{ra}$, as vezes com coloração mais clara no pronoto, ápice do escutelo e disco abdominal ventral. Mácula amarelada no ápice da veia radial. Jugas com ápice agudo, mais longas que o clípeo. Margem anterior do pronoto côncava no centro; as porções laterais atrás dos olhos truncadas e terminando em cada lado em um pequeno dentículo projetado lateralmente, agudo (Ruckes 1958).

Tamanho dos adultos: $19 \mathrm{~mm}$.

Metodologia de coleta: guarda-chuva entomológico.

Local de Coleta: Criciúma.

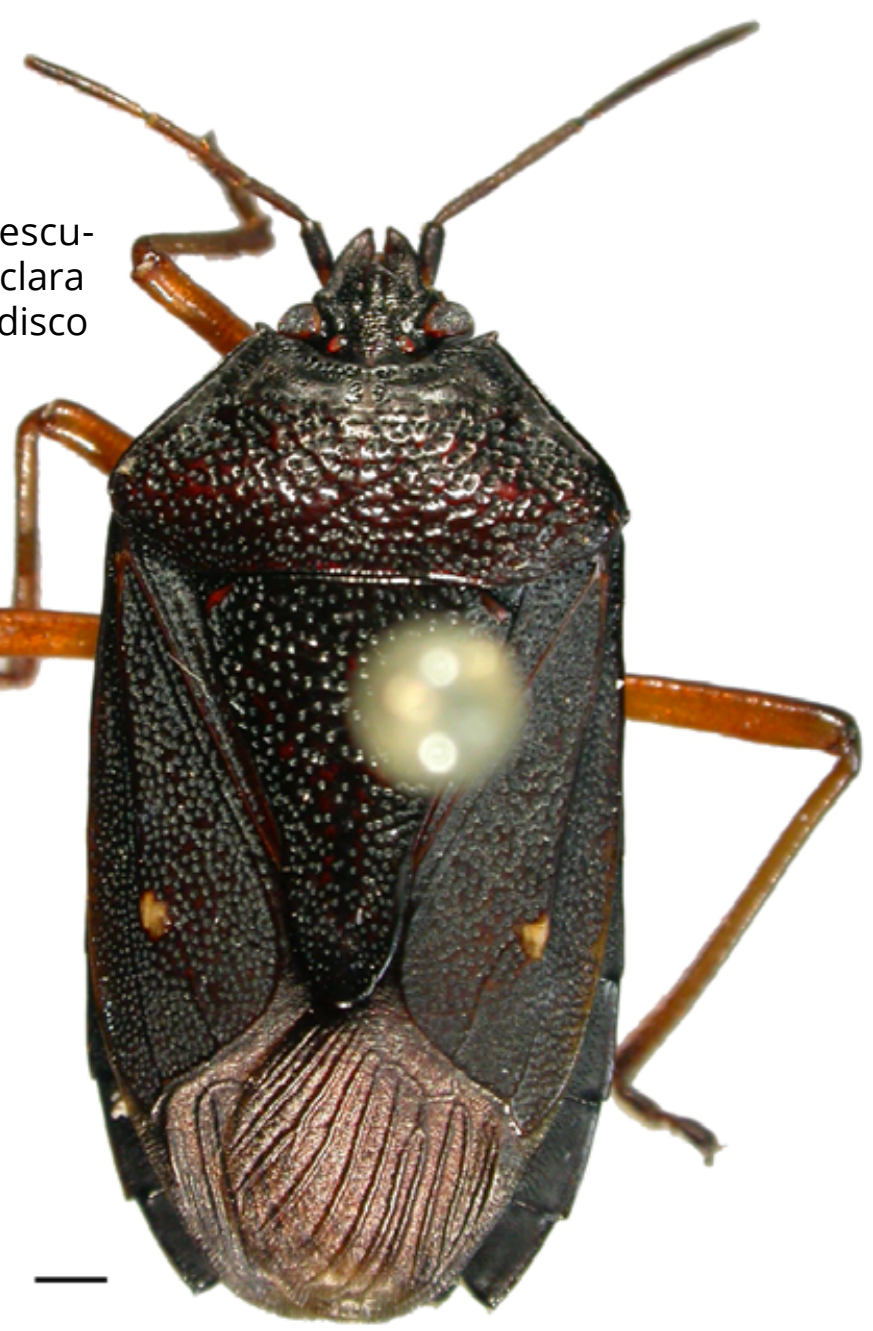

\section{Bibliografias:}

Kormilev, N.A. 1956. Notas sobre Pentatomoidea neotropicales V (Hemiptera). Acta scientifica de los institutos de investigación de San Miguel 4: 3-6.

Pirán, A.A. 1962. Hemiptera neotrópica VI. Sanderabdruck aus den mitteilungen der müchner entomologischen gesellschaft E.V. 52: 253-256.

Ruckes, H. 1958. New genera and species of neotropical Discocephaline and Halyine pentatomids (Heteroptera, Pentatomidae). American Museum Novitates 1868: 1-27. 


\section{Myota aerea}

\section{(Herrich-Schäffer, 1841)}

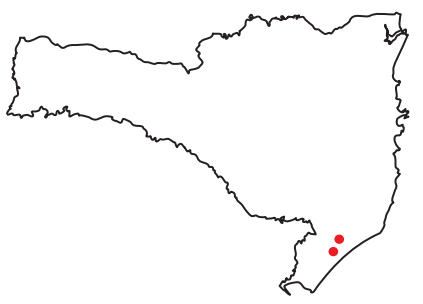

Diagnose: Coloração geral castanha com brilho verde-metálico. Cabeça com pontuações formando rugas refletindo o verde-metálico; $1^{\circ}$ segmento de antena mais claro que os demais, ápice do $2^{\circ}$ e base do $3^{\circ}$ albo. Pronoto com pontuações discretas e não confluentes (Spinola 1852).

Ângulos umerais desenvolvidos, afilados e com ápice recurvado posteriormente, pronoto declivoso anteriormente.

Tamanho dos adultos: $14 \mathrm{~mm}$

Metodologia de coleta: coleta manual e rede de varredura.

Local de Coleta: Criciúma e Maracajá.

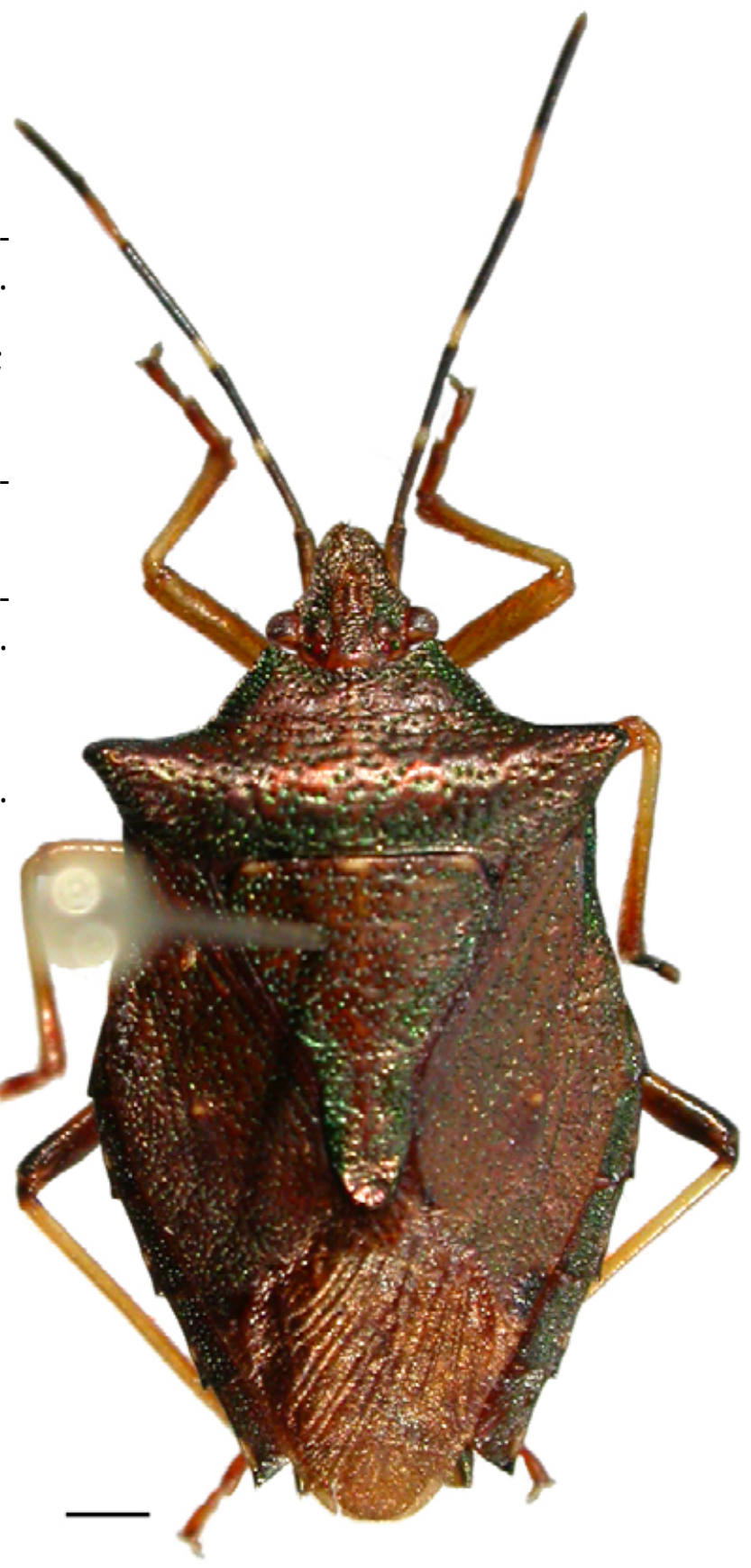

\section{Bibliografias:}

Spinola, M. 1852. Di alcuni generi d'inseti arthroidignati nuovamente proposti. Mem. Mat. Fis. Soc. Ital. Moderna 25 (1): 101-178. 


\section{Pallantia macula (Dallas, 1851)}

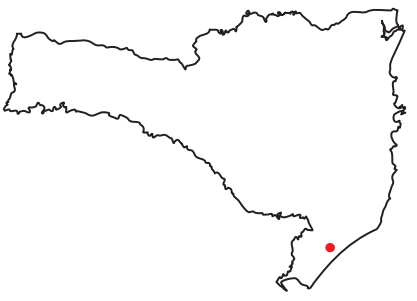
segmentos do conexivo mais estreita do que a das margens posteriores (Grazia 1980).

Tamanho dos adultos: $\sigma$ 8,86-9,62 mm; $९ 9,01-10,8$ mm. Metodologia de coleta: guarda-chuva entomológico. Local de Coleta: Maracajá.

Diagnose: Cabeça com uma série de pontos nas margens internas das jugas. Rostro pouco ultrapassando as coxas médias, atingindo o meio do metasterno. Metade posterior do pronoto de coloração mais escura. Faixa negra das margens anteriores dos

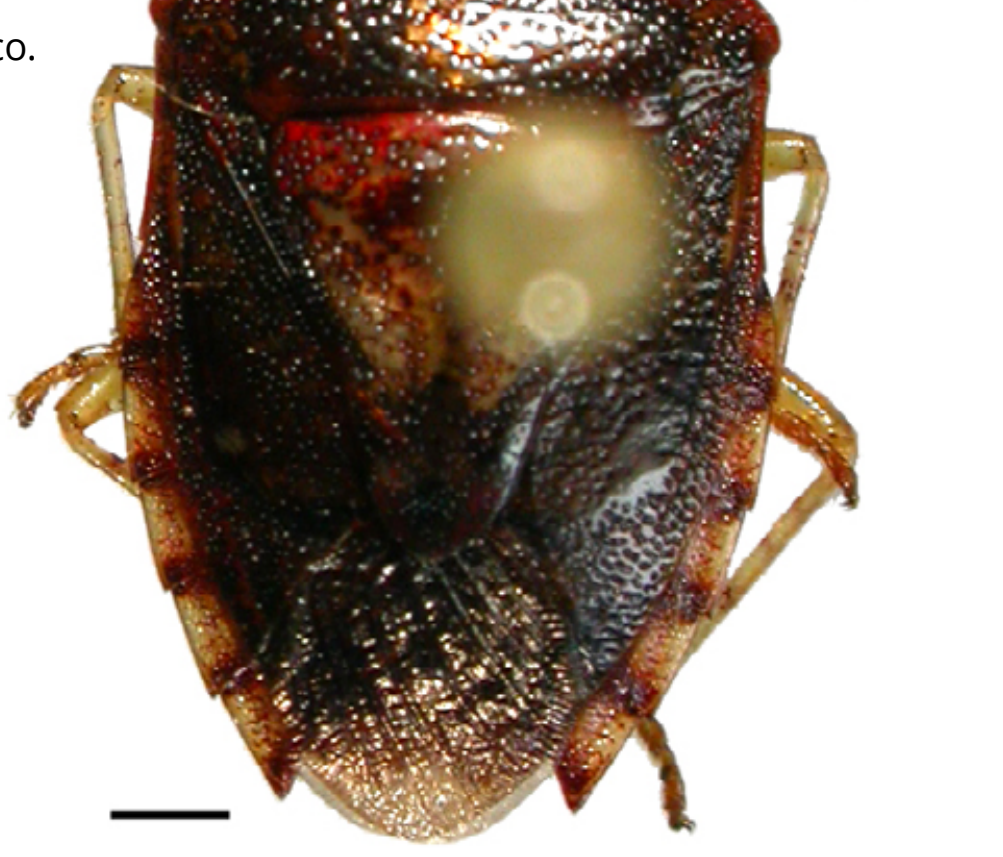

\section{Bibliografias:}

Grazia, J. 1980. Revisão do gênero Pallantia Stål, 1862 (Heteroptera, Pentatomidae). Rev. Bras. entomol. 24 (1): $15-27$. 


\section{Pellaea stictica} (Dallas, 1851)

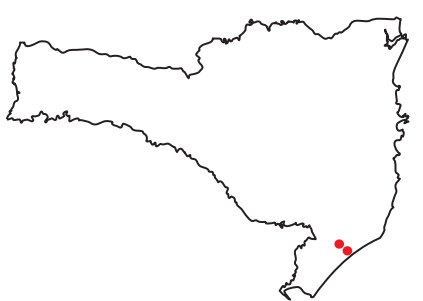

Diagnose: Indivíduos castanho-escuros ou avermelhados, salpicados de manchas amarelas. Ângulos umerais não desenvolvidos; espinho abdominal livre.

Tamanho dos adultos: $10 \mathrm{~mm}$ ou mais.

Metodologia de coleta: guarda-chuva entomológico e armadilha luminosa.

Local de Coleta: Criciúma e Içara.

\begin{tabular}{|l|l|l|}
\hline & Planta hospedeira & $\begin{array}{l}\text { Nome } \\
\text { popular }\end{array}$ \\
\hline Solanaceae & $\begin{array}{l}\text { Solanum } \\
\text { sisymbrifolium Lam. }\end{array}$ & Joá \\
\hline
\end{tabular}

$$
\text { . }
$$

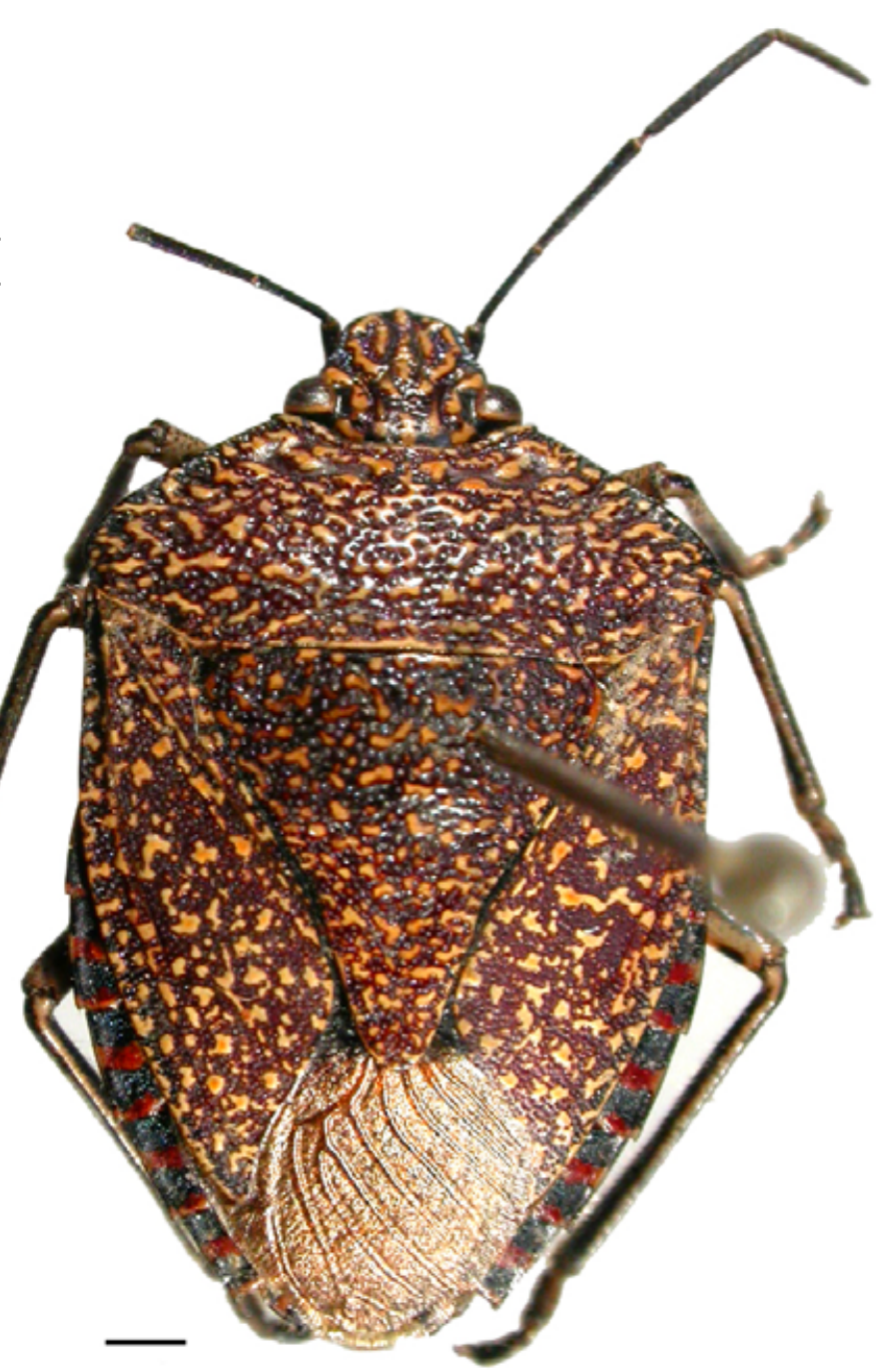

\section{Bibliografias:}

Link, D. \& Grazia, J. 1987. Pentatomídeos da região central do Rio Grande do Sul (Heteroptera). An. Soc. Entomol. Bras. 16 (1): 115-129.

Lopes, O.J.; Link, D. \& Basso, L.V. 1974. Pentatomídeos de Santa Maria - Lista preliminar de plantas hospedeiras. Rev. Centro Ciências Rurais 4 (4): 317-322. 


\title{
Serdia indistincta
} Fortes \& Grazia, 2005

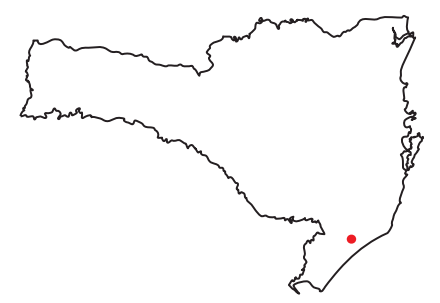

Diagnose: Coloração castanho-clara a escura; coloração amarelada na base do $4^{\circ}$ e totalidade do $5^{\circ}$ segmento de antena; pernas castanho clara a amarelada com pontuações ferrugíneas e tarsos avermelhados.

Pronoto com ângulos umerais retilíneos, não desenvolvidos, margens anterolaterais subparalelas ou suavemente côncavas. Escutelo com margem delicadamente delineada de negro nas laterais. Cório com mancha clara no ápice da veia radial (Fortes \& Grazia 2005).

Tamanho dos adultos: $\sigma$ 12,2-14,6 mm; O 12,1-16,8 mm.

Metodologia de coleta: coleta manual, guarda-chuva entomológico e rede de varredura.

Local de Coleta: Criciúma.

\footnotetext{
eia
}

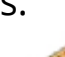

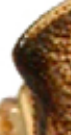




\section{Serdia maxima} Fortes \& Grazia, 2005

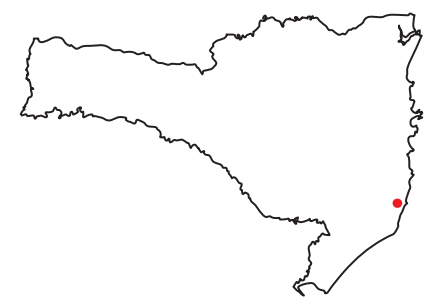

Diagnose: Coloração castanho-clara a escura; segmentos de antenas negros com ápice do $5^{\circ}$ amarelado; pernas castanho amareladas com pontuações castanho escuro e tarsos avermelhados. Pronoto com ângulos umerais amplamente desenvolvidos, obliquamente dirigidos para frente com ápice arredondado; margens anterolaterais fortemente côncavas e crenuladas. Escutelo com margem apical emarginada, recurvada e com $1+1$ pequenas manchas negras nos bordos laterais (Fortes \& Grazia 2005).

Tamanho dos adultos: $\sigma$ 13,3-14,8 mm; @ 14,7-15,6 mm.

Metodologia de coleta: espécie com registro apenas em literatura e sem indicação de método de coleta.

Ocorrência: Imbituba.

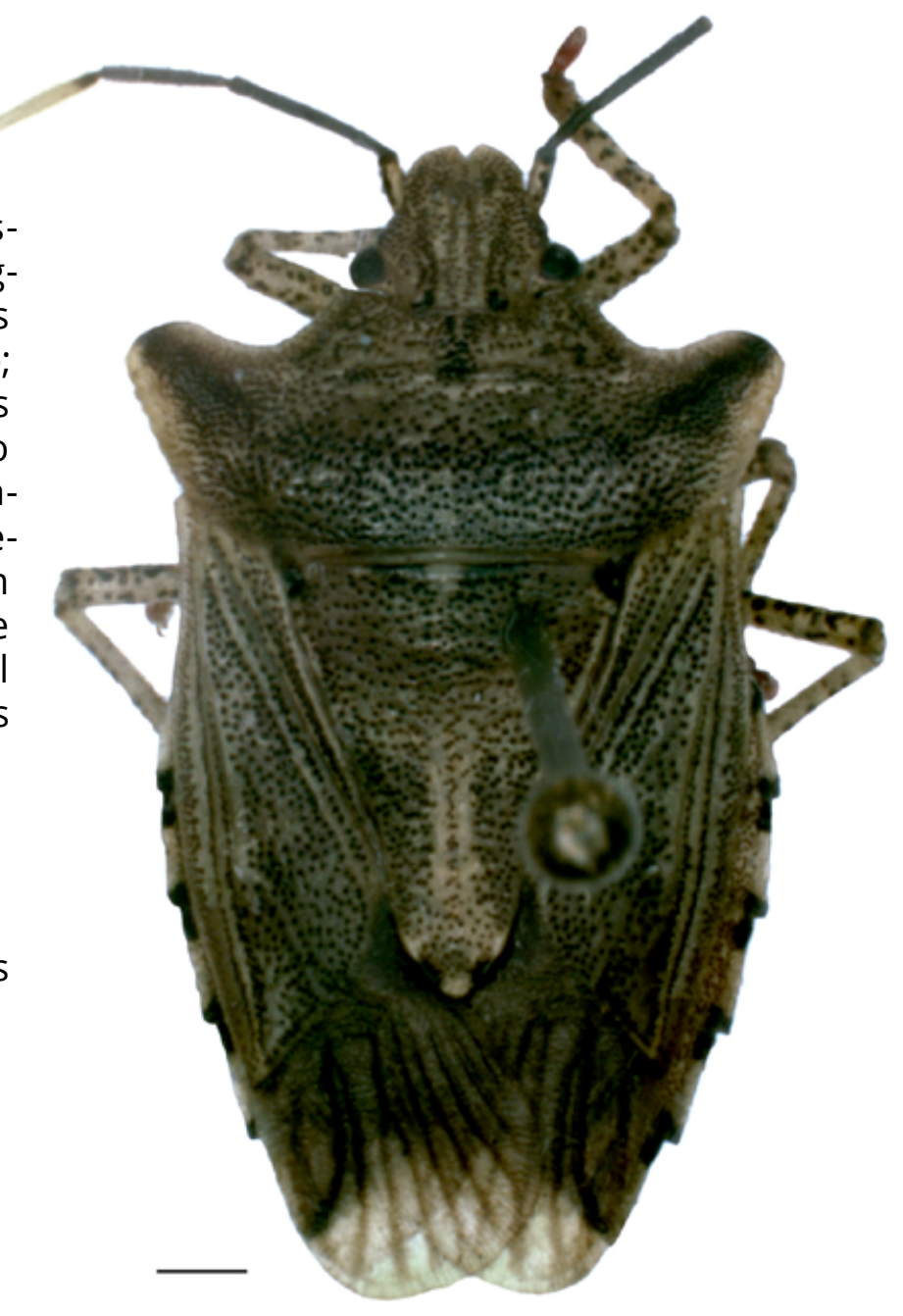

\section{Bibliografias:}

Fortes, N.D.F.de \& Grazia, J. 2005. Revisão e análise cladística de Serdia Stål (Heteroptera, Pentatomidae, Pentatomini). Rev. Bras. entomol. 49 (3): 294-339. 
Stictochilus tripunctatus Bergroth, 1918

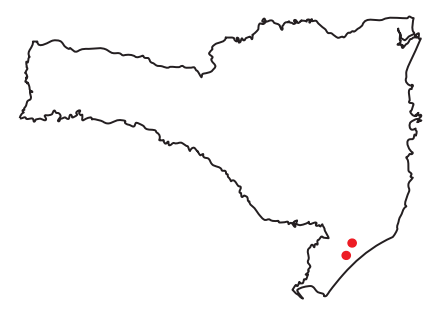

Diagnose: Jugas projetadas para além do clípeo, unidas apicalmente. Úmeros não projetados. Metasterno produzido ventralmente, arqueado em perfil, carenado medianamente, pelo menos na região anterior. Mesosterno fracamente carenado medianamente; carena em placa semicircular na região anterior (Rolston \& Rider 1986).

Tamanho dos adultos: 9,3-10,2 mm.

Metodologia de coleta: coleta manual e rede de varredura.

Local de Coleta: Criciúma e Maracajá.

\section{Bibliografias:}

Roston, L.H. \& Rider, D.A. 1986. Two new species of Stictochilus Bergroth from Argentina (Hemiptera: Pentatomidae). J. New York Entomol. Soc. 94 (1): 78-82. 


\section{Piezodorini}

Piezodorus guildinii (Westwood, 1837) 


\section{Piezodorus guildinii (Westwood, 1837)}

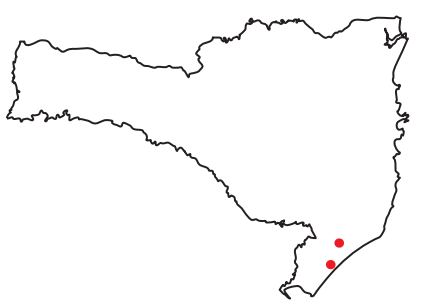

Diagnose: Coloração geral verde claro a amarelado, com uma faixa vermelha na base do pronoto, particularmente nas fêmeas (Panizzi et al. 2000).

Tamanho dos adultos: $8-9 \mathrm{~mm}$.

Metodologia de coleta: guarda-chuva entomológico e rede de varredura.

Local de Coleta: Araranguá e Criciúma.

Nome popular: Percevejo-verde-pequeno, verdinho, percevejo-pequeno-da-soja.

\begin{tabular}{|c|c|c|}
\hline & Planta hospedeira & Nome popular \\
\hline Apiaceae & $\begin{array}{l}\text { Foeniculum vulgare Mill. } \\
\text { var. capillaceum (Gilibi.) }\end{array}$ & Funcho \\
\hline Asteraceae & Helianthus annuus L. & Girassol \\
\hline Brassicaceae & $\begin{array}{l}\text { Brassica napus L. var. } \\
\text { oleifera Meitzg. }\end{array}$ & Colza \\
\hline Curcubitaceae & Sechium edule Swartz & Chuchuzeiro \\
\hline Fabaceae & $\begin{array}{l}\text { Phaseolus vulgaris L.; Lotus } \\
\text { corniculatus L.; Pisum sativum } \\
\text { L.; Lens culinarie Medik.; } \\
\text { Lotononis bainesii Baker.; } \\
\text { Desmodium intortum Urb. ou } \\
\text { uncinatum; Glycine max (L.) } \\
\text { Merrill; Lupinus luteus L.; } \\
\text { Lupinus albus L.; Trifolium } \\
\text { repene L.; Medicago polymorpha } \\
\text { L.; Lupinus angustifolius L.; } \\
\text { Medicago sativa L.; Crotalaria } \\
\text { sp.; Indigofera spp; Sesbania; }\end{array}$ & $\begin{array}{l}\text { Feijão; Cornichão; } \\
\text { Ervilha; Lentilha; } \\
\text { Lotononis; } \\
\text { Pega-pega; Soja; } \\
\text { Tremoço-amarelo; } \\
\text { Tremoço- } \\
\text { branco; Trevo- } \\
\text { branco; Trevo- } \\
\text { de-carretilha; } \\
\text { Tremoço-azul; } \\
\text { Alfafa;_;_;_. }\end{array}$ \\
\hline Linaceae & Linum usitatissimum L. & Linho \\
\hline Malvaceae & Chicorium indivia $\mathrm{L}$. & Algodoeiro \\
\hline Phytolaccaceae & Phytolacca dioica L. & Umbú \\
\hline Rosaceae & Fragraria vesca L. & Morangueiro \\
\hline
\end{tabular}

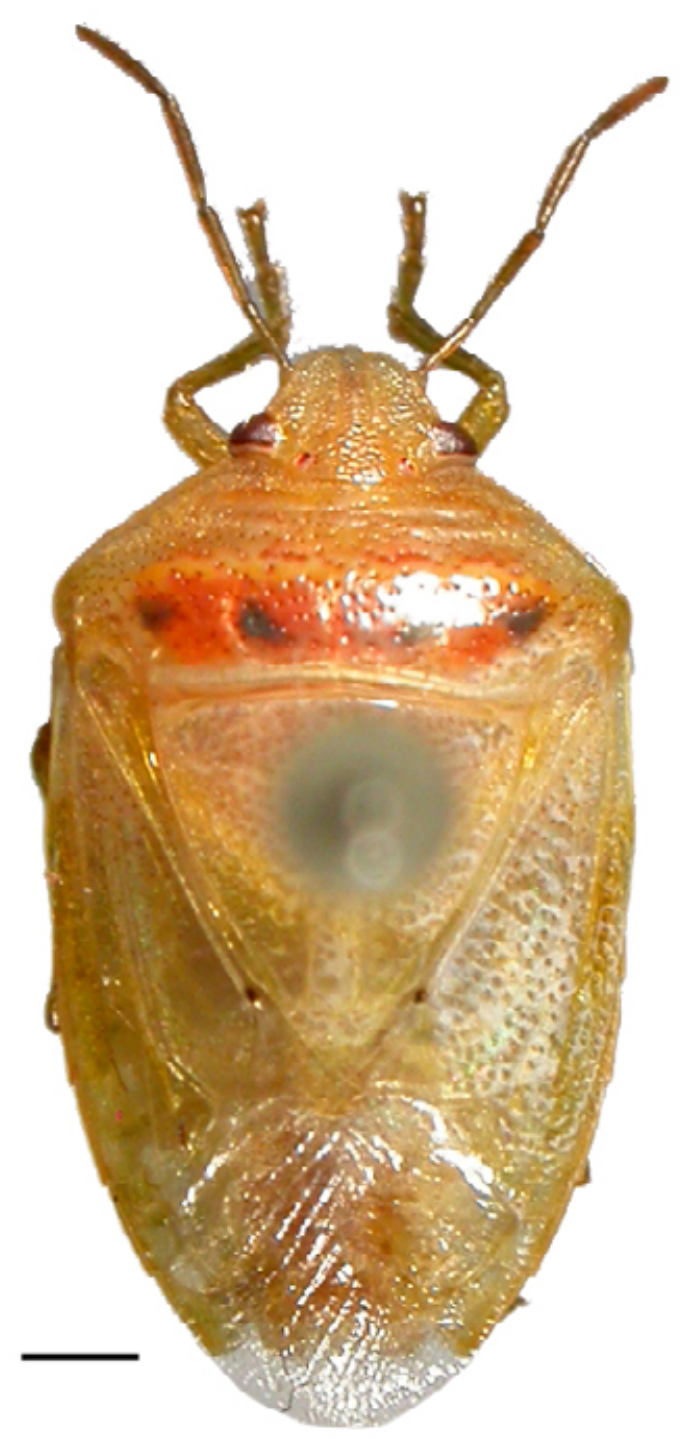

\section{Bibliografias:}

Corrêa-Ferreira, B.S. \& Panizzi, A.R. 1999. Percevejos da soja e seu manejo. Londrina, PR. Embrapa-CNPSo. 45p. (Embrapa-CNPSo. Circular Tecnica, 24). Disponível online em: http://ag20.cnptia.embrapa. br/Repositorio/circTec24_000ge7ag4ne02wx5ok0ylax2l2xuj1ts.pdf [Acesso em: 20 dez. 2013.] 
FMC. 2013. Percevejos.com.br. Disponível online em: http://www.percevejos.com.br/ [Acesso em: 19 dez. 2013.]

Grazia, J. 1977. Revisão dos Pentatomineos citados no Quarto Catálogo dos Insetos que Vivem nas Plantas do Brasil (Hemiptera: Pentatomidae, Pentatomini). Dusenia 10 (3): 161-174.

Link, D. \& Grazia, J. 1987. Pentatomídeos da região central do Rio Grande do Sul (Heteroptera). An. Soc. Entomol. Bras. 16 (1): 115-129.

Malaguido, A.B. \& Panizzi, A.R. 1998. Pentatomofauna associated with sunflower in Northern Paraná state, Brazil. An. Soc. Entomol. Bras. 27 (3): 473-475.

Panizzi, A.R. 1997. Wild hosts of Pentatomids: ecological significance and role in their pest status on crops. Annu. Rev. Entomol. 42: 99-122.

Panizzi, A.R.; McPherson, J.E.; James, D.G.; Javahery, J.M. \& McPherson, R.M. 2000. Stink Bugs (Pentatomidae) p. 421-474. In: C.W. Schaefer \& A.R. Panizzi (Org). Heteroptera of economic importance. USA, CRC Press. 


\section{Procleticini}

Thoreyella maracaja Bernardes, Schwertner \& Grazia, 2011 


\section{Thoreyella maracaja Bernardes, Schwertner \& Grazia, 2011}

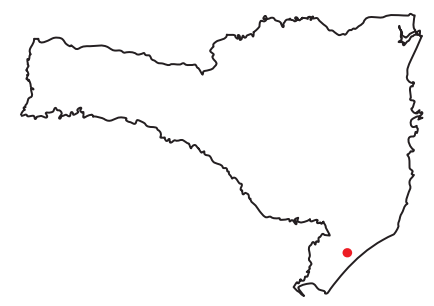

Diagnose: Coloração geral verde; pernas e antenas amareladas. Cabeça triangular; margens laterais das jugas delineadas de negro. Ângulos umerais negros, robustos e direcionados antero-ventralmente. Espinho abdominal ultrapassando as mesocoxas; tubérculos dos tricobótrios negros (Bernardes et al. 2011).

Tamanho dos adultos: 5,18 -6,08 mm

Metodologia de coleta: coleta manual e guarda-chuva entomológico

Local de Coleta: Maracajá

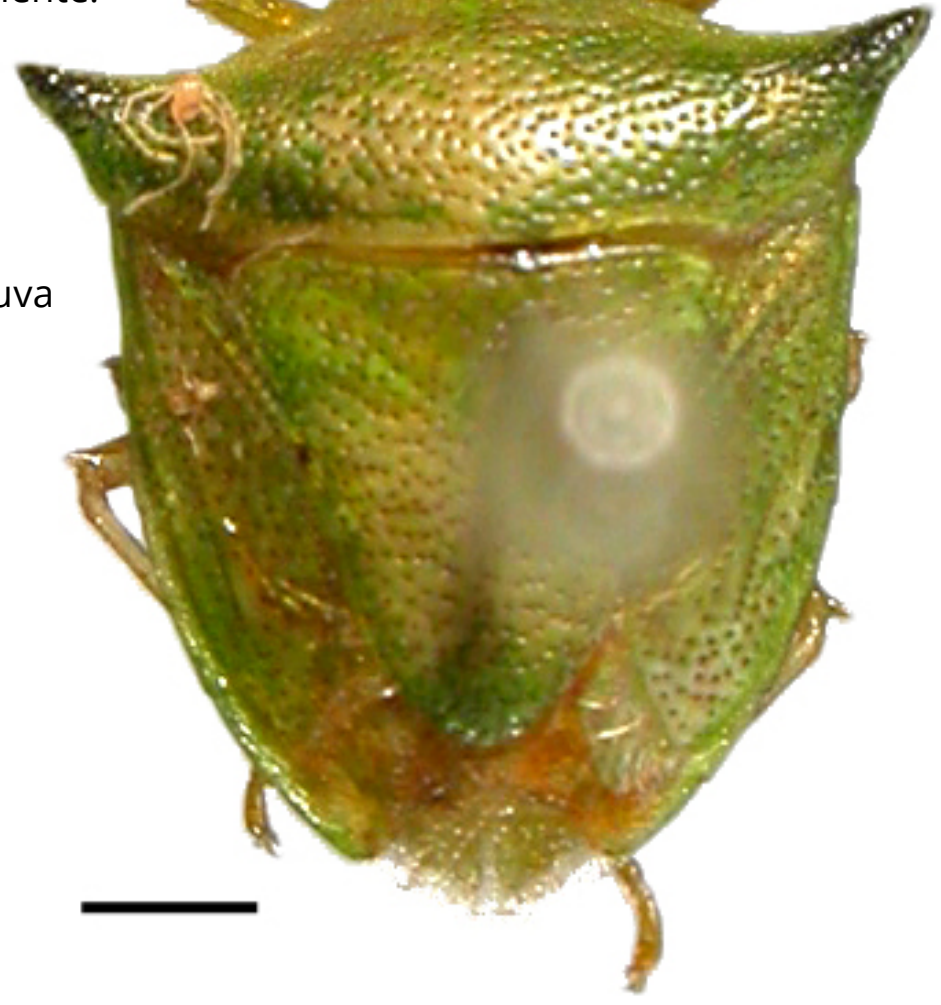

\section{Bibliografias:}

Bernardes, J.L.C.; Schwertner, C.F. \& Grazia, J. 2011. Review of Thoreyella Spinola with the description of two new species from Brazil (Heteroptera: Pentatomidae). Rev. Bras. entomol. 55 (3): 299-312. 


\section{Metodologias de coleta e conservação}

A maneira mais fácil de coletar percevejos é manualmente, porém assim ficamos restritos a coletá-los apenas quando os vemos sobre a vegetação. Existem diferentes métodos de coleta de insetos, dentre os quais os mais utilizados para coleta de percevejos são descritos a seguir.

Guarda-chuva entomológico: utilizado para a coleta de insetos que pousam em arbustos. É feito basicamente com um quadrado de tecido, preferencialmente branco, com reforços triangulares nos cantos onde serão encaixadas as pontas das varas intercruzadas (Fig. 3). Um bastão é necessário para bater nos arbustos, fazendo com que os insetos caiam sobre o guarda-chuva. Depois de caírem no guarda-chuva, os insetos são capturados e armazenados em potes plásticos.

Rede de varredura: é utilizada para coletar insetos que vivem na vegetação rasteira. Tem uma estrutura similar às 'redes entomológicas' que são utilizadas para capturar insetos durante o voo (como borboletas e abelhas), mas a rede de varredura é usada para bater na folhagem como se estivesse "varrendo" toda a fauna de insetos que se encontra ali.

A rede é feita de um tecido resistente costurado em forma de saco com uma borda por onde passará um aro de arame também resistente (é aconselhado que a borda seja reforçada com lona ou tecido duplo) preso a um cabo de madeira (Fig. 4). O tecido deve ser grosso para resistir aos danos, como perfurações, que os ramos de plantas poderiam causar à rede.

Todo o material coletado é recolhido em sacos plásticos contendo um chumaço de algodão embebido em acetato de etila e levado ao laboratório para triagem.

Armadilha luminosa: existem diferentes tipos de armadilha que utilizam a luz como atrativo para coletar insetos. Pode-se utilizar um pedaço de tecido branco esticado entre dois suportes (como um lençol), ou uma parede como área de coleta, iluminada por uma fonte de luz. O coletor fica por perto e coleta os insetos do grupo alvo que são atraídos.

Um outro tipo comum de armadilha luminosa é o modelo "Luiz de Queiroz" que consiste de um funil de alumínio que se encaixa a uma armação feita com quatro aletas de alumínio, montadas cruzadas ao redor de uma lâmpada fluorescente. Na parte inferior da armadilha, um pote com álcool $70 \%$ para aprisionar ou matar os insetos. A armadilha tem ainda um disco de alumínio sobre as aletas para proteção da água da chuva (Fig. 4). No centro deste disco, é colocada uma alça por onde a armadilha será suspensa entre a vegetação.

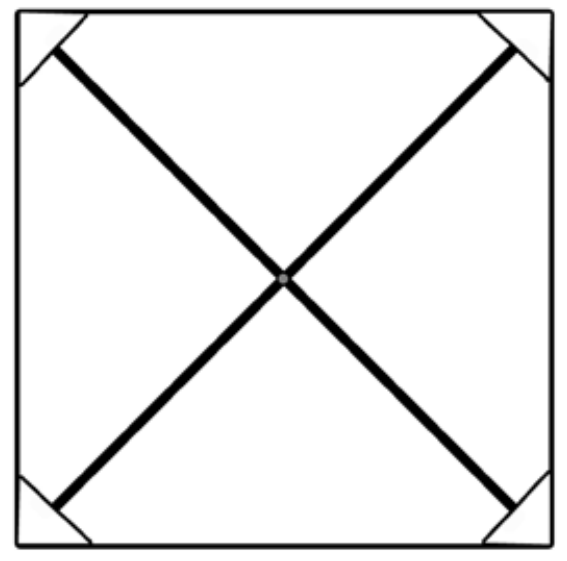

Figura 3: Representação esquemática de um guardachuva entomológico.

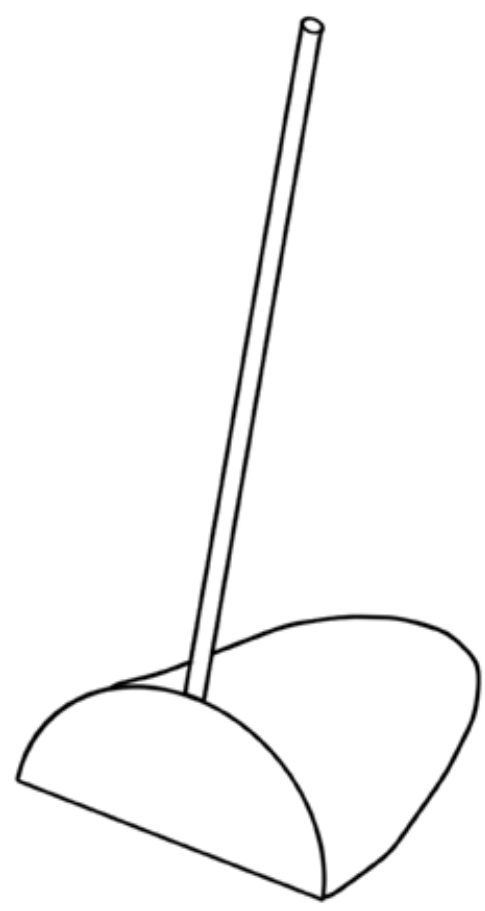

Figura 4: Representação esquemática de uma rede de varredura. 
Após a coleta, os insetos precisam ser montados e conservados de maneira adequada para trabalhos posteriores. No caso dos percevejos dois meios de conservação são mais utilizados: via líquida, com a conservação em álcool 70\%, ou a seco com o uso de alfinetes entomológicos.

Para conservação a seco, deve-se alfinetar os percevejos e secá-los em estufa para posterior armazenamento em caixas entomológicas. Para a montagem insira o alfinete no escutelo com um deslocamento à direita da linha mediana do corpo (Fig. 6), perfure o inseto até posicioná-lo entre o centro e a cabeça do alfinete, ou a cerca de $1,5 \mathrm{~cm}$ abaixo da cabeça do alfinete. Pode-se usar blocos com perfurações para ajuste da altura do exemplar no alfinete. Posicione as pernas e antenas adequadamente, leve o material à estufa e quando seco armazene em caixa entomológicas. Todo o material deve ser etiquetado com as informações de coleta (local, data, coletor) em etiquetas de aproximadamente $2 \times 2 \mathrm{~cm}$.

Para mais informações sobre estes e outros métodos de coleta e conservação de insetos veja os seguintes livros:

- Insetos do Brasil: Diversidade e Taxonomia - Rafael, J.A.; Melo, G.A.R.; Carvalho, C.J.B; Casari, S.A. \& Constantino, R. - Holos Editora (2012).

- Estudo dos insetos - Triplehorn, C.A \& Jonnson, N.F. - Cengage Learning (2011)

- Manual de coleta, conservação, montagem e identificação de insetos - Almeida, L.M.; Ribeiro-Costa, C.S. \& Marinoni, L. - Holos Editora (1998).

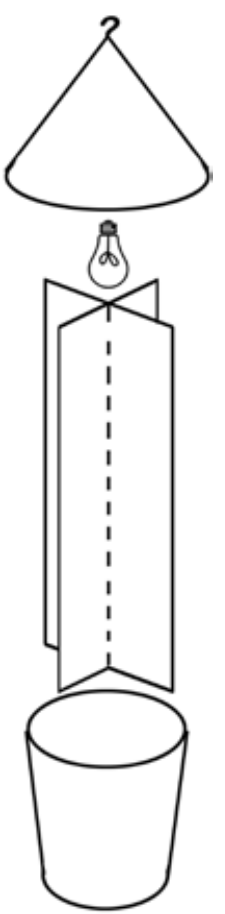

Figura 5: Representação esquemática de uma armadilha luminosa.

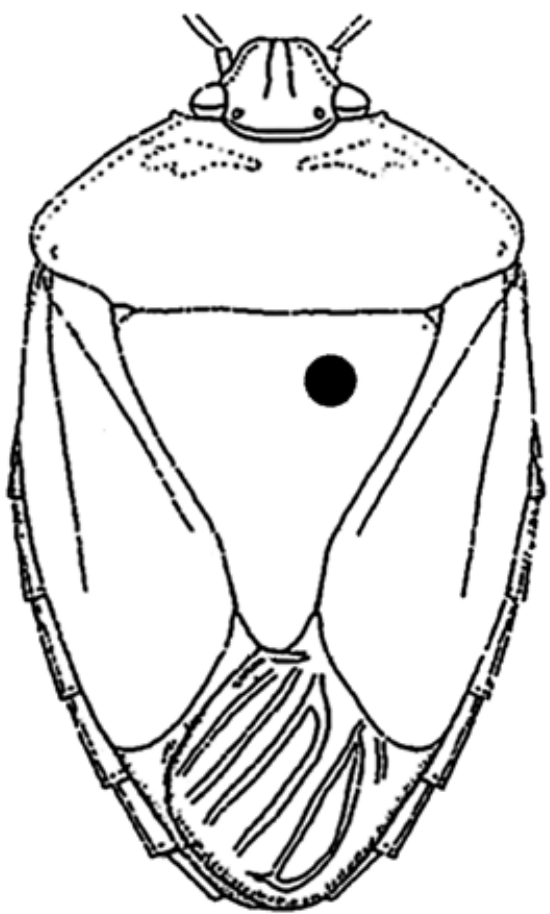

Figura 6: Indicação da posição correta para inserir o alfinete em um pentatomídeo. 


\section{Glossário}

A

Albo - branco.

B

Bordo anterior do pronoto - margem anterior do pronoto. (pigóforo).

Bordo Ventral - margem ventral da taça genital do macho

\section{C}

Carena - quilha; elevação.

Concolor - de mesma coloração.

Confluentes - que se unem.

Cório - região coriácea dos élitros.

Cosmopolita - com distribuição mundial.

Costa - margem externa do cório.

Crenulado - serrilhado com "dentes" disformes em tamanho (largura e altura).

\section{D}

Delgado - com pouca espessura. Fino. Delicado.

Distância Interocular - distância entre os olhos.

\section{E}

Espinho abdominal - projeção espinhosa da porção anterior do terceiro segmento abdominal que se projeta em direção ao metasterno.

Esternito abdominal - o mesmo que segmento abdominal.

$\mathbf{F}$

Ferrugíneo - avermelhado.

Freno - Depressão da margem lateral do escutelo que se estende mais ou menos até ao nível da constrição, onde se fixam as asas quando em repouso.

\section{G}

Glabra - desprovida de pelos.
I

Imaculado - sem manchas.

M

Mácula - o mesmo que mancha.

Margem lateral do pronoto - o mesmo que margem ânterolateral.

Meso- - mediano(a); segundo(a).

Meta- - posterior; terceiro(a).

0

Ocre - coloração parda.

Ostíolo - abertura da glândula de cheiro

P

Peritrema- o mesmo que ruga ostiolar; margem do ostíolo elevada com formas que variam entre os grupos.

Pigóforo - genitália do macho.

Pontuações - marcas circulares no exoesqueleto, ao se juntarem podem formar rugas

Pré-apicais - antes do ápice; próximo do ápice.

Pró- - anterior; primeiro(a).

Processo Anteocular - projeção de forma variada em posição anterior aos olhos, junto a base das jugas.

$\mathbf{R}$

Reticulado - que forma retículos; rede; malha.

\section{$S$}

Serrilhado - recortado como uma serra; que tem serrilha. Sulco Mediano Abdominal - depressão; ruga; corte; vinco em posição mediana no abdômen, em vista ventral.

$\mathbf{T}$

Truncado - incompleto; terminado abruptamente.

U

Úmeros - o mesmo que Ângulos umerais. 


\section{Referências}

Almeida, L.M.; Ribeiro-Costa, C.S. \& Marinoni, L. 1998. Manual de coleta, Conservação, Montagem e Identificação de insetos, p. 78. Ribeirão Preto, Holos Editora.

Brown JR, K.S. 1997 Diversity, disturbance, and sustainable use of Neotropical forests: insects as indicators for conservation monitoring. Journal of Insect Conservation 1: 25-42.

Brusca, R.C. \& Brusca, G.J. 2007. Invertebrados, p.968. Rio de Janeiro, Guanabara Koogan.

Campanili, M. \& Prochnow, M. 2006. Mata Atlântica: uma rede pela floresta, p. 332. Brasília, RMA.

Campos, L.A.; Bertolin, T.B.P.; Teixeira, R.A. \& Martins, F.S. 2009. Diversidade de Pentatomoidea (Hemiptera, Heteroptera) em três fragmentos de Mata Atlântica no Sul de Santa Catarina. Iheringia, Ser. Zool. 99 (2): 165-171.

Costa Lima, A.M. 1940. Hemípteros, v. 2, 352 p. In: A.M. Costa Lima (Org.). Insetos do Brasil. Rio de Janeiro, Escola Nacional de Agronomia.

Grazia, J. \& Fernandes, J.A.M. 2012. Subordem Heteroptera. In: J.A. Rafael; G.A.R. Melo; C.J.B. de Carvalho; S.A. Casari \& R. Constantino. Insetos do Brasil: diversidade e taxonomia. Ribeirão Preto, Holos Editora, 810p.

Grazia, J. \& Schwertner, C.F. 2011. Checklist dos percevejos-do-mato (Hemiptera: Heteroptera: Pentatomoidea) do Estado de São Paulo, Brasil. Biota Neotrop. 11 (1a): 1-12.

Grazia, J.; Fortes, N.D.F.F. \& Campos, L.A. 1999. Pentatomoidea, v.5, p.101-112. In: C.A. Joly \& C.E.M. Bicudo (Org.). Biodiversidade do estado de São Paulo, Brasil: síntese do conhecimento ao final do século XX. São Paulo, FAPESP.

Grazia, J.; Cavichioli, R.R.; Wolff, V.R.S.; Fernandes, J.A.M. \& Takiya, D.M. 2012. Hemiptera p. 347-406. In: J.A. Rafael; G.A.R. Melo; C.J.B. de Carvalho; S.A. Casari \& R. Constantino. Insetos do Brasil: diversidade e taxonomia. Ribeirão Preto, Holos Editora, 810p.

Grimald, D.A. \& Engel, M.S. 2005. Evolution of the insects. New York, Cambridge University Press, 755p.

Heringer, H. \& Montenegro, M.M. 2000. Avaliação e ações prioritárias para conservação da biodiversidade da Mata Atlântica e Campos Sulinos. Brasília, Ministério do Meio Ambiente - MMA, 46p.

Myers, N.; Mittermeier, R.A.; Mittermeier, C.G.; Fonseca, G.A.B. \& Jennifer, K. 2000. Biodiversity hotspots for conservation priorities. Nature 403: 853-858.

Panizzi, A.R.; McPherson, J.E.; James, D.G.; Javahery, J.M. \& McPherson, R.M. 2000. Stink Bugs (Pentatomidae) p. 421-474. In: C.W. Schaefer \& A.R. Panizzi (Org). Heteroptera of economic importance. USA, CRC Press.

Rider, D. A. (2011) Pentatomoidea Home Page: number of genera \& species of Pentatomidae. North Dakota: North Dakota State University. Disponível online em: http://www.ndsu.nodak.edu/ndsu/rider/Pentatomoidea/Classification/Genus_Species_Numbers.htm [Acesso em: 15 jul. 2013.]

Rolston, L.H. \& McDonald, F.J.D. 1979. Keys and diagnoses for the families of Western Hemisfere Pentatomoidea, subfamilies of Pentatomidae, and tribes of Pentatominae (Hemiptera). Journal of the New York Entomological Society 87: $189-207$.

Schuh, R. T. \& Slater, J. A. 1995. True bugs of the world (Hemiptera: Heteroptera): classification and natural history. Ithaca, NY, Cornell University Press, 336p.

SOS Mata Atlântica. 2008. Mata Atlântica. São Paulo, Fundação SOS Mata Atlântica. Disponível online em: http://www.sosma. org.br/projeto/atlas-da-mata-atlantica/ [Acesso em: 11 jul. 2013.]

Thomazini, M. J.; Thomazini, A. P. B. W. 2000. A fragmentação florestal e a diversidade de insetos nas florestas tropicais úmidas. Rio Branco, Emprapa Acre, 21p. (Embrapa Acre. Documentos, 57).

Triplehorn, C.A. \& Johnson, N.F. 2011. Estudo dos insetos: tradução da $7^{a}$ edição de Borror and Delong's introduction to the study of insects. São Paulo, Cengage Learning, 809p. 
Curitiba, 2014 